\title{
Temporary Road
}

\author{
Rebecca Fernando \\ Carleton University, Ottawa \\ September, 2005
}

A thesis submitted to Carleton University in partial fulfillment of the requirements of the degree of

Masters of Architecture (Professional)

(C) Rebecca Fernando, 2005 


\begin{abstract}
Linear narrative has been an enduring influence on the internal and external processes of human consciousness and action. The desires for closure and control in everyday life can be attributed, in large part, to the precedence of plot or teleology of traditional narrative form. Through plot, the author can create a directed sense of representation driven as means to an end. In architectural representation, the repercussions are evident in the role of the drawing and its reading: the effects of narrative. Architectural processes and practice typically follow linear form through conception to building. However, this linearity ultimately implies an end when architecture, no matter what its function, can never be defined as an absolute. Architecture changes through time and culture, appropriating and being appropriated. The peripheral site at Temporary Road (south of the Ottawa suburb of Barrhaven) will become the focus of a reevaluation of the implications of drawing and narrative in architectural representation, serving as possibility in opposition to its future annexation by developers.
\end{abstract}


Table of Contents

1. Introduction 1

2. Issues of Architectural Representation: Drawing and Narrative 3

2.1 Overview 3

2.2 Drawing 10

$\begin{array}{ll}2.3 \text { Narrative } & 15\end{array}$

2.3.1 Narratemes 18

2.3.2 Narrative I 21

2.3.3 Narrative II and III 24

2.3.4 Narrative Pictures 24

2.4 The Visual Sequence 25

2.5 Narrative and Architectural Representation: Reevaluation 35

2.5.1 Time 35

$\begin{array}{ll}\text { 2.5.2 Space } & 38\end{array}$

2.5.3 Reevaluation $\quad 41$

3. The Sequential Macro-Frame 45

3.1 Precedents 48

3.2 Rules of Operation $\quad 55$

4. Site 58

4.1 Overview 58

4.1.1 Early Vestiges $\quad 59$

4.1.2 Place/Consumption $\quad 62$

4.1.3 Suburbia/Utopia $\quad 68$

$\begin{array}{ll}\text { 4.2 Temporary Road } & 71\end{array}$

4.2.1 The McKennas $\quad 75$

5. Methodology 80

5.1 Parts for 'Tendential Narratives' $\quad 80$

5.1.1 Fragment 1: Silver Springs $\quad 80$

5.1.2 Fragment 2: Fire-pit 81

5.1.3 Fragment 3: Kids $\quad 82$

5.1.4 Fragment 4: Joady $\quad 83$

5.2 Previous Investigations 84

5.3 Development of the Sequential Macro-Frame 105

5.4 Design for Temporary Road 111

6. Conclusion 114

Bibliography 135 
List of Tables and Appendices

Table 1. Narrative, Narrativity, and Related Terms 


\section{List of Figures}

Figure 1. 'Three Studies of Figures on Beds'

Figure 2. Lascaux and Trajan's Column

Figure 3. 'The Marriage Contract'

Figure 4. 'Victims'

Figure 5. 'House'

Figure 6. Excerpts from Graphic Novels

Figure 7. Excerpt from Hold Me

Figure 8. Temporary Road 56

Figure 9. Nepean County Residence 59

Figure 10. Boxmalls

Figure 11. At Temporary Road

Figure 12. Remnants of the Barn

Figure 13. McKenna Homestead

Figure 14. McKenna Farm

Figure 15. A Fort in the Forest

79

Figure 16. The Sequential Macro-Frame 105

Figure 17. Images from the Sequential Macro-Frame, Fragment 1.

Figure 18. Image from the Sequential Macro-Frame, Fragment 2? 3? 106

Figure 19. Images from the Sequential Macro-Frame, Fragment $3 \quad 107$

Figure 20. A Reassessment of the Developer's Scheme (Site Plan). 111 


\section{List of Plates}

Plate 1. Silver Springs (Section 1) 85

Plate 2. Silver Springs (Section 2) 86

Plate 3. Silver Springs (Section 3) 87

Plate 4. Silver Springs (Section 4) 88

Plate 5. Fire-Pit (Section 1) 89

Plate 6. Fire-Pit (Section 2) 90

Plate 7. Fire-Pit (Section 3) 91

Plate 8. Fire-Pit (Section 4) 92

Plate 9. Fire-Pit (Section 5) 93

Plate 10. Fire-Pit (Section 6) 94

Plate 11. Kids (Section 1) 95

Plate 12. Kids (Section 2) 96

Plate 13. Kids (Section 3) 97

Plate 14. Joady (Section 1) 98

Plate 15. Joady (Section 2) 99

Plate 16. Joady (Section 3) 100

Plate 17. Joady (Section 4) 101

$\begin{array}{lr}\text { Plate 18. Joady (Section 5) } & 102\end{array}$

Plate 19. Joady (Section 6) 103

$\begin{array}{ll}\text { Plate 20. Joady (Section 7) } & 104\end{array}$

Plate 21. Images from the Sequential Macro-Frame: Fragment 1 (Silver Springs)

Plate 22. Images from the Sequential Macro-Frame: Fragments 2 and 3 (Fire-pit and Kids). 109

Plate 23. Images from the Sequential Macro-Frame: Disnarrated Elements. $\quad 110$

Plate 24. Details from Site Plan 112

Plate 25. Design \#1: A Row in the Housing Scheme 115 


\section{INTRODUCTION}

As the Ottawa suburb of Barrhaven extends its borders, the remnants of what came before become eyesores in the face of new developments. Caught in the interval between its agrarian past and suburban future, Temporary Road presents itself as a peripheral site standing in stark contrast to the suburb on its border. Slated for development in 2006, it demands an approach that will address its collective constitution: the exposed domesticity of a decaying homestead, traces left by unidentified visitors, and the fragmented narratives of occurrences and recurrences. Unlike the linear, functionally prescriptive nature of the development on its boundary, the site at Temporary Road is constantly constructed, deconstructed, and reconstructed - the effects of multiple users and their interventions on the site. The investigations of this thesis will work against the (time-, thought-, and cost-) efficient, repetitive suburban model destined to be applied to a rich and subversive site.

Architectural representation should not be adherent to the linearity and conventions propagated by the conditionings of traditional narrative form; it should advocate the multiplicity of human experience. This argument will be supported by explorations of the role of narrative in the realm of architectural representation.

The representational role of an architectural drawing, the "one unfailing communicant" of architecture should not be limited to that of an imitative device (dictating spatial and functional goals), but an exploratory means by which architecture and its aggregate makeup (as a discipline in service of myriad functions, institutions, and clients) are induced. ${ }^{1}$ Within the architectural drawing is where the architect's disposition towards

\footnotetext{
${ }^{1}$ Robin Evans. Translations from Drawing to Building and Other Essays (Cambridge, Massachusetts: The M.I.T. Press, 1997) 126.
} 
the issue becomes evident: to what degree of sensitivity the amniotic relationship between building and surroundings, site and social sphere are acknowledged. In representation, the implications of the framing begin to establish boundaries and connections between architecture and the outside world. The drawing becomes a forum not only for architectural discourse, but for questioning the roles of (the network of) constructs which frame human life. The spaces and consequent situations of the social sphere have a crucial place in the generation and representation of an architecture that frames them. Narrative conditions our absorption and understanding of events, not only in representation but in everyday occurrence. The communicative cues implanted by narrative on our everyday activities must be regarded critically in order to accommodate change and unpredictability rather than creations of dictating linearity and delusion. The experience of the human being in her environment supersedes idealized goals. Likewise, the creation of architecture should aim to supplant distilled goals and engage itself within the thickness of the world rather than deny it.

In order to devise an alternative scheme in acknowledgment of the diffracted nature of Temporary Road, the traditional (linear/teleological) narrative form in architectural representation must be relegated in favour of the primacy of experientiality and the user. For the purposes of this thesis I will draw grounds for the incorporation of narratological arguments into the realm of architectural representation from the studies conducted by Monika Fludernik (based in the literary realm) and Werner Wolf (who attempts to bridge certain literary notions into the pictorial/visual realm). This will culminate in the sequential macro-frame, a representational medium composed of (visual) narrative fragments, documentation, and the uncategorized explorations of 
Temporary Road. The macro-frame is unique to its site, adaptable, and bound to its consequent design.

This thesis will consist of creating and testing a prototype through which architectural representation (the sequential macro-frame) can play an active role and reassert itself in the design of an accretive housing scheme for a site on the brink of annexation. The result of this exploration will be an alternative to the solutions of the developer, a design for Temporary Road cultivated by "listening attentively to flows, the energies, the rhythms which the passing of time and the loss of limits have established."2

\section{ISSUES OF ARCHITECTURAL REPRESENTATION: DRAWING AND NARRATIVE}

\subsection{Overview}

Conventions in any discipline are assumed to create manageable parameters and refine communication. As society shifts to accommodate ever-changing cultural and scientific advances (resulting in new social situations), heavier emphasis falls on notions such as the global village, commerce, and digital/electronic media. These call for simplification for the sake of standardized discourse and relief from the flux of progress. In architecture, the simplification of architectural language for the sake of clarity and efficiency runs the risk or omitting important architectural truths, namely human experience on which the building plays a crucial role. This sensitivity cannot operate within a pared down architectural language and should acknowledge the aggregate

\footnotetext{
${ }^{2}$ Ignasi de Solà-Morales Rubió. "Terrains Vagues," ed. Cynthia C. Davidson, Anyplace (Cambridge, Mass.: M.I.T. Press, 1995) 123.
} 
composition of human experience. Trying to move conventional architecture and its aims (as embodied through its initial representations) towards accretion rather than imposition requires a reevaluation of the conventions around which typical practice is centered. As Catherine Smith says in her Essay Looking for Liminality in Architectural Space:

"Traditional, professional architectural practice is orientated around building procurement and objects rather than human experience" which stresses the need to reengage architecture with the people and places on which it accretes. ${ }^{3}$ The reevaluation should begin at the very conception of architecture with emphasis on its representation being made to engage any receiver rather than only those familiar with an exclusively architectural discourse. To consider architecture in terms of human experience, culture, and society it is necessary to break from this autonomy. As Jonathan Hill observes in Architecture - The Subject is Matter, "[t]he language used by architects and architectural historians has two obvious aims, to talk precisely about architecture and to exclude outsiders from the conversation." The exclusivity and impermeability substantiated by this remark only perpetuates a notion that human experience (the user) is subordinate to the discourse represented by designers. Infiltration can pose a threat to the vision of the architect that seeks to create a hierarchy where the architect stands above the user. The drawing remains a cue that the mentality of the "hierarchy of architect and user is evident in the discourse of architects even if it is expressed with less conviction."5 Graphic

\footnotetext{
${ }^{3}$ Catherine Smith. "Looking for Liminality in Architectural Space." Limen: Journal for Theory and Practice of Liminal Phenomena no.1 (2001): 02 May 2005<http://www.cartage.org.lb/en/themes/Arts/ Architec/ArchitecturalStructure/LookingforLiminality/LookingforLiminality.htm>

${ }^{4}$ Jonathan Hill(ed.) Architecture - The Subject is Matter (London and New York: Routledge, 2001) 3.

${ }^{5}$ Ibid. 58.
} 
reduction can maintain the architect's role as prime controller, excluding the variant user who may undermine function or intention and compromise this hegemony.

A reassessment should be made at the communicative source of ideas and intentions- the representation of architecture. Therefore in this thesis, two common recurrences in architectural (re)presentation in particular shall be called into question: drawing and the issue of narrative.

Architectural drawings, as the main communicants of an architectural design or proposition, are heavily weighed in regards to their success in conveying the intentions of the architect and of the issues of the site and function. Through these drawings, the designer also reveals the degree by which she attempts to communicate to those unfamiliar with architectural language. This is rendered through the level of experiential sensitivity attempted in order to engage the receiver rather than a design that "resorts to a limited modernist idea of form as the primary means of evaluation"6. The drawings should show consideration for fragments of life outside the architectural conventions as architecture always serves a purpose, whatever its specifics may be, centered on humanity in a variable world. At no point is architecture an absolute - it changes over the course of time, in its exposure to natural phenomena, through its use both accounted for and unknown. Architecture should be conceived of and built with the user in mind, not just as filler, but as active agents in the constant $r e$-realization that makes the architectural experience so human and unpredictably individual.

It is a convenient disposition when the architect reigns as form-giver and the user is subordinated in order to comply towards desirable use. The manipulation of the

\footnotetext{
${ }^{6}$ Peg Rawes "Animal Architecture," ed. Jonathan Hill. Architecture - The Subject is Matter (London and New York: Routledge, 2001) 209.
} 
experiencers of architecture yields an architecture that stands in support of control and in contrast to flexibility.

Although the implications that architecture should seek to reaffirm its tolerance for the arbitrary may seem detrimental, sensitivity to the variability of the world (in contrast to architecture being an open and shut case) addresses the multiplicity of culture, society, and nature and all of their constituents. These cannot be represented through generalizations, nor can the buildings they inhabit. Shouldn't these issues be relayed in the crucial stages of the (re)presentation of architecture? If it isn't the creator of the architectural object who brings forth these considerations, will they ever be proliferated? Representation should aim to reveal the multiple realities of (spatiotemporal) experience. As Solà-Morales says of topography, the architectural should employ a form of representation "that articulates rather than depicts: it reveals multiple topographies, rather than representing or reproducing one in the manner of a graphic simulacrum." Architectural representation should not limit itself to one facet, but many - if only through cues -where at least their recognition attempts a reestablishment with the many components of life with which architecture intertwines itself.

This necessarily restores the precedence of human experience within architectural understanding, creating a shift from the (self-sufficiency of) disciplinary autonomy and bipolarity of structuralist thinking, the "real/unreal, temporal/nontemporal, present/absent, male/female. ${ }^{\prime 8}$ Instead, a weak framework is established to entertain an abundance of variables. While thinking of architecture as language obviously reduces it

\footnotetext{
${ }^{7}$ Ignasi de Solà-Morales Rubió. Differences: Topographies of Contemporary Architecture (Cambridge, Mass.: The M.I.T. Press, 1997) 6.

${ }^{8}$ Gary Gutting. "Post-structuralism." Routledge Encyclopedia of Philosophy. ed. E. Craig. London:

Routledge (1998): 22 June $2005<\underline{\text { http://www.rep.routledge.com/article/N045SECT1 }>~}$
} 
to linguistic models, the definitions of these must be reconsidered to accommodate architecture beyond black and white categorizations that ease the conditioned human desire to clarify between as few choices as possible.

In his essay Translations from Drawing to Building Robin Evans says:

"Language, written or spoken, is replete with manifest sense; the structuralist account of language is emptied of it. An architecture modeled on structuralism, empty therefore of manifest sense, would not be like language at all." 9

What makes architecture like language is the interval between, that which lends to variant projections, interpretations, a multiplicity of experiences, and unforeseen outcomes. There must be an acknowledgment that much is beyond implemented control, both disciplinary and human. Through this understanding, architectural representation can open itself to the reality that it relies on borrowing from (and grafting onto) other places disciplines, histories, events, memories - and it is an impossibility for it to exist on its own. In this acceptance of the heterogeneity of our environment and experience, it is necessary to reassess the role of the narrative mechanisms on architecture, its proliferation, and its representation.

In architecture, the ambiguity of the definition of narrative is perpetuated in order that narrative becomes a device that is readily applicable for many purposes: a flexibility of convenience, not sensitivity. In Time and Narrative, Paul Ricoeur defines it as a semantic innovation where "[b]y means of plot, goals, causes, and chance are brought

\footnotetext{
${ }^{9}$ Evans 126.
} 
together within the temporal unity of a whole and complete action." ${ }^{10}$ Jean-François Lyotard refers to narratives as legitimations that "allow the society in which they are told, on the one hand, to define its criteria of competence and, on the other, to evaluate according to those criteria what is performed or can be performed within it." ${ }^{11}$ Narrative is, at least to some extent, the collection of events that tell or relay a story, the plot is the way in which the events are organized. The Russian Formalists related the story (fabula) to the chronological sequence of events and plot (syuzhet) to the order in which the events are presented in the narrative. ${ }^{12}$ In cinema, the story of a narrative film includes "all the events that we see and hear, plus all those that we infer or assume to have occurred, arranged in their presumed causal relations, chronological order, duration, frequency, and spatial locations..." while the plot refers to "all the events that are directly presented to us, including their causal relations, chronological order, duration, frequency, and spatial locations..." ${ }^{13}$ The constant reinvestigation of narrative and its constituents alone supports the claim that narrative applications are of importance to understanding of human nature. In his novel Waterland, Graham Swift outlines this tendency for narrativity:

“...only animals live in the Here and Now. Only nature knows neither memory nor history. But man...is a story-telling animal. Wherever he goes he wants to leave behind not a chaotic wake, not.

\footnotetext{
${ }^{10}$ Paul Ricoeur. Time and Narrative (Chicago: University of Chicago Press, 1984-1988) ix.

${ }^{11}$ Jean-François Lyotard. The Postmodern Condition: A Report On Knowledge (Minneapolis: University of Minnesota Press, 1984) 20.

${ }^{12}$ J. A. Cuddon. The Penguin Dictionary of Literary Terms and Literary Theory (London: Penguin Books, 1999) 328.

${ }^{13}$ David Bordwell and Kristin Thompson. Film Art: an Introduction (New York: McGraw-Hill, 1997) 481482.
} 
an empty space, but the comforting marker-buoys and trail-signs of stories. He has to go on telling stories." 14

Here, Swift acknowledges the notion that narrativity is employed to apply meaning to a chaotic world. Ultimately, narrative can be understood as a human construct.

When Werner Wolf noted the existence of: "the so-called 'natural narratives' of oral everyday conversation, film, and even architecture and music" he loosely identified some association with the architectural realm. ${ }^{15}$ This relationship stems from merger of the two human constructs and of experience of one through the other: architecture through human eyes. Narrative is constantly present in architecture whether it thrives in many forms through its conception, generation, resolution, or as influence.

Vague understanding of the definition of narrative in architecture (its composition and implications) poses the threat of being a convention lacking the critical reflection and sensitivity that should be constant in a world of unpredictability.

Both narrative and architecture define and redefine human civilization and society by inscribing and constructing themselves in the environment in order to create meaning and control from variability. By reevaluating the symbiosis of architectural representation and narrative form, a better understanding of the benefits of the interweaving two important human inclinations - building and storytelling - will result. Through the specifics of this exploration, a new conception for the representation of architecture (and narrative) will work to recognize the importance of the story-telling animal in her (built) environment.

\footnotetext{
${ }^{14}$ Graham Swift. Waterland (London: William Heinemann Ltd, 1983) 53.

${ }^{15}$ Werner Wolf. "Narrative and narrativity: a Narratological Reconceptualization and its Applicability to the Visual Arts." Word and Image 19.3 (2003) 180.
} 


\subsection{Drawing}

Representing only what the object should be (idealization) in design does not account for the variables that could effect the experience of its realization. The architectural drawing should not be an issue of mimicry but of transmission. Through its conception, transfiguration, and presentation, the architectural drawing could become a means of inviting the viewer to incorporate the possibilities afforded by the ascriptions of users: the individual histories, memories, and experiences that each person projects onto the design, creating a scheme of experiential multiplicity rather than a singular design outlined by function. These potentials could subvert intended programs, functions, and progressions while creating a dialogue between architectural issues and the variables of the world on which it builds.

While including the graphically accepted norms (plan, section, elevation) for architectural considerations, representations should attempt to establish connections with the heterogeneous environment that contributes to the realization of architecture.

Through the reading of these communicants, the viewer must attempt to spatially resolve the built thing without the advantage of being directly engaged with the physicality of the thing itself. Robin Evans regards this as "a peculiar disadvantage under which architects labour, never working directly with the object of their thought, always working through some intervening medium, almost always the drawing." ${ }^{16}$ Relying on these drawings as the primary means of understanding the intentions of their originator is the accepted method - the images in place of the object. Unlike other artistic forms, an architect's control over the creation of the product, especially in typical practice, is not absolute (due the various parties involved in its realization), nor is the architect's control of architecture

\footnotetext{
${ }^{16}$ Evans 156.
} 
in its built form as it must be exposed to the variability of nature, human inhabitation, and time. As Hill notes in his essay "Weather Architecture": "The ability of the architect to predict the form of the building is more accurate...but the architect's ability to predict use is especially uncertain." 17 Even in its 'final form' or as the 'end' product, architecture is constantly subject to change and the unpredictability of life's unknowns. Its object is not hermetic nor should we attempt to represent it as such.

The interpretation of a set of drawings relies heavily on the language employed from the author's implementation of graphic codifications to bind the parts in continuity to the actual placement of the drawings or images - their absorption by the viewer is guided through learned cues. Though the subjective interpretation of an architectural scheme will vary between viewers, it is typically encouraged (both for the sake of presentation as well as retaining a barrier-free architectural language) to create drawings that promote a certain purity. Desiccation in representation does not always imply that it considers other realms, their potential relationships, and affects on the design. This reduction is also heavily reliant on a specialized understanding of architectural language. The idea that "architecture is a kind of writing" is a repercussion of linguistics, the idea that writing "not just means something (a condition difficult to avoid), but that it means so very much, being so very little." 18 The use of linguistic models in realms such as the architectural, however, poses problems as assumptions about conveyed potency (through eradication of the non-architectural) can work against the conception of an architecture that attempts contact with its surroundings. As Evans says of Eisenman's "Fin d'Ou T Hou S":

\footnotetext{
${ }^{17}$ Jonathan Hill. "Weather Architecture," ed. Jonathan Hill, Architecture - The Subject is Matter (London and New York: Routledge, 2001) 70.

${ }^{18}$ Evans 123.
} 
"Behind it lies the presumption that, structure being essence, the structure must be iridescent with potential meaning. But what if it were not? What if instead, after this process of divestment undressing the architectural object of is customary associations, stripping it down until it is as nearly as possible a formation from which ordinary iconographic analysis could yield nothing the effect were not one of iridescence but of muteness?",19

Rather than attempt a richer representation through visual means, Eisenman has supported his object through insistent writing that leaves the final work seeming as if it is dependent on the illusory effect of text rather than architectural language. This denies the object its own credibility as architecture. Undressing architecture to convince the receiver of potential can easily work against these wishes by failing to engage the represented with those things beyond an architectural predisposition. Representation should seek to entertain the richness imparted by other realities, rather than pare itself down only to be reliant on some other excursus. Those drawings that lean towards the sterile end of the spectrum of cleanliness - that is, the technically pristine - isolated set of architectural drawings (purged of all the roughness and uncertainty present in their development) encourage the thinking that architecture operates autonomously, within its own boundaries. Similar to the object presented in a gallery, the architecture is stripped of context. This tends towards a controlled vision and product, but architecture differs from certain other artistic pursuits in that it is to be inhabited, exposed, and appropriated. Evans notes that it is "understandable that, in the interest of the integrity of our art, we should imagine it contaminated by other forms of communication, just as it is understandable that, in the interest of its aggrandizement, we should imagine it

\footnotetext{
${ }^{19}$ Robin Evans. "Not to be Used for Wrapping Purposes," Translations from Drawing to Building and Other Essays (Cambridge, Massachusetts: The M.I.T. Press, 1997) 124.
} 
comparable to language. But this is only to offer excuses for the possession of incompatible ideas." ${ }^{20}$ Architecture must seek to engage itself with the world, even in its conception; it also furnishes bodies, needs, and the changes that these will inevitably carry into their occupied spaces. While many of these can be predicted - through programs and intent - no one person could forecast the way the next will occupy and interpret a space. Therefore, a drawing stripped down for the sake of the clarity of vision does not lend itself willingly to the bodies and needs of the world outside the realm of architecture for it fails to develop itself beyond the constraints of its own conventions. Rather than inviting the viewer to conjure a mental space in which she can inhabit, it denies the heterogeneous composition that converges in the architectural work: a merger of materials, implementers, agents, and the subsequent realities brought in by each. The denial of architecture's aggregate makeup works to direct the viewer into an understanding of what the architect would prefer to bring forth, the production of which has a very 'marketable' aftertaste. Evans pinpoints this directedness and notes its potential pitfalls:

"Fastidiousness about the purity of vision arises from a fear that all distinction will be lost as one category forces itself into another. We protect it because we think it in danger of being overwhelmed by a more powerful agency. With our minds fixed on the predominance of language we might even risk enclosing architecture within its own compound, denying it communication with anything else to preserve its integrity.",21

\footnotetext{
${ }^{20}$ Evans 155 .

${ }^{21}$ Ibid.
} 
An attempt at an honest genesis for architecture would allow for not only program and goal, but for the tendencies of human nature: for, as Marcia Tucker remarks in $\underline{\mathrm{Mr}}$. Wilson's Cabinet of Wonder, the "marvelous field for projection and transference.",22 Architecture frames experience, but cannot dictate it. Therefore, it should lend itself to the variability and interloping of human appropriation rather than eradicate this tendency through deliberately narrowing the design to autonomous architectural form.

The exclusion of the evidence that communicates the existence of the realities outside of (or engaged with) architecture robs the design of its interpretation in regard to its many potentials. Architecture can be pliant, an incorporator; acknowledging the effects of variables on the built world. Human experience (memory, the sensory, temporality, spatiality), disciplinary categorizations (the artistic, scientific, political, historical, ethnological, cultural), natural forces (weather, heat, gravity), and even the unknown (the extrasensory and supernatural) can change architecture from forms to places. These factors become both agents and ascriptions of the relationship forged between the frame, its contents, and the matter that intermingles between the spaces they create.

Stripping evidence of architecture's potential for flexure can create a linear and sterilized understanding of a design. This may be a security for many schemes, directing attentions to the grand vision rather than seeking the viewer's personal engagement. But, as SolàMorales wrote: "All spaces are contaminated. Every precinct has doors and windows that communicate with other precincts and spaces. ${ }^{, 23}$ Not only can value be extracted from seeking a new means of representing these potentials of architectural experience, but relationships that may not be conventionally considered can assert their presence and

\footnotetext{
${ }^{22}$ Lawrence Weschler. Mr.Wilson's Cabinet of Wonder (New York: Vintage, 1992) 40.

${ }^{23}$ Solà-Morales Rubió, Differences, 7.
} 
purport new implications. Awareness of the culturally acquired adhesion to linear tendencies for organization of experience is the first step towards reconstructing architectural representation to suit interdependency and variability. This is done to guarantee that architecture and its representation serve as stimuli beyond some human construct for clarity and meaning in fear of the unknown.

\subsection{Narrative}

Exploration of traditional narratives and their effects will clarify the compulsion towards the idea of a linear time in opposition to a conception of contemporary time that "presents itself as a diffracted explosion in which there is no unique and single time from which we can construct experience. There are, instead, various times, the times with which our experience of reality produces itself." ${ }^{24}$ The difference lies in the closed causal chains of traditional linear narrative and the fragmented, disordered nature of a time that opposes it. Here, time is acquired through narrative conditioning, supporting the organization of events into plot-based and therefore, manageable parameters. The constant reevaluations of the contemporary world (scientific, artistic, political etc.) and the consequence of contemporary time seem to dissolve this security by offering instability and disruption. Like the Copernican demotion of the Earth, revisions to fundamental human hard-wiring, especially that as durable and encompassing as narrative form, can be seen as unfavorable as they shift away from the manageable and towards the uncontrollable - even if it is human progress that brings these issues to the forefront.

\footnotetext{
${ }^{24}$ Ibid. 67.
} 
As traditional narrative follows a logic supported by its effect through time, it does not accommodate variability. But as a construct, was this linearity of time and narrative ever a reality? As Paul Willemen states in his essay "Reflections on Digital Imagery: Of Mice and Men”: “narrative constantly loops back and branches out, condenses and proliferates uncontrollably, which is precisely why the 'meaning' of a story can never be fixed once and for all. Narrative never was linear..."25 A reevaluation of narrative is no new feat in the midst of ever-emerging media where it has been shifted from its primacy and been relegated to vague applications in various realms. In architecture we should seek to apply such terminology with more resolve, addressing narrative not only as an exploitable resource for conceptual support, but as a redefined framework from which representation can be experienced by multiple receivers because, like Willemen says, “interactivity has always been a feature of any representational media...",26

An understanding of the traditional narratological view is beneficial, as well as reasons for which these should be revised. As Martin Reiser and Andrea Zapp illustrate in their opening statement in New Screen Media: "We are entering an age of narrative chaos, where traditional frameworks are being overthrown by emergent experimental and radical attempts to remaster the art of storytelling...,27

This radical restructuring should be approached with sensitivity rather than discrediting past norms for the sake of pure mutiny. The necessity for this reevaluation is derived

\footnotetext{
${ }^{25}$ Paul Willemen. "Reflections on Digital Imagery: Of Mice and Men," New screen media : Cinema/Art/Narrative, eds. Martin Rieser and Andrea Zapp (London: British Film Institute Publishing, 2002) 14.

${ }^{26}$ Ibid.

${ }^{27}$ Martin Rieser and Andrea Zapp. New screen media : Cinema/Art/Narrative (London: British Film Institute Publishing, 2002) xxv.
} 
from the dynamism of progress in all fields - these factors take us further from the fundamentals we have come to rely on and make them less and less relevant. Here linear narrative has left deep-seated marks on our sense of being such that we will be resistant to any reconfiguration of what we feel we have come to know. As Lefebvre says: "human rhythms...determine the way in which we perceive and conceive of the world and even the laws we discover in it." ${ }^{28}$ George Butte affirms this by saying "stories narrate human consciousnesses. ${ }^{29}$ The inclination to adhere to this will not be released without good reason. Through an exploration and evaluation of traditional narrative form, its translation and value to the architectural realm can be better understood. This process will also reveal the relevance of restructuring old narrative frameworks in recognition of the fleetingness of perceived realities from one moment to the next in the contemporary world.

A thorough exploration as to where narrative fits in relation to both architecture and the realm of visual arts will stem from the literary realm, where heavy discourse on the subject naturally occurs. In his essay, Narrative and Narrativity: a Narratological Reconceptualization and its Applicability to the Visual Arts, Werner Wolf attempts just this for the visual arts and forms, for issues of architecture, the means from which an architectural reconceptualization can begin.

\footnotetext{
${ }^{28}$ Henri Lefebvre. Dialectical Materialism (London: Cape, 1968) 142.

${ }^{29}$ George Butte. I Know That You Know That I Know: Narrating Subjects from Moll Flanders to Marnie (Columbus: The Ohio State University Press, 2004) vii.
} 


\subsubsection{Narratemes}

With reference to a 'narrativist turn' experienced over the past century into many streams of cultural practice, the feeling that "[n]arratives are everywhere" justifies the analysis of this notion's repercussions into the realm of architecture. ${ }^{30}$ Narrativity, the defining quality of a narrative, is comprised of syntactic elements Wolf (as well as Gerald Prince in his book Narratology: the Form and Functioning of Narrative) refers to as 'narratemes'. (Terminology and concepts used in Wolf's arguments can be found in the (Table 1). In order for a text to be rendered narrative, it need not include all these factors, but the intensification of a narrative is dependent on how many narratemes are employed. "Narrativity hence emerges not as a categorical quality admitting only the binarism of a yes or a no, but as a multifactorial and gradable quality." ${ }^{31}$ For the most part, it is along this gradient where opinions seem to differ, grading narratives as 'strong' or 'weak' depending on which narratemes one considers to be of importance, and which are employed. For instance, while agreeing with her in her isolating 'experientiality' as a core narrateme, Wolf disputes Monika Fludernik's emphasis (derived from the 1996 book Towards a 'Natural' Narratology) on the term since he feels she "devalue[s] the element of plot, which hitherto has been a cornerstone of virtually all conceptions of narrativity," and that this demotion is an "iconoclastic gesture." 32 Fludernik argues against merely plot-driven narratives though "they are traditionally endowed with proto-typical narrativity." 33 And, while both Wolf and Fludernik agree on experientiality (and thus the inclusion of an anthropomorphic experiencer/being), Fludernik believes that narratives

\footnotetext{
${ }^{30}$ Michael J. Toolan. "Concepts of Narrative.” Style 34.2 (2000): 168.

${ }^{31}$ Wolf 181.

32 Ibid. 182.

${ }^{33}$ Monika Fludernik. Towards a 'Natural' Narratology (London; New York : Routledge, 1996) 13.
} 
without plot can exist. Her redefinition of narrativity is a proposal in which the setup works "qua experientiality without the necessity of any actantial groundwork...This radical elimination of plot from my definition of narrativity is based on the results of research into oral narrative, where, as I illustrate, the emotional evolvement with the experience and its evaluation provide cognitive anchor points for the constitution of narrativity. ${ }^{34}$ Wolf's unease with this notion appears to stem from his stance that a telos is integral to the degree of narrativity.

It must be noted that, for his purposes, Wolf has isolated what he believes to be 'strong' narratives based on his preferences; since these initial narratives are of a traditional verbal nature, there is a heavy emphasis on plot and outcome - the explicit unfolding of events - which makes the argument somewhat difficult in its adhesion to traditional narrative composition. While he negatively implies that Fludernik's motivation is her drive to adapt her theory to modern fiction, her stance remains true to Alain Robbe-Grillet's arguments for the nouveau roman, "that the systematic repetition of forms of the past is not only absurd and futile, but that it can even become harmful: by blinding us to our real situation in the world today, it keeps us, ultimately, from constructing the world and man of tomorrow." ${ }^{35}$ Her attempts are, at least, willing to address emergent forms rather than debase them in order to fortify traditionalist narratological notions.

\footnotetext{
${ }^{34}$ Ibid.

${ }^{35}$ Alain Robbe-Grillet. For a New Novel: Essays on Fiction (Salem, New Hampshire: Ayer Company Publishers Inc., 1984) 9.
} 


\section{(I) constituents}

(1) narratemes

(2) narrativity

(3) narrative I narrative(s) II

(4)
$=$ factors of Narrativity and basic traits. 'building blocks' and 'syntax rules' of narrative(s)

$=$ the multifactorial and gradable defining quality of narrative(s)

= a cognitive (macro-)frame defined by the predominance of narrativity, used as an approach to factual or imagined reality and as a basic mode of organizing verbal discourse or other forms of representation. = abstract, as of yet media-unspecific realization of the frame narrative in a particular story-substance/story

(II) forms of transmission

(5) oral storytelling, fiction, drama, film, painting (?),...

= media able to transmit narrative(s)/ stories

(6) joke, short story, novel, comedy, historical painting...

$=$ media-specific genres able to transmit narrative(s)/stories

(7) narrative representation

vs. descriptive representation, argumentation...

$=$ media-specific discourse modes/modes of transmission which also serve to transmit stories

\section{(III) concrete results}

(8) narrative(s) III

$=$ (parts of $)$ concrete narrative works/texts as realizations of the frame narrative (narrative I) and of particular stories (narrative II) through specific media and other forms of transmission

Table 1. Narrative, Narrativity and Related Terms. ("Narrative and narrativity: a Narratological Reconceptualization and its Applicability to the Visual Arts." 2003) 183. 
Wolf's second core narrateme is representationality, which differentiates the narrative from other basic discursive frames such as those that communicate information "rather than to permit a meaningful (re-)experience." ${ }^{36}$ Argument, for instance, is a communicative element and is differentiated from narrative in its lacking both experiential qualities and temporality. The representationality of narrative creates a storyworld. This world that is (re-)created the process of representation parallels the notion of the diegesis in film: "the world of a [film's] story. The diegesis includes events that are presumed to have occurred and actions and spaces that are not shown." 37

Other narratemes (categorized under the term content elements) are the classical constituents of characters, action, and setting which make up the story and discourse. Since the narrative is not a static framework, the temporality of setting becomes integral in the experience of change and of space. Action is linked with the temporality of setting and the experience and decisions of the players within the diegesis. Characters or as mentioned before, anthropomorphic experiencers (ascribing human traits to non-human entities) are also listed as they are essential to the experience in the diegetic world. These content elements help achieve the two core narratemes through providing a time, place, and experiencer(s) of change and action based on these changes.

\subsubsection{Narrative I}

Using Fludernik's idea of narrative as a 'macro-genre' under the revised title 'narrative I', Wolf defines the term as "an abstract (and uncountable) concept denoting a cognitive (macro-) frame, in other words, a culturally acquired and hence not 'natural'

\footnotetext{
${ }^{36}$ Wolf 185.

${ }^{37}$ Bordwell and Thompson 478 .
} 
approach to factual or imagined reality and a basic way of organizing verbal discourse and other forms of cultural signification." ${ }^{, 38}$ For the sake of his 'intermedial' argument, Wolf's 'narrative I' is subdivided into three cultural/basic functions: the experiential, philosophic, and communicative. Each of these frameworks is developed from the analysis of retrospective literary narratives of the aforementioned traditional kind, thus each frame works in a teleological fashion or to some end and relegates those dealing less with a traditionally structured plot to non-typical cases. Naturally, Wolf aligns his ideology with that of Paul Ricoeur whose notion that time becomes human time to the extent that it is organized after the manner of a narrative" coincides with what Wolf considers to be the experiential function of narrative: "creating and stabilizing a central epistemological category as a basis of human experience." ${ }^{39}$ The exposure to narratives in our everyday world is a "precondition for developing an idea of time... which cannot be experienced as such." ${ }^{40}$ Here, there is an acknowledgement that we do not actually experience time as narrative, but narrative is an imposition upon time to clarify it. As Ricoeur states early on in Time and Narrative, "[b]y means of plot, goals, causes, and chance are brought together within the temporal unity of a whole and complete action. It is in this synthesis of the heterogeneous that brings narrative close to metaphor." ${ }^{41}$ Wolf notes that adhering to a plot which addresses a definite past and future attributes any perceptions within a narrative as resulting from these satisfying "twofold human desire: the desire to connect a given state of affairs to an explanatory past and the desire, fear or

\footnotetext{
${ }^{38}$ Wolf 182.

${ }^{39}$ Ricoeur 52, Wolf 184.

${ }^{40}$ Wolf 185 .

${ }^{41}$ Ricoeur ix.
} 
curiosity to see the end or outcome of certain states, decisions, events etc. in the future." Again, this does not take into consideration the fact that despite human desire, human experience is not constantly aware of an end - but this plot driven viewpoint naturally establishes itself further by extending into Wolf's second narrative function: the philosophical.

The philosophical function deals with the "exploration and often affirmation of a meaning in the flux of experience. ${ }^{43}$ With regards to this frame he notes an intimate relationship between narrative, meaning, and explanation, where narrative is an integral tool with which we give our existence meaning. But, as Wolf notes: "the very affirmation or even exploration of meaning presupposes a latent uncertainty, an acknowledgement of counter-forces, a fear that the vicissitudes of existence may be pointless, contingent and inexplicable." ${ }^{44}$ As a result of this fear, or in spite of it, narrative becomes an application for explanation.

The communicative function is rooted in the idea that a frame narrative also communicates to others, and is not just clarification for the narrator. Inviting and sharing a narrative provides the receiver with insight and experience of the Other. Human beings are storytelling animals and the interest in the stories of others and their storage stems from this designation.

\footnotetext{
${ }^{42}$ Wolf 185 .

${ }^{43}$ Ibid.

${ }^{44}$ Ibid.
} 


\subsubsection{Narrative II and III}

When 'narrative I' "appears to inform certain contents and results in the story...[here], the second meaning 'narrative II', applies: namely a 'narrative' or a 'story' as a particular, and hence countable, realization of the frame narrative." ${ }^{45}$ (see

Figure 1). This narrative level is 'transmedial' or media-unspecific; according to Wolf, only after 'narrative I and II' - and thus, frame narrative - are realized in a specific medium (i.e. fiction), using its media-specific genres (i.e. novel or short story) can 'narrative III' be reached and to which the label "narrative" applies.

\subsubsection{Narrative pictures}

Using this framework, Wolf moves from the literary realm to the realm of the visual arts. (The framework applies only to works which satisfy the necessity of the core narratemes; therefore, ornamental and abstract paintings were not included in the argument). Dealing with singular (monophase) compositions containing anthropomorphic characters provided a sense that numerous narratemes could be relayed through the visual arts: representationality, and to some extent experientiality and communicability/tellability. The visual arts can create references to known contexts through implicit cues (within the composition) but are often supported by explicit factors like title or textual caption. Wolf notes that "purely visual works have difficulties with the representation of the inner world of thoughts, hence the crucial aspect of the motivation and intention for action, and, even more importantly, with the vital narrative element of time. ${ }^{, 46}$ This does prove problematic, as the unfolding of time (however that

\footnotetext{
${ }^{45}$ Wolf 183

${ }^{46}$ Ibid. 189.
} 
may be understood), separates narrative from a frozen moment. Bearing that in mind, the reception of a work as 'static' proves difficult to be absorbed in any other way by the receiver. Fludernik notes that "[d]efinitions of narrative have traditionally made (a series of ) action(s) the prime constituent of narrativity." ${ }^{, 47}$ Therefore there is usually a conditioned expectation on the part of the viewer to follow the action to some teleological end, or closure. In painting, this is often remedied through the depiction of "pregnant moment monophase pictures" that replace the missing temporality and consequent dynamics by "the spatial dynamics of gestures and movements or 'frozen action.",48 These 'pregnant moments' are often depictions of events from what Wolf refers to as 'cultural scripts': events based on known narratives, often of a religious or mythological nature, which allow the transmission of meaning to the viewer who can then infer (for example: the setting, the preceding and proceeding events) based on his/her knowledge of the narrative in question. This depicted moment is often a turning point where some important change has occurred or is about to occur therefore allowing for narrative expectations to be satiated to some degree.

\subsection{The visual sequence}

As an alternative to the monophase painting, however Wolf suggests that " $[\mathrm{t}] \mathrm{he}$ most obvious and efficient way of creating relatively visually 'strong' narratives by predominantly intrinsic means is to supply the necessary ingredients of temporality and its narrative by-products by employing a sequence of discrete yet coherent

\footnotetext{
${ }^{47}$ Fludernik 20.

${ }^{48}$ Wolf 191.
} 
representations... ${ }^{, 49}$ Fludernik's qualms concerning literary sequence are notable here where she warns that by "installing actionality and event sequences in their definition of narrative, most narrotological paradigms actually treat of narrative in a categorizing, descriptive mode, with the result that narrative in these typologies appears to be static, spatial. This paradox can be resolved if one observes that sequentiality per se, even if it provides cause-and-effect patterns of interpretation (post hoc propter hoc), is ultimately unable to embody narrative dynamics. ${ }^{, 50}$ The importance that can be extracted from these observations cumulatively is that the employment of a visual sequence can be a means of communicating temporality but that sequence alone will not support this nor the implication of action. Although Wolf's allusions to multiphase paintings (works that include multiple temporal events within a single composition) are only briefly discussed and based, for the most part, on religious examples (Poussin's 'Isrealites Gathering Manna in the Desert,' John Martin's 'Belshazzar's Feast,' Benozzo Gozzoli’s ‘The Dance of Salome and the Beheading of John the Baptist') they naturally rely on the understanding of the aforementioned cultural scripts. Secular examples such as those works of Francis Bacon that employ the multiphase are of interest as they not only combine temporally discrete moments involving an anthropomorphic subject, but they can do so in superimposition rather than sequential juxtaposition. This 'multiphase' reveals itself as a superimposed sequence as it requires the viewer to digest the multiple temporal occurrences only, as opposed to the explicit breakup of the successive sequence, this deduction must be made from the merger of times contrary to the understanding of linear time, even of linear sequence. Bacon's multiplicities, whether time, force, or figure

\footnotetext{
${ }^{49}$ Ibid. 189.

${ }^{50}$ Fludernik 20.
} 
related, should be considered more experimental than narrative. These works serve as evidence that it can be the viewer's tendency to narrativize the painting, despite the author's intent. As Deleuze wrote in Francis Bacon: The Logic of Sensation: "we have seen that, according to Bacon, the painter could not give up the idea of putting several Figures in the painting at the same time, although there was always the danger of reintroducing a "story" or falling back into narrative painting.", This tendency of the viewer, particularly with Bacon, may again be derived from the notion that narrative serves as a means of explanation against the unease brought about by the unknown. As Bernard Cache's remarks on Bacon support, the 'unnaturalness' or unease often associated with the reception of these works are "the true nature of the aberration of modern movement: the absence of trajectory allows for impossible recoveries on a smooth background of nonadherence." 52
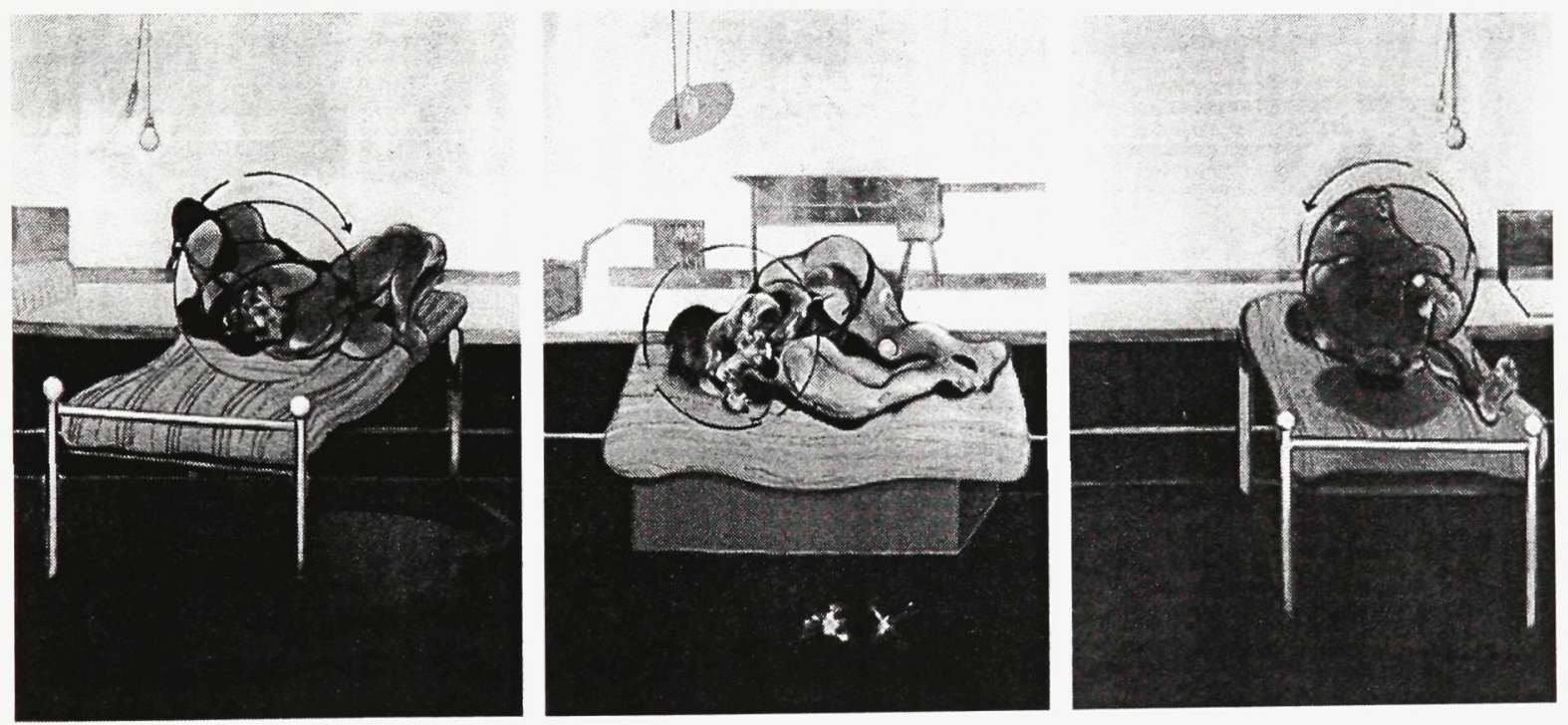

Figure 1. 'Three Studies of Figures on Beds,' 1972. Oil on canvas. (http://www.francisbacon.cx/1972_73.html)

\footnotetext{
${ }^{51}$ Gilles Deleuze. Francis Bacon: The Logic of Sensation (Minneapolis: University of Minnesota Press, 2003) 55.

${ }^{52}$ Cache 26.
} 
Of Bacon's many aims and attempts, another one of significance here was the desire to bring forth those forces and sensations through painting that would not otherwise be observed. Deleuze remarks:

\footnotetext{
"From another point of view, the question concerning the separation of the arts, their respective autonomy, and their possible hierarchy loses all importance. For there is a community of the arts, a common problem. In art, as in painting and music it is not a matter of reproducing or inventing forms, but of capturing forces. For this reason, no art is figurative. Paul Klee's famous formula "Not to render the visible, but to render visible" - means nothing else." 53
}

This trajectory for painting seems to break from any idea of (narrative) closure in favour of explorations caught in moments with no foreseen end, playing not only with temporality, but duration and force. Subjective introjections of experience and memory will occur even here, for it is unrealistic to assume that these explorations could ever be purely experimental just as it would be to assume any representation purely architectural. Even Bacon's attempts at rendering sensation cannot prevent that. But it is here that the need for construction of narrative can be reformed to suit the sensory by stressing the indisputably anthropocentric narrateme of experientiality.

Through the sequence (like Bacon's couplings and triptychs) discrete moments can graft in multiplicity, rather than one coalescent, synthesized form. This extraction from narrative form can be used for the exploration of relations between frames that are "nonillustrative and nonnarrative (and not even logical), and could be called, precisely,

\footnotetext{
${ }^{53}$ Deleuze. Francis Bacon: The Logic of Sensation 48.
} 
"matters of fact." "54 With reference to Bacon's triptych 'Three Studies of Figures on

Beds' (1972) (Figure 1), Deleuze emphasizes that what is painted is sensation:

\begin{abstract}
"[the Figures] do not merge with each other, but are rendered indiscernible by the extreme precision of lines...There is one Figure common to two bodies, or one "fact" common to two Figures, without the slightest story being narrated...Far from contradicting the principle of isolation, the coupled Figure seems to make the isolated Figures simple particular cases. For even in cases where there is a single body or a simple sensation, the different levels through which this sensation passes already necessarily constitute couplings of sensation. Vibration already produces resonances." 55
\end{abstract}

The 'nonnarrative' phenomena explored here reconstruct the body or bodies into new forms through the rendering of otherwise unseen forces (such as gravitational, frictional, or tensional). These indications towards the invisible work to encourage the acknowledgement of potential (energy, movement, forces) that such positioning and representation of figures provokes. A work in three parts, however, can fall into narrative reading, as sequence typically implies. But since it plays on sensation, the formation of any story tends towards issues of experientiality, direct observations: forces and sensations become the suggested matter of contemplation, infinite resonances rather than a finite reading. Here, the sequence becomes a framework that can yield multiple readings of sensational representation, as illustrated by Deleuze's aforementioned contemplation of the Figure. Suggestion becomes a result of placing frames in sequence, but their end is uncertain and purposefully unsought. Bacon is well aware of the potency

\footnotetext{
${ }^{54}$ Ibid. 55 .

${ }^{55}$ Ibid. 56
} 
of unpredictability, as he said in a 1989 interview: "I don't think one can come down to anything specific, one doesn't really know. I mean you could glance at an advertisement or something and it could suggest just as much as Aeschylus. Anything can suggest things to you." 56 This observation becomes strong evidence that plot can be relegated to a position of lesser authority as, through human experience, emphasis in reading varies according to the receiver. Open-endedness is not necessarily rejection of narrative, but reconsideration of the way in which things are represented in spite of its conclusive (traditional) nature. When Lyotard suggests that determinism (as embodied by narrative form) is "losing its preeminence as a paradigm of knowledge and prediction," 57 he advocates the use of narrative shards rather than submitting to the grand narratives circulated as teleological paradigms. This is legitimation by parology, not defined in $\underline{\text { The }}$

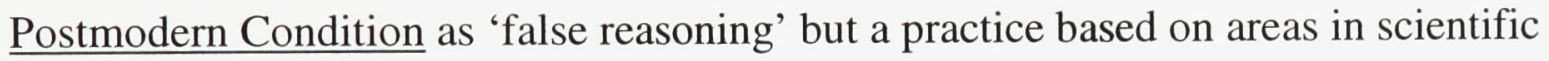
research that seek out instabilities in current theory:

\footnotetext{
"Postmodern science - by concerning itself such things as undecidables, the limits of precise control, conflicts characterized by incomplete information, "fracta," catastrophes, and pragmatic paradoxes - is theorizing its own evolution as discontinuous, catastrophic, nonrectifiable, and paradoxical. It is changing the meaning of the word knowledge, while expressing how such a change can take place. It is producing not the known, but the unknown." 58
}

Here, there is emphasis on those areas of research which seek out instabilities in current theories, imaginatively moving away from the theory-based trajectories of traditional

\footnotetext{
${ }^{56}$ Francis Bacon. Francis Bacon: A Retrospective, (co-curator) Farr, Dennis (New York: Harry N. Abrams, 1999) 46.

${ }^{57}$ Lyotard 60.

${ }^{58}$ Ibid.
} 
scientific work. Lyotard draws parallels between this theory-based research and the grand or meta-narratives that form traditional knowledge. With regards to the presence of cybernetics that drastically differentiate today's societies and economy from those of the past, these grand narratives can be perverted from their emancipating goals (Lyotard uses Marxism and Stalinism as examples). He notes that "the little narrative [petit récit] remains the quintessential form of imaginative invention." ${ }^{59}$ This acceptance of the fragmentary narrative makeup in society, seeking the unknown, tends towards ideas that fall into place with Bacon's rendering of the unseen. Here the strength of the sequence presents itself as a constituent of narrative form that can be adapted to the reformations brought about by these observations. Supporting both the narrative and non-narrative elements of the juxtaposition of Bacon's figures as well as Lyotard's drive towards parology and the petit récit serves as an underpinning for the multiplicity of readings against the traditional narrative grain.

Historically, the sequence has been employed in narrative depiction with recurrent examples including the cave paintings at Lascaux (Figure 2, left), the depictions around the perimeter of the Parthenon, and Trajan's Column (Figure 2, right) in Rome. Here, the sequence has provided a visual means to manifest human stories and epics.

${ }^{59}$ Ibid. 

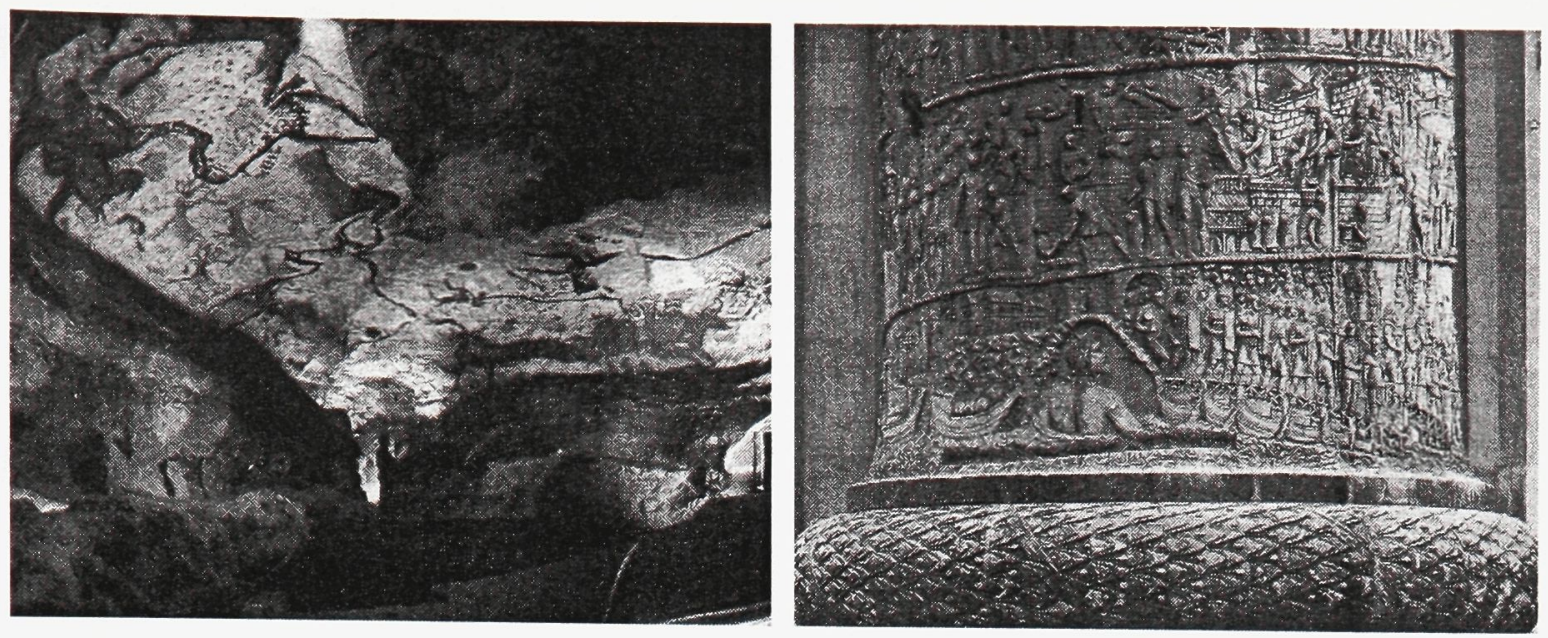

Figure 2. From left: paintings in the caves at Lascaux, detail of the base of Trajan's Column. (Art History, Revised Edition, 1999) 44, 261.

In Lascaux (c.15, 000 - 13, 000 B.C.E.), the depictions of the hunt, animals, and geometric figures are often thought to be ritual images that are read and interpreted in order to understand the conditions surrounding the first traceable marks of humankind. The sculptural decorations on the Pantheon convey "a number of political and ideological themes: the triumph of the democratic Greek city-states over Persia's imperial forces, the preeminence of Athens thanks to the favour of Athena, and the triumph of an enlightened Greek civilization over despotism and barbarism. ${ }^{, 60}$ Trajan's column included a detailed frieze which connected depictions from the Dacian wars which, according to many scholars, could be likened to a cultural script to the typical Roman at the time, eliminating the need for one to experience the relief in entirety, and having the column serve as a monument.

Wolf's discussion of serial pictures also follows recurrent examples of sequential media, however he isolates the examples to those that follow traditional narrative frameworks and follow cultural scripts like the 'moral genre' developed in eighteenth century Britain and France. These works marked a shift from subtleties to heavier

\footnotetext{
${ }^{60}$ Marilyn Stokstad. Art History, Revised Edition (New York: Harry N. Abrams, 1999) 188.
} 
diatribes depicted through multiple paintings as in William Hogarth's 'Marriage a la Mode,' (Figure 3) which also notably depicted a new trend shifting concerns from those of the nobility to the civic realm. However, these sequences were created to focus on a particular, directed point, and therefore easily fulfill their purpose within Wolf's argument.

Generally, these serial pictures are presented as "a sequence of significant phases," and create "intelligible connections between them."61 Through the recurrence of the anthropomorphic experiencers in some time (the notion of which can be propagated through the reading of the sequence as a coherent story) and some place, identification and narrative deduction towards the presented images can take place. Extrinsic means such as captions or titles within a work can further support this narrativization and unification of the serial makeup. "As a result of this mode of narrative transmission, individual representations coalesce into a narrative complete with setting, characters, and action...,62

Wolf concludes that visual arts can be narrative, but still insists that the intensification of the visual arts as narrative coincides with the gradable quality applied to literary narratives. The only visual narratives Wolf proposes to use the term "“narrative' tout court in the full sense of 'narrative III' only with reference to the 'strong' narrativity of a meaningful series of representations in serial or multiphase pictures, provided they depict at least two temporally and causally connected phases of a specific, non-iterative action and contain some uncertain, suspenseful telos centered on anthropomorphic

\footnotetext{
${ }^{61}$ Wolf 189.

${ }^{62}$ Ibid. 190.
} 


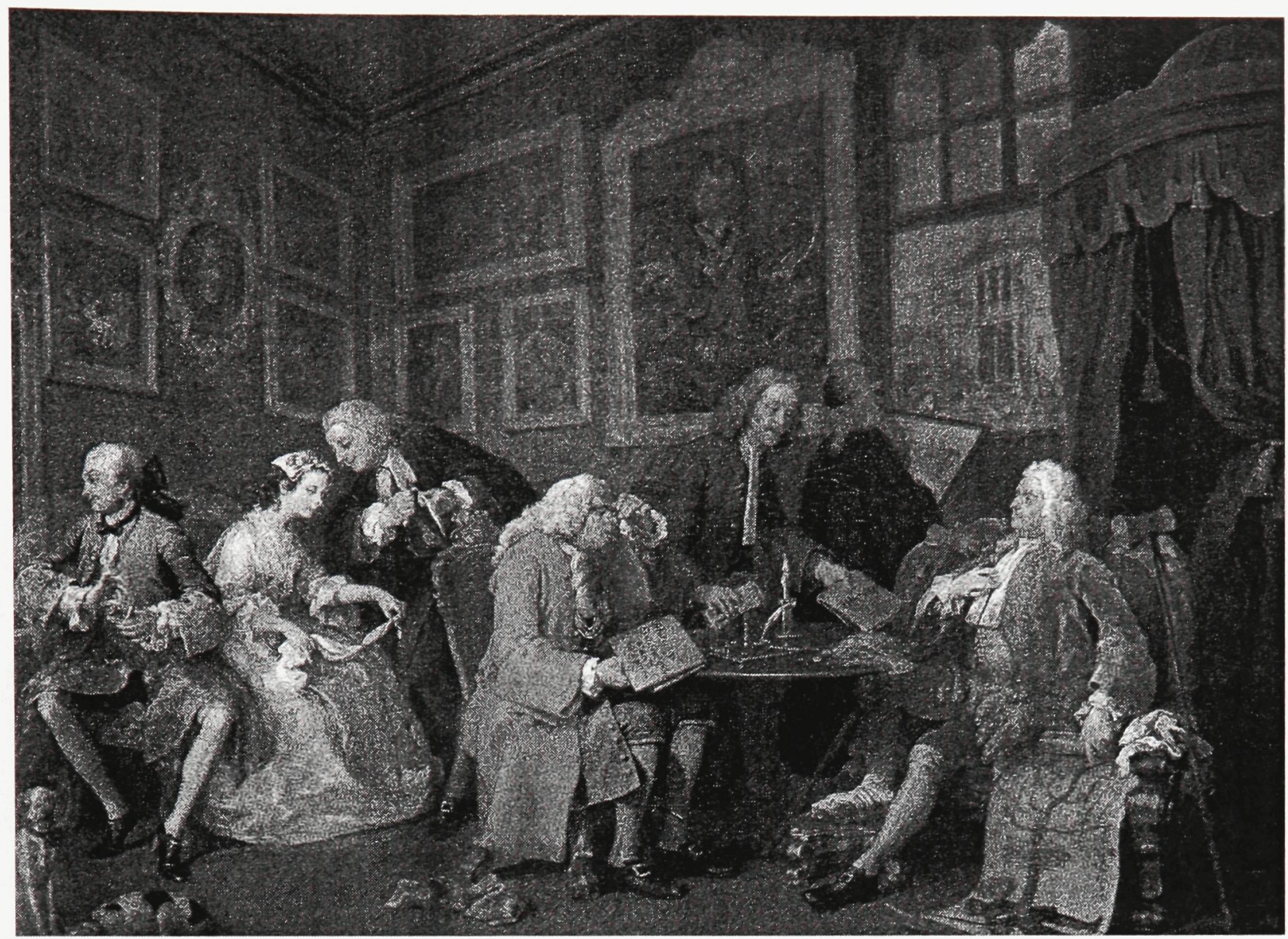

Figure 3. 'The Marriage Contract.' From William Hogarth's 'Marriage a la Mode,' 1743. Oil on canvas. (Art History, Revised Edition, 1999) 931.

beings. For other, 'weaker' cases in which chronology, causality and suspenseful teleology can only be inferred... one could reserve the term 'tendential or quasinarrative. ",63

Herein lies the means for bridging narrative into another realm that relies heavily on the visual throughout its conception and design: the architectural. Through a reevaluation of the pictorial framework of narrative (as offered by Wolf, through the work literary explorations of Fludernik), criteria can be selected as to what can be translated from narrative to architectural representation. In addition to its application, the sequence itself can become an exploratory option; whether it is in juxtaposition of images

\footnotetext{
${ }^{63}$ Ibid. 193.
} 
or their superimposition to convey the evidence of force and the effects of these over time, or to provide a formwork that allows for the integration of many fragments (narrative, sensory, perceptual, temporal) while inviting the uncharted space in between room for personal projection.

\subsection{Narrative and Architectural Representation: Reevaluation}

\subsubsection{Time}

Time in relation to architecture is a key issue of this thesis. It is of obvious importance that some sense of time be imparted through narrative, as narrative is a construct that involves the human tendency for storytelling, which has some implicit order to the receiver, whether or not this order is directed. This is the story/fabula, the mental reconstruction of a chronology based on the presented events of a narrative. Regardless of the intent of the author, it cannot be assumed that each unique individual will envision the same 'story-world' or diegesis, as the next. Through the narrative structure, more specifically, the plot/syuzhet, the author can govern the receiver's digestion of the events in order to create effects (such as suspense or closure) by organizing events to play on expectations. These two ingredients of narrative are conditioned by and condition our notion of time, both in and out of the narrative worlds.

Riceour said time is "human to the extent that it is articulated through a narrative mode, and narrative attains its full meaning when it becomes a condition of temporal experience." ${ }^{64}$ Narrative is defined in part by temporal experience, otherwise there would be no progression of story. The reliance of story on the plot, however, is of concern as plot is used in conjunction with a telos, which makes no sense architecturally as

\footnotetext{
${ }^{64}$ Ricoeur 52.
} 
architecture is not absolute; architecture has no true conclusion. Its only known trajectory is the realization of its design; beyond that it is subject to the uncalculated and unknown future despite foreseeable function. To extend this into the realm of human experientiality, we as humans do not know the logical succession of life's events.

Though humans are easily tempted to appropriate time to create meaning and logic in the world, there are other ways to invite human transference and projection without investing in the linearity of a time with a definite beginning and end. As Bernard Tschumi says in Architecture and Disjunction, "The use of plot may suggest the sense of an ending, an end to the overall organization. It superimposes a conclusion to the openendedness of the transformational (or methodological) sequence. Whenever a program or "plot" (the single family house, or "Cinderella") is well known (as are most architectural programs), only the "retelling" counts: the "telling" has been done enough." ${ }^{65}$ Here Tschumi makes two important insights, he parallels the architectural program with plot, and he refers to the aforementioned cultural scripts. By addressing retelling as today's priority, he acknowledges the need for adaptation. The plot is a construct which tends not to allow for addition or open-endedness which is primary to this particular argument. Likewise, the conventions of architectural representation should duly note that traditional narrative structure may serve well as inspiration but simplifies the issues of experientiality and temporality to a linear level that sheds invitation for interaction, projection, and transference - all of which play key roles in the experience of the object itself. This reassessment of time lends itself more to the acceptance that between our experiences, even our narrative experiences, there are integral spaces; gaps that induce a

${ }^{65}$ Tschumi 164. 
sense of time and create our personal diegetic understandings of the presented. These spaces are the stuff from which subjectivity transforms the narrative into story, appropriating given events to personal experience and memory, making each experience individual. Bernard Cache wrote in Earth Moves that "[e]xperimental imprecision, the occurrence of unexpected events, are signs that reality is a hollow image and that its structure is alveolar. Intervals always remain and intercalated phenomena always slip into them, even if they finally break the frames of probability apart." unsettling understanding of reality is only so because it proves itself beyond human control; this can also be the case for architecture - a human intervention subject to the effects ascribed by unpredictable factors (such as users or the environment).

Vonnegut observed in Breakfast of Champions: “And then I had come suddenly to pity [my countrymen], for I understood how innocent and natural it was for them to behave so abominably, and which such abominable results: They were doing their best to live like people invented in story books. ${ }^{, 67}$ The desires for closure and even of control may be derived from this presence of plot and narrative linearity. The effects of this notion are found deep within human culture; this is exemplified in what Lyotard describes in The Postmodern Condition as "the preeminence of the narrative form in the formulation of traditional knowledge." ${ }^{68}$ This, for post-modernists such as Vonnegut, includes the conception of time. As narratives become legitimizing forms through their projection within the human sphere, they become a means to fabricate manageable parameters within which humans can operate in a systemized fashion. "Thus the narratives allow the society in which they are told, on the one hand, to define its criteria of competence and,

\footnotetext{
${ }^{66}$ Cache 23.

${ }^{67}$ Kurt Vonnegut. Breakfast of Champions, or Goodbye Blue Monday (New York: Dell., 1973) 215.

${ }^{68}$ Lyotard 19.
} 
on the other, to evaluate according to those criteria what is performed or can be performed within it." ${ }^{69}$ The narrative, here, becomes a system of control. Wolf demotes those potentials that are not offered in support of teleological realization or narrative closure as "disnarrated elements" ${ }^{70}$ as if without some direct effect on the unfolding of events, these situations or moments are of little consequence to the overall structure of the reading. These disnarrated elements may work against a smooth plot but can provide rich grounds from which architectural representation can reach beyond its own realm and convey realities often overlooked or thought to be undesirable to an idealized object. The reassessment of plot in narrative yields products that induce open representation when translated into architecture rather than, as Solà-Morales notes, “An ideal, resolute and sure of the real possibility of quantitatively controlling the requirements of an architectonic program so as to provide it with an elegant and economic response that lies at the base of an architecture that assumes the false modesty of being simply the appropriate technical answer to the well-defined requirements."

\subsubsection{Space}

Any understanding of space must be considered in tandem with time. The diffracted time that stands in opposition to traditional (linear, narrative) time requires a space that refutes Lefebvre's observation in The Production of Space: "[s]pecialized works keep their audience abreast of all sorts of equally specialized spaces." 72 This harkens back to the similar notion of an ambiguous and convenient delegation of

\footnotetext{
${ }^{69}$ Ibid. 20.

${ }^{70}$ Wolf 188.

${ }^{71}$ Solà-Morales Rubió, Differences 84.

${ }^{72}$ Henri Lefebvre. The Production of Space (Oxford and Cambridge, Mass.: Blackwell, 1991) 8.
} 
narrative; space here is a deployable human construct. Therefore, space requires a similar reassessment. The traditional (geometric) space is Euclidian, and as Lefebvre implies, a conception of space viewed as absolute and guaranteeing utility:

\footnotetext{
The reduction of this homogenous Euclidean space, first of nature's space, then of all social space, has conferred a redoubtable power upon it. All the more so since that initial reduction leads easily to another -- namely, the reduction of three-dimensional realities to two dimensions (for example, a "plan," a blank sheet of paper, something drawn on paper, a map, or any kind of graphic representation or projection). ${ }^{73}$
}

This reduction and rereduction form a system that works easily towards a representation of idealism. Ideal conditions for an ideal design, neither of which - reductions considered - could possibly encourage any true sense of variability. To operate solely in traditional space does not encourage consideration of the spatial workings of the body, the sensory. Rather than attempting to simulate ideal conditions, representation should aim to transmit a notion of space that can allow the viewer to explore intervals between the givens, yielding an individual sense of represented space. Since the emphasis is shifted from definitive form or dimension to experientiality, overly descriptive modes are replaced by fragments and what Cache would refer to as the intercalary spaces in between. Fludernik noted that the majority of narratological paradigms tend towards a descriptive mode of narrative, the result being that narrative in these typologies seems spatial and static and sequence in of itself is not necessarily dynamic. ${ }^{74}$ What can be noted here is though these descriptions may seem static and of lesser value in literary narrative, they can be seen on

\footnotetext{
${ }^{73}$ Lefebvre, The Production of Space 285.

${ }^{74}$ Fludernik 20.
} 
the other hand, architecturally, as potential; spatial settings that can allow for projections that are free from explicit cues. Rather than playing out the action integral to narrative, it embodies its many possibles. The needs of architectural representation to relay a sense of spaces and times for the object rely on both descriptive qualities and dynamic qualities. This can be achieved through the inclusion of description without closure (fragments allowing for the additions of subjectivity) and sequences allowing for interpretation by loosening the hold of plot in the narrative. Space, out of a traditional geometric or narrative context is fundamental to architecture. Architecture is the creation of spaces which are the settings for human life and, consequently, stories. These stories are not dependent on the explicit function of the setting, or as Tschumi might say, the sequence of events is not dependent on the programmatic sequence: "The linearity of sequences orders events, movements, spaces into a single progression that either combines or parallels divergent concerns. It provides "security" and at least one overriding rule against architectural fears."75 The plot-driven sequence allows more spatial and temporal control as a result of defining the parameters. In our experience of architecture, we are not closed in, but framed by the object. The frame is a recurrent narrative and architectural device, as well as the elemental constituent of the sequence. As Tschumi observes:

"Partial control is exercised through the use of frame. Each frame, each part of a sequence qualifies, reinforces, or alters the parts that precede and follow it. The associations so formed

\footnotetext{
${ }^{75}$ Tschumi 161.
} 
allow for a plurality of interpretations rather than a singular fact. Each part is thus both complete and incomplete...,76

In literature, frame narrative refers to a technique whereby a number of smaller narratives are incorporated into a larger one which binds its otherwise fragmented parts (the story within a story). Using Wolf's terminology, this binding would be categorized as narrative I with narrative II including the 'stories' that allow for the frame narrative to be realized. It is in the idea of narrative II where the tendency towards a telos is stressed.

\subsubsection{Reevaluation}

Here, the core narrative elements applicable to architectural representation can be extracted. Referring back to the terminology of Fludernik and Wolf, the reevaluation should start from the elemental narratemes. Of those outlined as 'core', both experientiality and representationality are integral to architectural representation. The narrateme of experientiality is of importance because it stresses the inclusion of an anthropomorphic experiencer which should be an element of architectural representation regardless of narrative applications since architecture is a definitively human intervention. This inclusion should move beyond simple figures included in drawings, which only tend to denote some sense of scale and occupation. These applications of figures do not explore the experience of a person within space, and reduce the potential brought forth by the inclusion of the experiencer. The sense of drawings being more concerned with their composition rather than the wealth of informative possibilities is echoed through Evans when he says "their consumability has most often been achieved

\footnotetext{
${ }^{76}$ Ibid. 163.
} 
by redefining their representational role as similar to that of early twentieth-century paintings, in the sense of being less concerned with their relation to what they represent than with their own constitution." 77 The emphasis of the anthropomorphic experiencer in architectural representation breaks from the idea of (pared) spectacle in order to sell an architectural idea. This means that using a figure for the sake of compositional sleekness should be forfeited for representation that pursues the effects of the experiencer on the built environment and the effects and affects of architecture on the experiencer. It can be likened to what Deleuze notes about the attempts of Bacon in painting who "distinguishes between two violences, that of the spectacle and that of sensation, and declares the first must be renounced to reach the second, it is a kind of declaration of faith in life.",78 Therefore, architectural representation should not only include the anthropomorphic experiencer, but be aware of its experiential value over reductive usage.

The narrateme of representationality is of importance as well in that it addresses the creation of the story-world or diegesis. In architectural representation, the diegesis is integral to the receiver's engagement with the presented idea. Here, drawings should attempt to embrace the differences projected by each viewer rather than purge themselves of the means to do this for the sake of purity of vision. The diegesis should not be composed solely of elements that denote a single time/moment/possibility. Rather, the representation should seek to invite, explore, and adapt the drawings; both to unforeseen activities and out of the realm of architecture. Like the works of Bacon, the representations should not only embody what is seen, but imply those things that are not to thicken both the subject matter represented and, consequently, its potential for new

\footnotetext{
${ }^{77}$ Evans 160.

${ }^{78}$ Deleuze. Francis Bacon: The Logic of Sensation 52.
} 
possiblities. By introducing the receiver to the design in this way - without the exclusion of the fragments of the site's own (hi)stories, various possibilities for the outcome of the architecture, and its integration into a past, present, and future - there will be less need to find some end. The viewer can be saturated in the experience of a representation that remains sensitive to variation and accepts it as part of its structure. This of course, in opposition to the linearity of representation that cannot encompass all buildings despite the global pressures for efficiency. Tschumi supports this by accepting that "[n]ot all architecture is linear, nor is it all made of spatial additions, of detachable parts and clearly defined entities. Circular buildings, grid cities, as well as accumulations of fragmentary perspectives and cities without beginnings or ends, produce scrambled structures where meaning is derived from the order of experience rather than the order of composition.,"79 This order of experience cannot be defined by a single plot. People should be free to wander/wonder in their own diegeses. This is how architecture (both represented and built) becomes a frame for people, their activities (whether or not they are forecasted), and the means for new possibilities.

Wolf refers to narrative $I$ in terms of organizing reality by cultural acquisition. This 'unnatural' approach stands in contrast to the fragments that, without this frame, do not necessarily submit to meaning or symbolism within the human realm of control. However, where Wolf accepts this organization, architectural representation may do well to contest it; embrace the unknowns and spaces as part of our existence. There is no need, after all, to delimit a design to any one narrative framework if it is human tendency to create one in its absence. Where Wolf might seek a prearranged end, let architectural narrative be as adaptable as architecture can become. So, in terms of narrative in

\footnotetext{
${ }^{79}$ Tschumi 161.
} 
architectural representation one can replace narrative I, where of its three functions, only the communicative function seems viable. The experiential tends to dwell on issues of a certain past and future rather than multiple options while the philosophical heavily insists on enforcing meaning and explanation (in the vein of the grand narrative) in contrast to acknowledgement of the unknown and acceptance of some uncertainty. In substitution for narrative I, the media will serve as a cohesive agent. Rather than organizing narrative within leitmotif (as in a recurring 'base' story binding otherwise unrelated 'fragments' as in frame narrative) or an unnatural cultural acquisition as a conditioned way of reading a story, the representative body will act as the macro-frame. This macro-frame will provoke the receiver to question how she senses and perceives the body without the aid of an understood method such as deducing diegesis through plot, or searching for a teleological 'answer' or truth. Where Wolf might see this replacement as unsatisfactory with regard to fulfilling both narratives II and III, it can be argued that even fragmented events/stories can be made intelligible, if desired, within a given context/frame/medium. In film, the famous example of this phenomenon is the Kuleshov experiment of the 1920’s. Lev Kuleshov, a Soviet filmmaker, conducted experiments where he eliminated the establishing shot in a sequence in order to construct spatial relations by inference.

Taking unrelated scenes and juxtaposing them, the audience assumed they were causally linked. In reality, the scenes had been shot in different times and places that were completely unconnected. Film scholars refer to any series of shots that, in the absence of an establishing shot, prompts the spectator to infer a spatial whole on the basis of seeing only portions of the space as "the Kuleshov Effect." ${ }^{80}$ Is there really a need to subcategorize the uncountable narratives through some cultural means that Wolf himself

\footnotetext{
${ }^{80}$ Bordwell and Thompson 281.
} 
deemed 'unnatural'? Mental resolution on the part of the receiver is presented here as a choice rather than forced through organization. As Solà-Morales mentions in Weak Architecture: "The signified is not constructed by means of an order but by means of pieces that may ultimately touch, that approach one another, at times without touching; that draw nearer to one another yet never make contact; that overlap, that offer themselves in a discontinuity in time whose reading as juxtaposition is the closest approximation to reality at our disposal." ${ }^{81}$ This fleetingness is strength in this realm of representation, it breaks past the boundaries of one discipline and allows others to leak in and mingle, thickening experience even in the absence of the presented architecture. Thus, Roland Barthes” definition of a sequence as “[a] logical succession of nuclei bound together by a relation of solidarity, ${ }^{, 82}$ will become, for the purposes of architectural representation, 'a succession of nuclei bound together by a relation of solidarity' where the 'nuclei' are fragments (narrative, disnarrated, or non-narrative elements) and the 'relation of solidarity' is the representational body (frame) through which the sequence is transmitted to the receiver.

\section{The Sequential Macro-Frame}

Here, narrative fragments, those parts found throughout the recounting of a site, shall be contained within a framework serving as a representational body beyond that of a typical architectural language (plan/section/elevation). This will tie the architecture to the strata of its site through representational means, in lieu of promoting architecture as an autonomous and linear discourse.

\footnotetext{
${ }^{81}$ Solà-Morales Rubió, Differences, 66.

${ }^{82}$ Roland Barthes. Mythologies (London: J. Cape, 1972) 155.
} 
This is the sequential macro-frame, a term originating from Wolf's definition of Narrative I: "a cognitive (macro-)frame defined by the predominance of narrativity, used as an approach to factual of imagined reality and as a basic mode of organizing verbal discourse or other forms of representation." ${ }^{83}$ Since there is no aim for the parts of Narrative I to fulfill a frame narrative and no aversion to the potential of layering (image and text), Wolf would likely categorize this body as tendential or quasi-narrative. Perhaps to those who adhere to the traditional narrative form this is an understandable demotion. But for this thesis, this fragmented form provides the means to move the receiver beyond the position of a reader and invite her to investigate the frame as an experiencer, playing an active role in the digestion of the (re)presented.

This macro-frame forms a model for architectural representation as both generator and indicator of ideas. New architecture is induced by the assemblage, disassembly, and reassembly of parts by translating fragments (forms, spaces, relationships, etc.) into design and reinserting the results into the frame so as to consistently fuse and interchange the sequence of process and product.

This approach seeks to induce the unknown and unseen into architectural representation through a restructuring of the conventional architectural procedure: a "legitimation that has nothing to do with maximized performance, but has as its basis difference understood as paralogy." ${ }^{84}$ Rather than designs of strategic efficiency and plot-based goals, this approach aligns itself with an acknowledgement of instability rather than denial of it. In place of linear processes that have been likened here to traditional narratives, this inquiry

\footnotetext{
${ }^{83}$ Wolf 183.

${ }^{84}$ Lyotard 60.
} 
seeks new answers for architectural representation (through questioning old methods) with the intention of outfitting a site with a unique solution to its particular situation. The resultant design will inevitably seek to employ a heterogeneous sense of narrative, time, and space in conjunction with its representation to yield an accretive scheme grafted from its own unique situation rather than narrow the output and repeating old forms.

The sequential macro-frame was created to understand and extrapolate from narrative fragments that culminate in a tendential (quasi-) narrative of the site. Its components (narrative fragments, dis-narrated elements, and non-narrative elements) must be explored within their separate contexts (as disjunctive parts) while lending themselves to an aggregate reading induced by the macro-frame. The reinsertion of each design aided by the contents of the macro-frame keep this representational body linked with its output; a scheme emphasizing reintegration and reevaluation. The macro-frame also allows for the integration of new fragments and implies their narrativity solely through inclusion. Extracted from the narratological arguments of Wolf and Fludernik, the key points for structuring the framework are:

- The inclusion or implication of some anthropomorphic experiencer, implicitly or explicitly so as to reestablish the role of the user in architectural representation. (narrateme: experientiality)

- The employment of fragmentary constituents (narrative, dis-narrated, or nonnarrative) that induce diegesis beyond that of an architectural nature. (narrateme: representationality) 


\subsection{Precedents}

In addition to narratological arguments and their translations into architectural representation, this thesis investigates several affective works: John Hejduk's 'Victims,' Rachel Whiteread's 'House', and the genre of the graphic novel. These three works have served to support and influence the explorations of this thesis through their approach to the notion of time, space, representation and narrative. Each in its own case presents an alternative to the norms of its realm. The directions taken here have been considered with regards to the macro-frame as these precedents illustrate ways in which forms, ideas, and images can induce a fragmented yet intelligible sense of experience.

\section{$\underline{\text { Victims }}$}

John Hejduk's unrealized proposal (1986) for the city of Berlin presents the citizens with guidelines by which this memorial could be constructed. By providing a loose outline (time limitations, boundaries), supplanting a traditional program identified in the competition brief with narrative fragments, and supporting these parameters with numerous structural possibilities, Hejduk employed the idea of incremental time accretion. This project suggests the role of the citizen be elevated from passive to active, a groundwork has been laid towards uncertain outcomes over two thirty-year time periods. Not only does Hejduk ask Berlin to create this landscape, but he directly forces reflection on the task and the motivations behind it. The proposal encourages the reassembly of given components; consequently, the experiential possibilities (through the weaving of characters, narratives, and forms) become endless. There is no adhesion to a specified, linear realization; rather there are numerous possible paths, which enrich the 
undertaking while compensating the receiver with sought connections. Prominent in Hejduk's 'Victims' is the conscious employment of fragmented narratives in an accretive sense of time in application to numerous fixed forms; in this the proposal became an event. The citizens of Berlin were encouraged to play a more active role in the consideration of the formation of a memorial landscape.
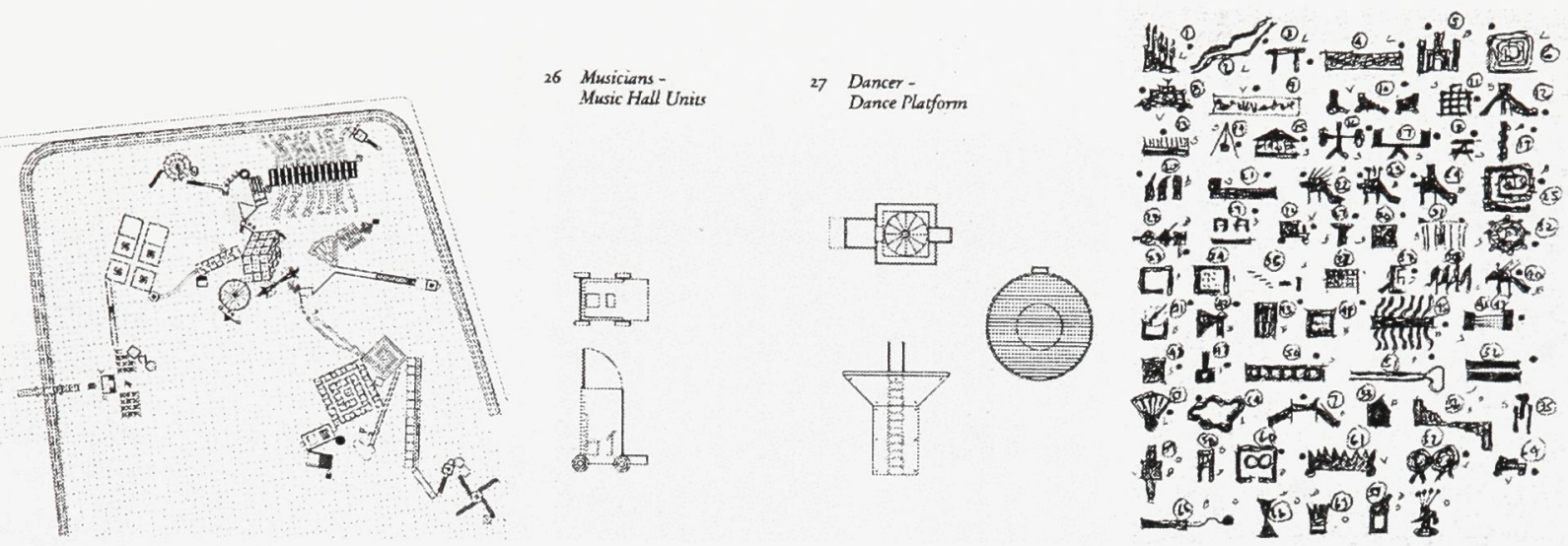

Figure 4. 'Victims.' (left to right): site plan, characters with corresponding structures, sketches. (Victims, 1986)

Similarly, the macro-frame and its resultant design will employ fragments of narratives that, other than their inclusion within the parameters might seem inconsistent. However, they will all be extracted from the site itself and in a sense, rebuild it and reestablish themselves within it.

\section{$\underline{\text { House }}$}

Rachel Whiteread's ephemeral installation 'House' (1993-4) was materialized and destroyed within the span of a year. It investigated the vestiges left on a concrete cast of the interior of a house. This event was highly publicized and documented, leading to public focus on a work that both froze and memorialized the domesticity and banality of 
a house in the working class area of East London. The result became a memorial, criticism, portrait, and replica. The negative of the house revealed traces of a newly publicized intimacy that stood in contrast to the conservative street on which the installation intervened. Constantly rehashing issues of nostalgia, spectacle, privacy, and temporality, the forum provided by this work delves into the significance of its title and the intimacies of everyday life.
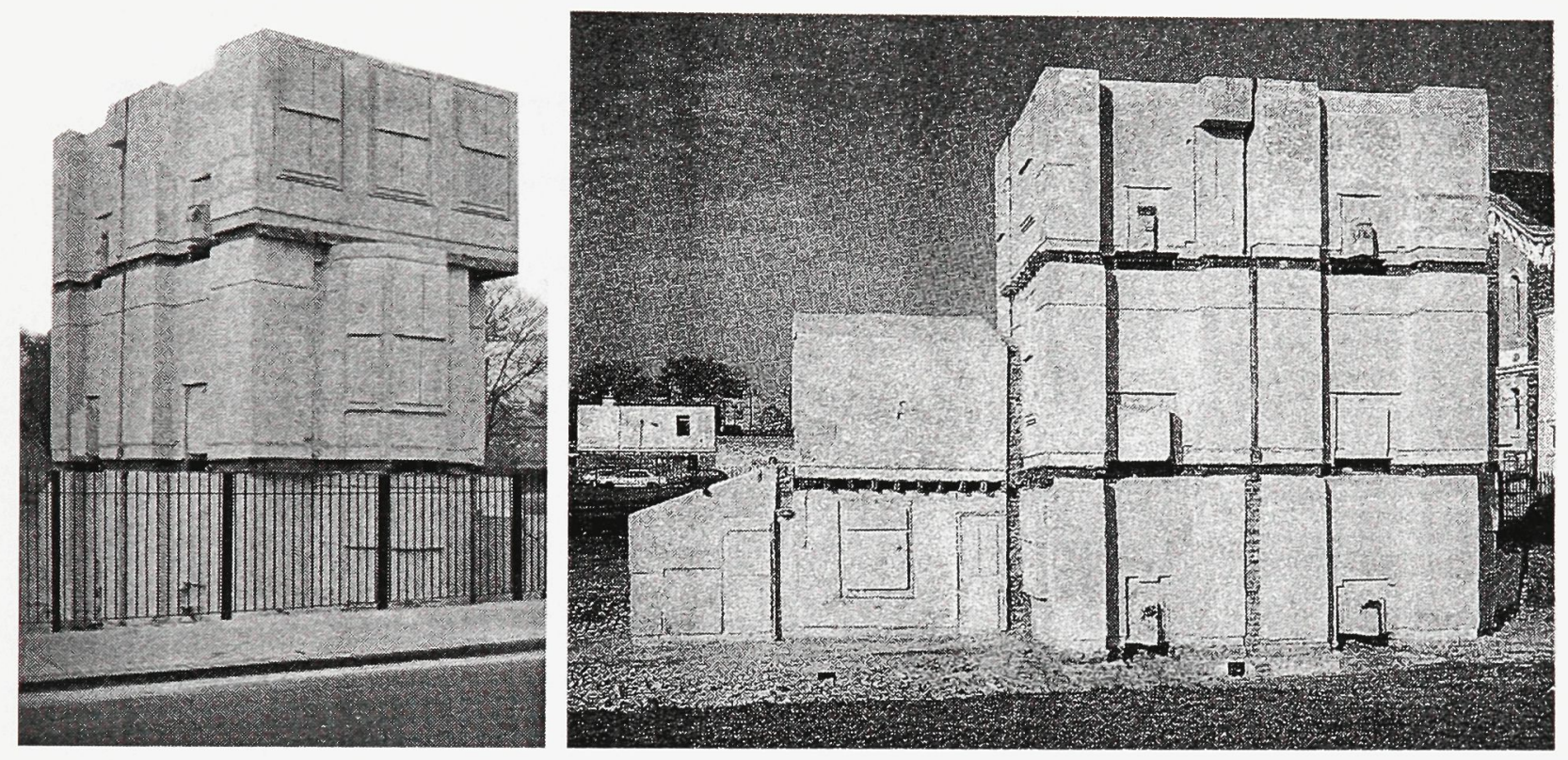

Figure 5. 'House.' (House/Rachel Whiteread, 1995)

\section{The Graphic Novel}

Stephen Tabachnick noted that this particular derivative of the traditional comic book employs "a richer sense of time and space and a deeper involvement of the senses than is available from any other novelistic or sequential art medium" ${ }^{\prime 85}$ Often this offshoot of the comic book medium explores and subverts the conventions of its

\footnotetext{
${ }^{85}$ Stephen E. Tabachnick. "Of Maus and Memory: The Structure of Art Spiegelman's Graphic Novel of the Holocaust." Word and Image 9.2 (1993): 154-156.
} 
predecessor. In many cases, like Wolf's discussion of multiphase and pregnant moment artworks, the imagery employed in the graphic novel attempts to capture and articulate movement and progression beyond the mere sequencing induced by consecutive frames. The frame presents itself not only as a defining feature separating contents from one to the next, but as a decisive cue to the receiver who will develop her own diegesis as a consequence of its placement with others. In Architecture and Disjunction, Tschumi observes:

\footnotetext{
"Partial control is exercised through the use of frame. Each frame, each part of a sequence qualifies, reinforces, or alters the parts that precede and follow it. The associations so formed allow for a plurality of interpretations rather than a singular fact. Each part is thus both complete and incomplete." 86
}

Wagner and William's Tell Me, Dark (Figure 6, left) challenges the conventional comic book layout (frames arranged and read left to right, top to bottom) through arrangement of image and text. Frames are maximized and instead of controlling the reader's diegesis by means of presenting many consistent, distantly framed images (much like the 'establishing shot' in cinema) to outline spatial relations. Larger disconnected images allow for a more personalized interpretation of setting on the part of the reader by utilizing the intercalary spaces between images. This example also illustrates how conventional left-right reading has been employed to imply the passage of time and movement as characters shift from frame to frame, left to right, and the background remains static (evident on the bottom potion of the page). This sequence rations the same

\footnotetext{
${ }^{86}$ Tschumi 163.
} 
setting for three distinct moments, each for which text and figures remain unique. The narrative accumulation of the setting, figures, and text fragments what could have been summarized easily in one frame but allows (through this diffraction) a sense of duration to be established.

Tschumi's remark that "[f]rames are both the framing device - conforming, regular, solid - and the framed material - questioning, distorting, and displacing" ${ }^{, 87}$ can be demonstrated in the pages of Eric Drooker's Flood (Figure 6, centre), which uses the rhythm of the sequential layout to intelligibly illustrate the transition from the protagonist's experience to his inner thoughts. The frames themselves are expanded and contracted to create different sensations allowing for the understanding of multiple states through their reading. In Ted McKeever's Plastic Forks (Figure 6, right), half-page framing abstracts the subject of focus and allows the reader to distance or familiarize herself with the represented object. The frame and framed material work in conjunction to allow for this possibility; the greater size and decreased number of frames work to increase the interchangeability of the images.
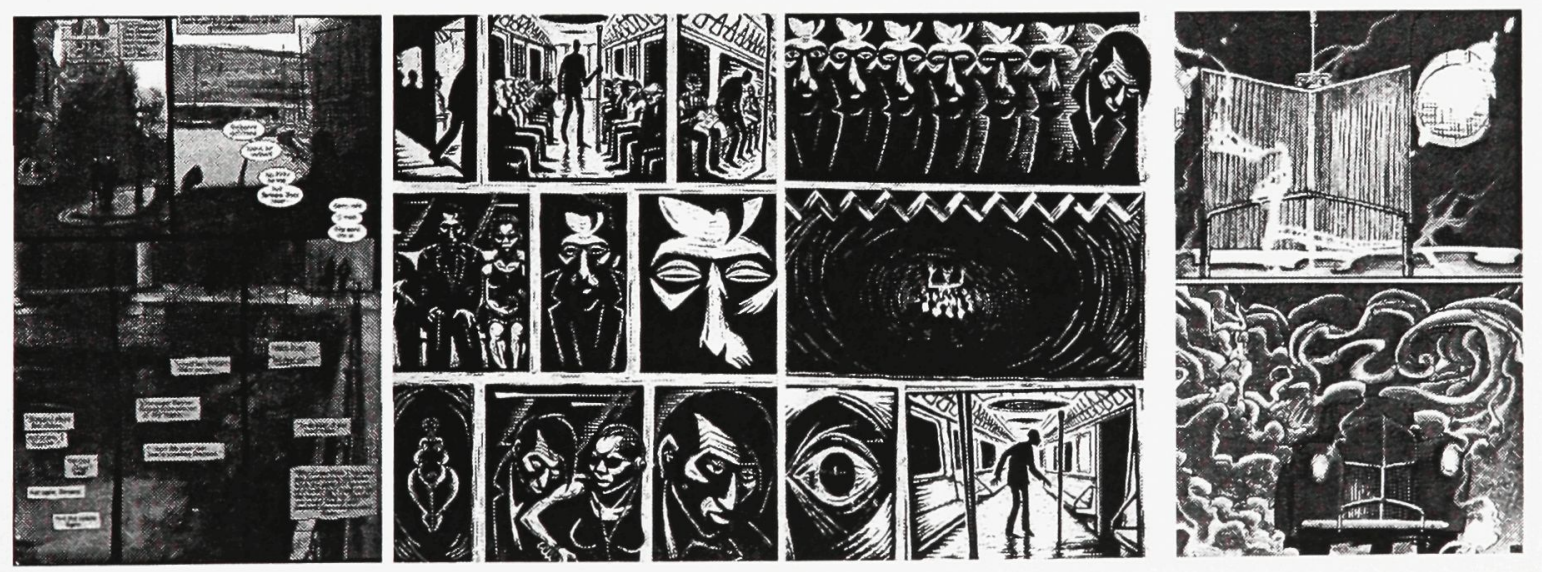

Figure 6. Excepts from Graphic Novels. (From left) Wagner and Williams' Tell Me, Dark,Eric Drooker's Flood, Ted McKeever's Plastic Forks.

\footnotetext{
${ }^{87}$ Tschumi 166.
} 
Cache notes that one function of the frame is to "reestablish connections selectively." 88 Like adjustments to focus, distance, and detail play into the interpretations of importance of the represented, frame can similarly affect the reader's understanding by mere association: why is this being represented? What is its importance within this context? The questions brought about by inclusion often operate automatically in communications between images and eyes. In Gaiman and McKean's Hold Me (Figure 7), irregularly shaped frames offer ample images of the apartment interior so that the single frame depicting an uninvited stranger appears abrupt and focal. The selection of a detailed face emphasizes the importance of the stranger and allows the reader to infer unrepresented possibilities through the interpretation of the particularities of the singular image. This possibility for divergence enriches the images of a two-dimensional medium. Not only do they adhere to the storyline, but they allow for the reader to stray.
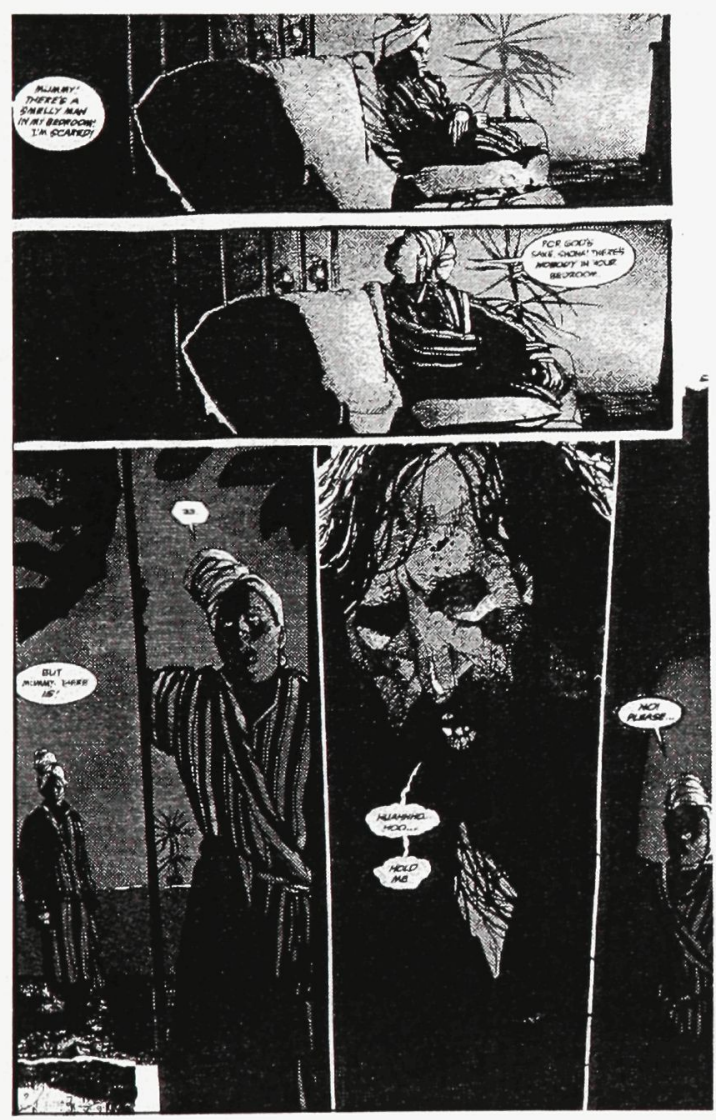

\footnotetext{
${ }^{88}$ Cache 24.

${ }^{89}$ Tschumi 163.
}

Figure 7. Gaiman and McKean's Hold Me.

Like Tschumi said in regards to these possibilities, "indeterminacy is always present in the sequence, irrespective of its methodological, spatial, or narrative nature." ${ }^{, 89}$ The spatial relationships established in these frames between 
the woman and stranger relay a hazy mix of enclosure and exposure that emulates the experience of unknown spaces.

The various techniques and relationships explored here have heavily influenced the images inserted into the macro-frame. The richness of imagery and text, the push against the most efficient, clarified representations and organization make these examples of the graphic novel work as aides in support of fragmented, non-linear narratives. But furthermore, they introduce the notion of the frame, a device easily found in the many stages of architecture (where the frame is never a singular), though its manifestations change. Here, frames contain and juxtapose images, their size and placement making for a great number of effects. Cache describes architecture as "the art of the frame: architecture thus escapes its traditional role of housing and grounding and becomes a practice of framing images in such a way that they induce new forms of life." 90 This important statement is realized through the building: a defining structure that separates us from our landscape and selectively reintroduces us to it through perforations. Cache also insists that, as framing moves into building:

"There is an essential difference between the frame of probability and the effect that is produced within it... The rigid form of the frame cannot coincide with that of an effect that is always subject to variations and is only probable. That is why the frame belongs to a register of autonomous forms whose principle must still be defined... We will now consider architecture to be nothing but the interlocking frames.", 91

\footnotetext{
${ }^{90}$ Cache xviii.

${ }^{91}$ Ibid. 29.
} 
The constrictive qualities of framing cannot prevent the intercalary space from being subject to interpretation, nor can they (in the case of the graphic novel) completely force the eye to follow a forged path. Bearing this in mind, architecture cannot always force function into spaces, it can only induce.

Using Cache's arguments, framing has quite convincingly moved from two-dimensional representation into the third-dimension. The sequential macro-frame will operate on this premise. The potential for diversion from the typical path creates an investigatory facet that allows the reader to participate, renouncing complete control on the part of the author. In this way, the design will attempt to enhance the experience of the user/viewer.

\subsection{Rules of Operation}

The proceeding rules will form parameters to guide the design of this thesis; they are derived from narrotological discourse from previous chapters as well as the guidelines for the macro-frame and precedents. The design will maintain resistance to the linearity of traditional narrative but employ (paralogical) rules to guide the design within that vein. The notions of time as accretive ('Victims'), the ephemeral and enduring qualities of the 'home' ('House') and the challenge of the frame (graphic novel) will all be weighed heavily in the creation of a housing scheme. The result will create and test a new prototype for architectural representation in application to a peripheral site occurring between the farmland and suburb of Barrhaven, Ontario.

The rules will be used in conjunction with the site's tendential narrative formed by the macro-frame. (Detailed discussion of the is found site in the next section) 
Firstly, the designs will pay heed to the developer's intentions for the site.

This not only works with the inevitable future plan but also creates a challenge and subversion of a product of developer logic.

\section{(1.) Each house must be adapted to the footprint laid out in the developer's plan.}

The (Phoenix Homes, 2005) plan subdivides each lot on the site into rows of 3-7 townhouses. Like the fragments within the macro-frame, each individual house is inherently bound to its row through its constitution (frame). In this vein, each row will be treated as a fragment amongst fragments, or parts of the whole. Therefore, each row will operate similarly to the narrative fragments of the macro-frame and employ like fragments in their design. (Figure 8).

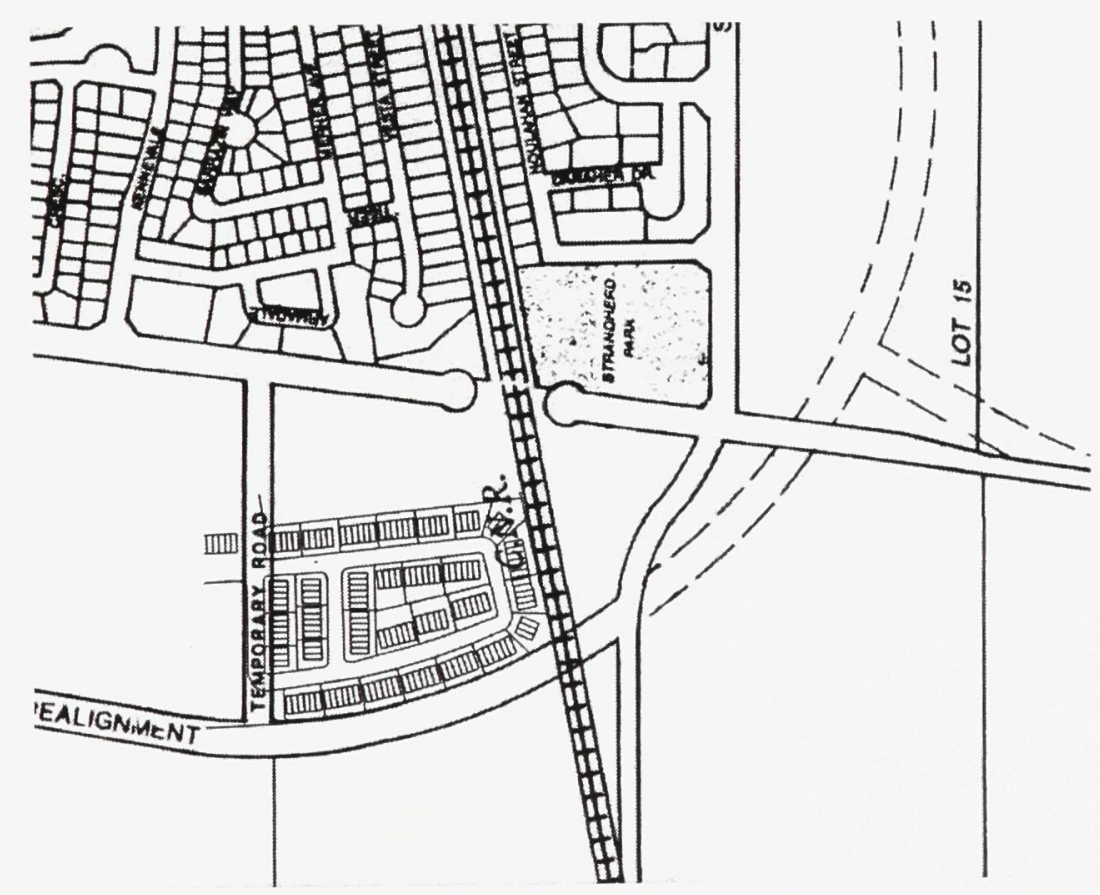

Figure 8. Temporary Road. (With developer's plan superimposed). 
(2.) Each row of houses in the subdivision will draw from the same (narrative) fragments for exploration from the macro-frame.

To introduce a defining feature to each row that can be employed differently in each house, a common element will be employed in each row. Cache discussed in Earth Moves separation (the wall) and selection (the opening) are functions of the frame. drawing on this, an element will be designated as a separator of the row from others of its kind (at once binding and defining component units) and another will act as selector, framing public and private relationships within the row. This will create a formal relation in addition to a narrative one (rule 2).

(3.) A wall will frame/separate each row from others in the scheme. It will occur in each unit of the row.

(4.) A perforation will frame/select conditions unique to each row demonstrating public and private moments occurring in linked units.

In order for the macro-frame to continually serve as both generator and representation, images or fragments of the structures are to be reinserted into the macroframe fulfilling a representation of multiple times, accretion of a site, and re-framing of design. This fusing of process and product is the realization of the prototype. 


\section{Site}

In order to apply the rules extracted from the preceding arguments, a site was chosen in Barrhaven between the agricultural expanse and the suburban development. The tension between the rural farming practices and the prescriptive suburb is best exemplified at this threshold on Temporary Road on Barrhaven's southwestern border. A brief introduction to the site and the conditions of its surroundings shall serve as a starting point from which design solutions can be assembled.

\subsection{Overview}

Over the past 30 years, the Ottawa suburb of Barrhaven has flourished with undeniable speed. However, it is just as quickly drifting away from any sense of history, identity, or vernacular tradition; rather, it is losing itself in the rapidity and shortsightedness of a developer-built phenomenon - efficient, often careless planning, hasty responses to the residential swelling, profitable solutions with little emphasis on durability. By mapping its growth and development, supported by cartographic material where other sources were scarce, notable events and trends can be decoded while revealing a richer representation of what many see solely as an example of suburban sprawl. Temporary Road, on Barrhaven's Southwest corner, will serve as a case study to support the notion that the utopian image of suburban living cannot suppress the richness and variability of the human condition. 


\subsubsection{Early vestiges}

The resources outlining the growth and development of what is now known as Barrhaven proved scarce; therefore the available cartographic material will map the history of the area for the means of this paper.

The earliest traces to be found of the Barrhaven area date back to an 1830 map of the area that outline what are said to be the 1814 bush trails of Ira Honeywell, one of the first settlers of what would soon become Nepean Township. At this time, the square plots of land (divided by what would become the regional road system) were allotted to the Crown and the clergy (Appendix 1). In 1867 the Beldon Atlas of Ottawa and its surrounding townships was published. Nepean Township, particularly the settlement at Fallowfield (Appendix 1), was inhabited by settlers of primarily Irish and British decent;

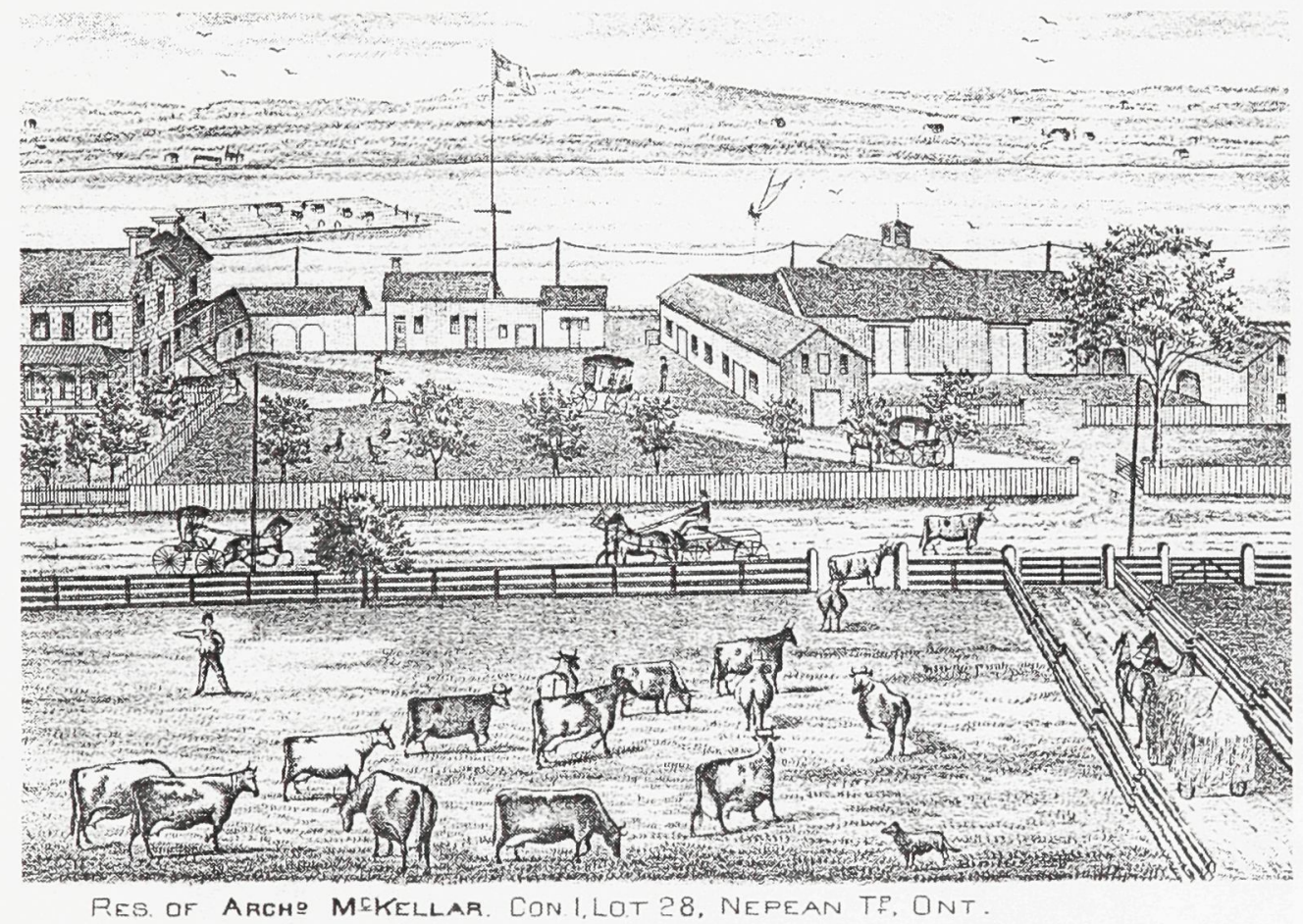

Figure 9. Nepean County Residence. An illustration from the Beldon Atlas of 1867. 
the names of some would be still be associated with Barrhaven over a hundred years later, harking back to its agrarian past.

Though maps of Ottawa during the following years were abundant, those of the southern Township of Nepean were few. A 1938 census map (Appendix 1) revealed that most of the names from the 1867 map had remained consistent over the years. New homesteads and subdivisions had been introduced since, but the land was still farmed for the most part. An integral event in the future shaping of Barrhaven was the creation of the 1948 Ottawa Master Plan created to address the expansion of the National Capital Region. Included in the plans was the Greenbelt zone that would be preserved for the containment of Ottawa's growth. In the late 1950s and early 1960s speculative purchases below the Greenbelt were made anticipating growth. Most were made at the junction of the Rideau an Jock Rivers (the latter runs south of Barrhaven).

Barrhaven as a community had first been proposed in 1969, envisioning a growth west of the present area. The northern part of Barrhaven had already been developed by contractor Mel Barr (from which the name Barrhaven originated) in the late 1960s. Barr had bought the 200 acres belonging to the Larkin family, one of the families who had inhabited the area since settlement in the mid-1800s, to build a race course. When the Rideau Carleton Raceway was erected too close to the vicinity for profitable gain, Barr subdivided, serviced, and sold the lots. In the 1970 s a dominant role was assumed by Nepean's Planning Department in designing new subdivisions under Mayor Andrew Haydon's supervision. The area known now as Barrhaven was expected to be the site of a new satellite city. Haydon was to put the gears in motion, making Barrhaven a reality rather than recurring rumour. The Planning Department wanted to take community- 
building out of the hands of private developers for greater emphasis on long-range planning. The site was to encompass a ceiling population of 25,000 residents. The Haydon council immediately changed zoning categories to exercise greater control over development. Council retained Project Planning Associates out of Toronto to draft an official plan. It was around this time that Bill Leathem was appointed Senior Planner, he was "appalled by the draft official plan that Project Planners presented to council in December 1970." ${ }^{92}$ Leathem was to draft a new plan, consequently. By 1972, Leathem had sketched out his ideas for two satellite developments, both resting on the other side of Ottawa's Greenbelt - Barrhaven and Bridlewood. Leathem designed these communities to employ the notions of 'neighbourhood and community units' referring to areas developed around the distances children can be expected to walk to school, leading to parks and schools being central, "internal streets are laid out to discourage throughtraffic.... and only as wide as traffic volume required. Residential crescents fed commuter traffic onto collector roads that emerged onto arterials between neighbourhoods." ${ }^{.93}$ The neighbourhood unit was created by Clarence Perry around 1910, and he implemented it to some degree in the New York regionl plan of 1929. Humphrey Carver's 1948 book 'Houses for Canadians' popularized the idea north of the border. It was applied in the 1952 Don Mills development by the team who later set up Project Planners. The units were described as "far from original." "94 This example became one of the only planning models for suburbs in Canada. Unfortunately, this was not ameliorated by the time Nepean's Plan was drafted, even the Project Planners had referenced it. Leathem's intent

\footnotetext{
${ }^{92}$ Bruce S. Elliott. The City Beyond : A History of Nepean, Birthplace of Canada's Capital, 1792-1990 (Nepean, Ont.: City of Nepean, 1991) 314.

${ }^{93}$ Ibid. 315.

${ }^{94}$ Ibid.
} 
appeared to be uniform building strategies, consistencies. As for Mel Barr's development that came before the plan, Leathem saw the typical 60's subdivision as 'an abortion' stating: "if we wanted a properly developed community, we couldn't let developers do their own thing." 95 Leathem By 1975, the official plan was approved by Council and the pace of growth quickened (see Appendix 1). By 1991, Barrhaven had completely filled the regional road grid flanked by four the four main roads - Cedarview, Fallowfield, Strandherd, and Greenbank. Rather than adhere to Leathem's vision of westward growth, Barrhaven filled up the regional road grid towards the Rideau River. In 2001, it had grown past the envisioned population of 25, 000 to almost 40, 000. Now that Barrhaven's realization has expanded beyond those early plans, solutions for growth have changed as well.

\subsubsection{Place/Consumption}

Throughout the years preceding Barrhaven reaching it ceiling population, Nepean's Planning Department retained its position that the involvement of many developers may work against long-term planning strategies. For the years before the mid1990's, a small number of developers worked in shaping the satellite community. Today, Barrhaven hosts a slew of developers, moving even further away from the intended parameters. And yet, although it may not have seemed probable a decade ago, Leathem's projected westward growth is on the verge of becoming a reality. Phoenix Homes, who are responsible for quite a bit of present reshaping in the capital area, has already set up plans for a complete residential sweep over the farmland on Barrhaven's western border. After Nepean was amalgamated into the City of Ottawa, plans for the future of Barrhaven

${ }^{95}$ Ibid. 322. 
were also produced. Originally the land being developed by Phoenix Homes was slated for an industrial sector, emphasizing a shift to Barrhaven becoming a self-supporting community, however residential areas won out as capital has taken a central position in the formation of this community.

In the late 1990s, Barrhaven began to grow with such rapidity that a lot could be unrecognizable (due to from one week to the next. In the early 2000s, a commercial area began to form on what was then Barrhaven's southeastern border. This area consists of what will be referred to here on in as 'boxmalls.' These cost-efficient, unimaginative edifices once only seen along the transitional highways of the United States have come to infiltrate almost every Canadian suburb. In the City of Ottawa's proposals for BarrhavenLongfields, this accumulation of commercial spaces had been dubbed 'marketplace' and is now, officially, the Riocan Marketplace. Far from recalling marketplaces of old, rich perceptual playgrounds of trade and commerce, this 'marketplace' is the epitome of sterility - cream and white stucco walls, no attempt at design - an economic solution to gain maximum profit. The décor of these places consists of, at most, an illuminated sign denoting which business can be found inside an allotted space. Since parking space is left up to the designer of each area, none of the parking coincides with the rest and it is a vehicular nightmare mediated by signs - referring the driver to isolated lots that exist only for a particular box, signage instructing the driver where to go. These boxmalls recall some of Marc Augé's non-places; centres for consumption where one gets a true sense that "alone, but one of many, the user of a non-place is in contractual relations with it (or with the powers that govern it). He is reminded, when necessary that the contract 
exists." ${ }^{96}$ Sterile shopping environments that are contained within vast spaces all provide a sense of banality that could be transplanted into any suburb in North America without having a drastically different effect on the user. The reality of these structures is that they do not attempt to engage themselves with the communities on which they intervene. The spotless, austere façades of these complexes do not add to any sense of community, rather they assert the harsh realities of contemporary shifts towards consumption. Their placement and imposition oppose the nature of old Barrhaven, not only the natural surroundings which were once readily available to enjoy, but the possibilities for meandering, wandering, satisfying and embracing a richer experience of place. These are areas we must drive to. They are destinations, the journeys to which have become as efficiently planned as possible so that the only pausing done is at traffic lights. All entrances overlook parking lots, not the streets. Ironically, priority has been given to the automobile in this community modeled on the neighbourhood unit, a concept whose elemental basis is a child's walking capacity. This marketplace borders a walkable community, but inverts its goals by creating a driving destination rather than any attempt at true integration. Adversely, these structures assimilate Barrhaven by making it like any other community that may encompass such a commercial area rather than searching for any sense of individuality.

Unfortunately, Barrhaven has never been given the chance to explore its identitywith its beginnings as a satellite community for Ottawa, the use of planning principles derived from other suburbs in the 1970s, developer-built homes expanding its size, and a commercial area that could be found almost anywhere in North America - it has been

${ }^{96}$ Marc Augé. Non-places: an introduction to an anthropology of supermodernity (London: Verso, 2000) 101. 
overshadowed by the priorities of larger-scale ventures. This, in turn, resulted into general acceptance of major changes over the years.

Slowly, when the shock of the existence of boxmalls dissipated, they became the new reality of Barrhaven, with easily increased shopping in the allocated areas since their borders are so close they require little pre-planning to be reached. It is not unusual to hear the cries of relief that Barrhaven has become so convenient that there is no need to leave its boundaries anymore; as if Barrhaven is a sort of contemporary utopia. But as Augé asserts: "The non-place is the opposite of utopia: it exists, and it does not contain organic society." 97 Farm land was supplanted with superstores that created a drastic shift in the way Barrhaven was being considered - from community to consumption. As Maureen Sherlock observes in her essay Moral Minimalism and the Suburban Spectacle, "In escaping from the epicenter of the city, the suburb also created its own nightmare, for it is not so much a locale or container as an agent of production as well as of consumption.."98 It seems as if convenience has taken precedence over the pleasure of the experience of the surroundings. Outings are not often seen as events, but rather as necessary fulfillments within busy schedules, means to ends. Structures like those at the Riocan Marketplace debase commercial experiences to transactions; but by offering new conveniences beyond the local's wildest dreams, people are finding joys in things as if they can't contest them. The influx of this suburban structuring has become such a dominant reality that resistance seems futile. The goal takes precedence in the developerbuilt suburb.

\footnotetext{
97 Augé 111.

${ }^{98}$ Maureen P. Sherlock. "Moral minimalism and the suburban spectacle." Art Papers 22.3 (1998): 23.
} 
At the immense Barrhaven Loblaws, people can be proud to say they shop at one of the largest grocery stores in Canada, an experience that attempts to satiate the visitor within its confines, relieving them of the need to seek things elsewhere. "““'Creating a destination" is the key buzz-phrase for the superstore builder: these are places not only to shop but also to visit, places to which tourists make ritualistic pilgrimages." 99 This illustrates how Barrhaven has fallen victim to planning strategies of capitalist thinking while forfeiting its own sense of place; if residents are proud because Barrhaven has everything that they want, the desires of its residents have been strongly affected by these strategies - they have fallen right where the developers want them. This simplified wantneed basis for commerce bleeds into the way people treat each other in the allocated consumer areas. As Sherlock notes: "Each shift in the structural flow of capital produces itself in any number of social formations and institutions as well as in the construction of human subjects equipped to deploy themselves in its functional landscape--subjects such as "consumers" or "managers," for example."100 This reductive approach to one another keeps residents at a convenient distance from one another which enables further transactions to occur efficiently with the least degree of interruption. It opposes the Notion that "all individuals--however they are currently defined as subjects--also bear within themselves the fragmented stories of a past when they were primarily identified as "immigrants," "working class," or even "citizens." It is this conflicted duality of ideology and self-creation which the artist brings consciously or unconsciously to his or her work, just as much as the critic, or the viewer/interpreter, does."101 The eradication of these diffracted realities in our everyday social situations creates a directed, plot-based

\footnotetext{
${ }^{99}$ Naomi Klein. No Logo: Taking Aim at the Brand Bullies (Toronto: Vintage Canada, 2000) 151.

${ }^{100}$ Sherlock 22.

101 Ibid.
} 
framework with emphasis on capital over long-term planning, thus Barrhaven stands as a developer's playground. If this type of thinking made for Mel Barr's early housing to be described as a developer-built abortion, what could one come up with for Riocan?

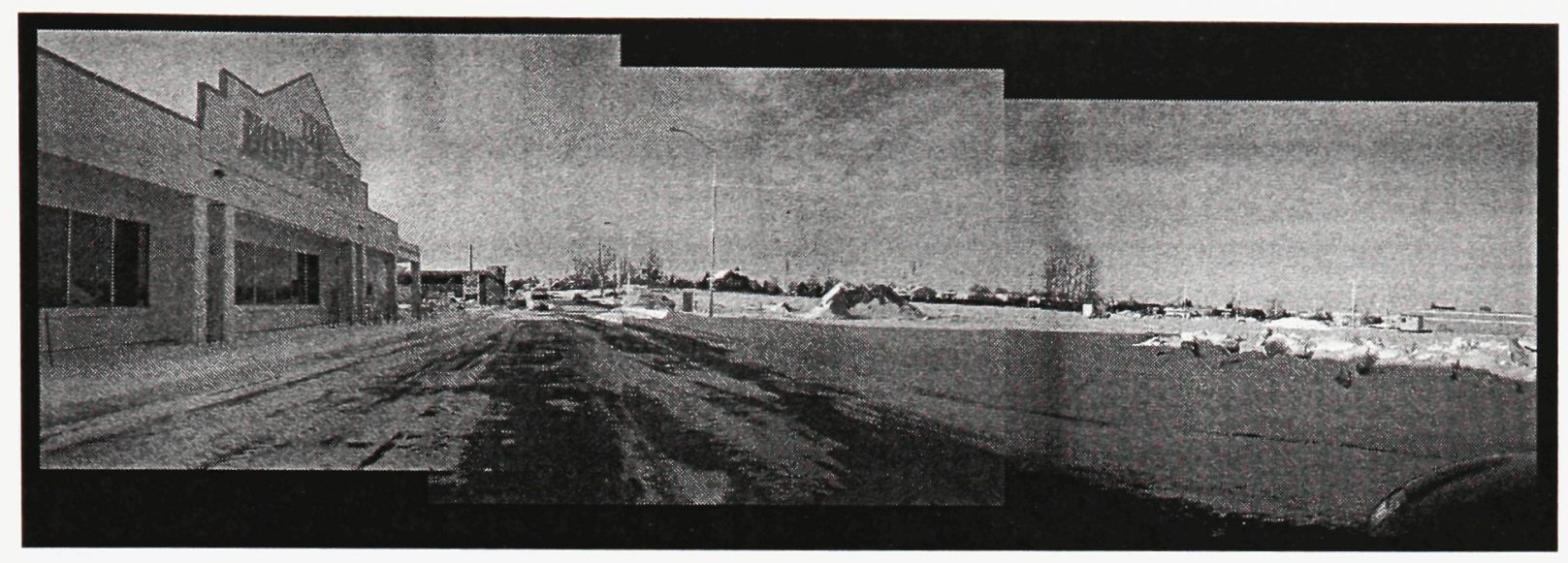

Figure 10. Boxmalls. During construction phase in Barrhaven.

Developers' attempts at homage manifest themselves in street names for the most part. Larkin, Longfields, Houlahan, and Davidson all reference settler families. These titles or anything these names should allude to however, stand in stark contrast to that to which they are applied - as if these named suburbs are compensation for a history forgotten. As Barrhaven was created to absorb some of the population of a growing Capital, it was never planned to expand past its ceiling population. This being the case, when it grew to the size where it may be in need of its own definitions, it was lost and continues to lose itself. Developers made this community with little concern for history, less concern for an engagement between the land and its residents. While Barrhaven changes rapidly to meet the goals of the city which it was absorbed into, it faces the threat of becoming an appendage rather than its own reality. 


\subsubsection{Suburbia/Utopia}

Barrhaven is a prescriptive community, it is the nature of developer-built suburbs - it adheres to a desired control of traditional narrative time. Here humans can live according to implicit and explicit guidelines that uphold the standards that keep surroundings manageable. Through bylaws, notices, a word, or even gossip, residents are kept under the influence of mass regulation and in check. One would never know, superficially, who lives where - there are many different demographics, cultures, and personalities behind closed doors. This is not deduced from the outside of the homes, but from those contaminations: random flashes inside a house, noise penetrating the walls, fragments of the intimacies of the domestic filtering out. Barrhaven's prescriptive nature appeals to those who adhere to the utopian vision propagated through idealized suburban living. This choice is understandable, but the issue arises when community does not account for unprescribed realities, instabilities, and breaks from confection. This disposition inevitably affects the development of its residents, creating indelible marks on many while others strive to resist. From this develops tendency to conflict in order to continue living in the most efficient and 'productive' manner based on suburban social structure; what Sherlock refers to as the underlying 'managerial mentality' that "has no desire for confrontation, rarely even pursuing wrongdoing. Living isolated existences, the possessors of this mentality sustain short term relationships even in family constellations. Conflict is seen as a social contamination to be avoided at virtually any cost; the creating of tension is an embarrassment to all, and avoidance the preferred method of mediation." 102 A fissure occurs between the propagated ideal and the existence of the undesirable in Barrhaven, which tends to deny the latter. Barrhaven stands in favour of

\footnotetext{
${ }^{102}$ Ibid. 24.
} 
time and understanding as conditioned and supported by traditional narrative form rather than acknowledging wandering, escape, constructing, hiding, congregating outside the confines of structured plot. This mentality is addressed by Foucault when he wrote: "This is why utopias permit fables and discourse: they run with the very grain of language and are part of the fundamental dimension of the fabula..." ${ }^{\prime 103}$ However, this cannot in itself destroy opposing notions occurring within the suburb - often it is this very structure that stimulates hostility towards it through its stifling influence. As Sherlock notes: "Suburbia is such a divided site, one which promised safety, health, and home for some while excluding others...The source of our neurotic anxieties, it is also the promise of our pleasure; the threatening sexuality of the city is domesticated.." ${ }^{104}$ Here, she addresses how difference is tamed through assimilation to deter those factors that may stray from the controllable. These ideals usually propagate themselves as the logical solution to a given problem. Doubtless, there is an ease in simplified life: no surprises, no regrets. But denial of the complexities of life or the tensions that build when they are not addressed can result in unease when one is confronted with them. As Foucault said: "Utopias afford consolation: although they have no real locality there is nevertheless a fantastic, untroubled region in which they are able to unfold; they open up cities with vast avenues, superbly planted gardens, countries where life is easy, even though the road to them is chimerical." ${ }^{, 105}$ The application of the word utopia on suburban islands seems fitting given the etymological implications of the word: for developer built suburbs can be seen as domestic extensions of non-places in that they now appear globally and give such a similar illusion from within their confines that it would be hard to tell if, for example, one

\footnotetext{
${ }^{103}$ Michel Foucault. The Order of Things (New York: Routledge, 2002) xix

${ }^{104}$ Sherlock 22.

${ }^{105}$ Foucault xix.
} 
where in Canada or Spain if it weren't for the indigenous flora. They supply structure to remedy issues that concern those desiring defined convenience and interactions. But, as Doreen Massey said in her essay Space-time and the Politics of Location: "Social space is not an empty arena within which we conduct our lives; rather it is something that we construct and which others construct about us. It is this incredible complexity of social interactions and meanings which we constantly build, tear down, and negotiate."106 Living under the latent laws of suburbia and ensuring their deployment cannot completely banish suppressed curiosities and inclinations. These can manifest themselves through action or remain secrets held in fear.

The instabilities that border the suburb are primarily seen as such since they do not adhere to this suburban structure. Maintenance and time run according to different schedules and, in some cases, there are no schedules to be found. In Barrhaven, this creates a contrast between the suburban realm and the agrarian that works beyond obvious physical difference. The demographic shift brought on by subsidized housing, immigration, and ageing creates small fractures that eat at the structure. Many individuals influenced by alternatives in media, arts, politics, and culture are apt to resist or reject the parameters. As Barrhaven still requires transit to escape, buffered by the Greenbelt, those inhabitants who are quarantined to its confines must seek outlets to evade suburban banality. This tendency stands in support of what Foucault called the heterotopia :

Heterotopias are disturbing, probably because they secretly undermine language, because they make it impossible to name this and that, because they shatter or tangle common names, because they destroy 'syntax' in advance, and not only the syntax with which we construct sentences but

\footnotetext{
${ }^{106}$ Doreen Massey. "Space-Time and the Politics of Location," ed. James Lingwood, $\underline{\text { House/Rachel }}$ Whiteread (London: Phaidon, 1995) 36.
} 
also that less apparent syntax which causes words and things (next to and also opposite one another) to 'hold together'... heterotopias (such as those to be found so often in Borges) desiccate speech, stop words in their tracks, contest the very possibility of grammar at its source; they dissolve our myths and sterilize the lyricism of our sentences."107

Setting itself against the idealism of planned communities, the heterotopia offers valuable insight: it assumes that life is composed of variables, both seen and unforeseen, and in this, a developer-built suburb can face failures. Theft, vandalism, violence, and substance abuse are common themes recurring in this present day suburb. Residents are afraid, yet these are acts of residents - teenagers in particular have no outlet other than an unimaginative skate-park thrown together outside the Walter Baker Sports Centre. Graffiti seems to signal the restlessness of the community's youth, but is whitewashed or covered as soon as it is detected. If Barrhaven is to thrive as its own entity, surely these issues should be addressed, commercial and industrial pursuits aside.

\subsection{Temporary Road}

Left in the wake of this heavy transformation from farmland the housing is a site directly on the boundary between the Barrhaven suburb and the farmland, at what used to be the intersection of Cedarview Road and Strandherd Road. This was once the site of a farm and its homestead. As outlined in the 1867 Beldon Atlas map (Appendix 1), the lot was originally the property of Samuel McKenna. This family name was still associated with the property in the 1938 census map (Appendix 1). In the mid-1990s the remains of the farmhouse became a strange playground for neighbourhood children, an escape for

${ }^{107}$ Foucault xix. 
teenagers evading the suburb. Domestic items were strewn about as the house was abandoned for reasons unknown. The very thought that this site was once a home shrouds it in a unique sense of mystery that cannot be paralleled with that of an untouched forest; Temporary Road contains traces of human dwelling which provoke a swelling of curiosity, assumptions, and analysis. Like the effect of Rachel Whiteread's public sculpture House, the concrete cast of inside of an old East London home, the remains at the Barrhaven boundary "turned the space inside out. The private was opened to the public view. The little intimacies were exposed...seeming so personal, so vulnerable now. By this means, the intimate was made monumental and yet retained its intimacy."108

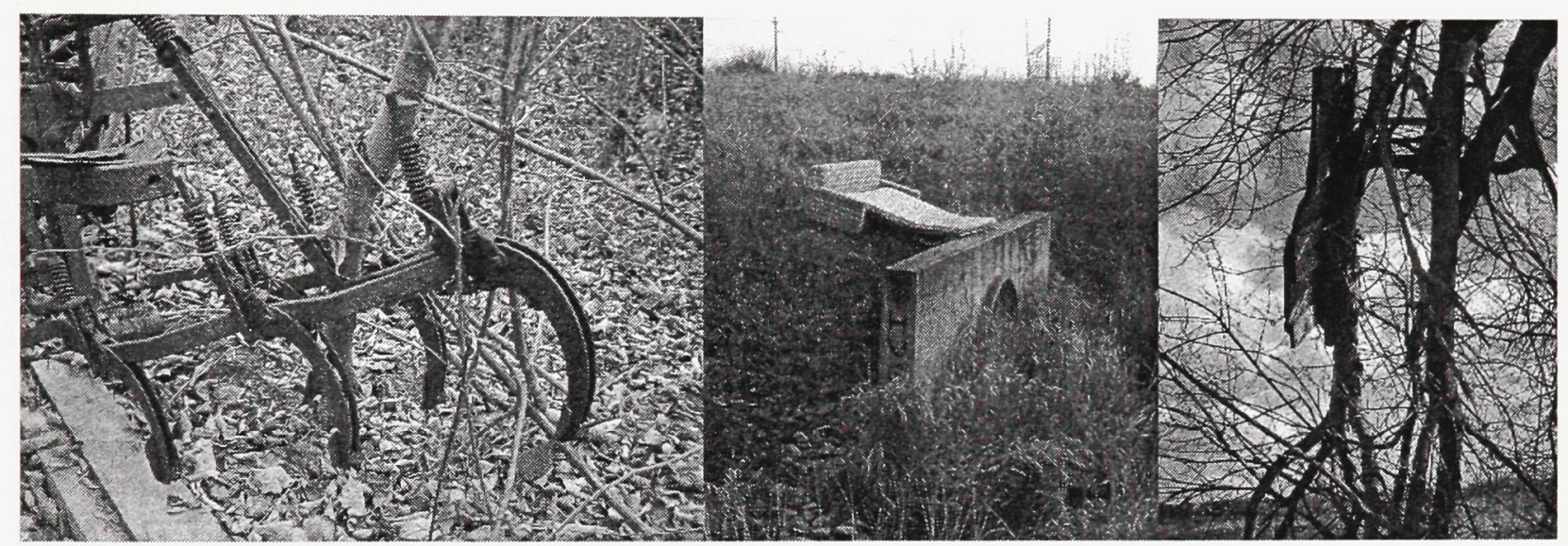

Figure 11. At Temporary Road. (From left): an abandoned plough, a makeshift lounger, remnants of a treehouse.

The shards and remains of the McKenna house disrupt the social structure of Barrhaven that contains the intimate and domestic within its banality.

This has created tension between the site and the bordering suburb. The strange ruin was extremely accessible as it stood right on the edge of the development. Its contrast with the rest of Barrhaven was instantly sensed by the spectator. The order of the suburb, even the intimacies hidden within, appears corrupted. Richard Shrone's essay A Cast in Time

${ }^{108}$ Massey 36. 
addresses a parallel rupture in a domestic space from To The Lighthouse by Virginia Woolf:
"The orderly sense of space containing objects of personal significance - a chair, a chest of drawers, a mirror - is shattered. They no longer maintain their human usefulness. Time re-moulds, decays, transfigures them. They become vessels of memory and touchstones of experience. In order to assume a substantial structure in the mind, they must be divested of their mundane physical presence...,"109

Shrone addresses a context where everyday items are purged of their syntactic structure. At the Barrhaven site, the inversion of the personal to the public destroys and reconfigures notions of the home, the elemental institution and unit of the suburb. The inversion of parts (private to public) inadvertently sensationalizes something hidden typically behind closed doors. In this, the site became the stuff of imagination and an escape. It proved itself not only an alterative for those who were aware of its whereabouts, but the stuff of local lore (rumours circulated about a mental patient who hid out in the barn and killed herself) which made it all the more intriguing by applying a fantastic context that is hard to come by in Barrhaven. When the Strandherd Road realignment occurred in the mid-1990's (Appendix 1), Cedarview Road was reconnected to Strandherd by a small access road. First thought to be a joke by most residents, this egress was named Temporary Road, equipped with a City of Nepean street sign; it ran directly adjacent to the site of the house. This name became illustrative of the way developers had come to address farmland of the peripheries - as profitable land for

\footnotetext{
${ }^{109}$ Richard Shrone. "A Cast in Time," ed. James Lingwood, House/Rachel Whiteread (London: Phaidon, 1995) 55 .
} 
profitable housing, waiting for imminent assimilation. In the late 1990s, the decaying structures on the site were destroyed, leaving only the foundations of the old house and the aggregate walls of the barn intact (Figure 12).

If this was a measure to deter visitors, it did not work. Graffiti filled the tarred cistern within the basement, names were scrawled on the walls. Remnants left by the visitors intermingled with the relics of the barn - paintball players had been using the barn, leaving fluorescent ammunition stains. People were using the site to dump unwanted items from the suburbs: sod, planks, and tires. Each move to change the site at Temporary Road was thought to be the last, threatening to make its temporality no more than memory, but the road has existed some thirteen years, now equipped with a City of Ottawa sign. Another transformation to the site occurred around 2000 when the foundations where filled in and the walls of the barn demolished. It would seem that this site could no longer serve as a hideaway. During recent site visits in early 2005, however, evidence proved otherwise, as tracks and remains of visitors were left on the ground as if to say the site is still in use: the paw and foot prints of walkers, graffiti, domestic items, beer cans, cigarette butts.

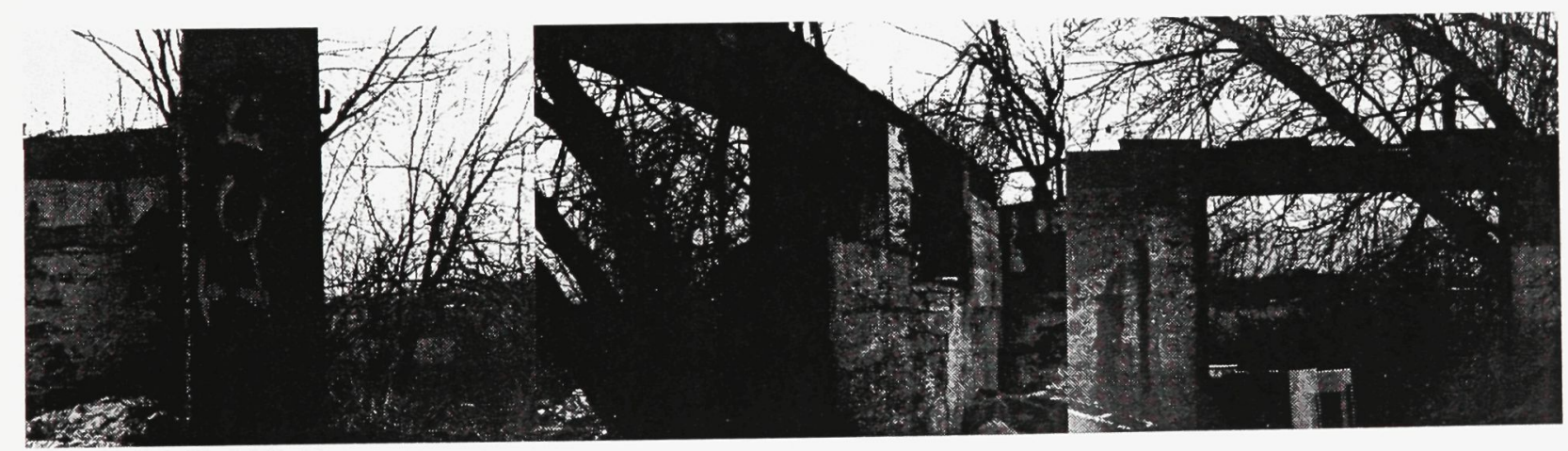

Figure 12. Remnants of the Barn, 1999. 
Referring back to old maps became the only solid indicator of directions to be taken in understanding how this enigmatic site tied into the changes in Barrhaven. Since McKenna was the only name that remained linked through the few maps, it became the only lead. The present generation of McKennas were found to be living outside Barrhaven, very far down Fallowfield Road, in a completely rural location. After agreeing to meet at their farmhouse, I equipped myself with all the photographs I had taken out of interest over the years, copies of old maps, and a slew of questions.

\subsubsection{The McKennas}

The McKennas were extremely informative as they had lived on that site for six generations. Charles, the current McKenna, spoke of the changes to the site from a very intimate perspective. He noted that they had "sold the house to speculators for personal reasons" around $1988 .{ }^{110}$

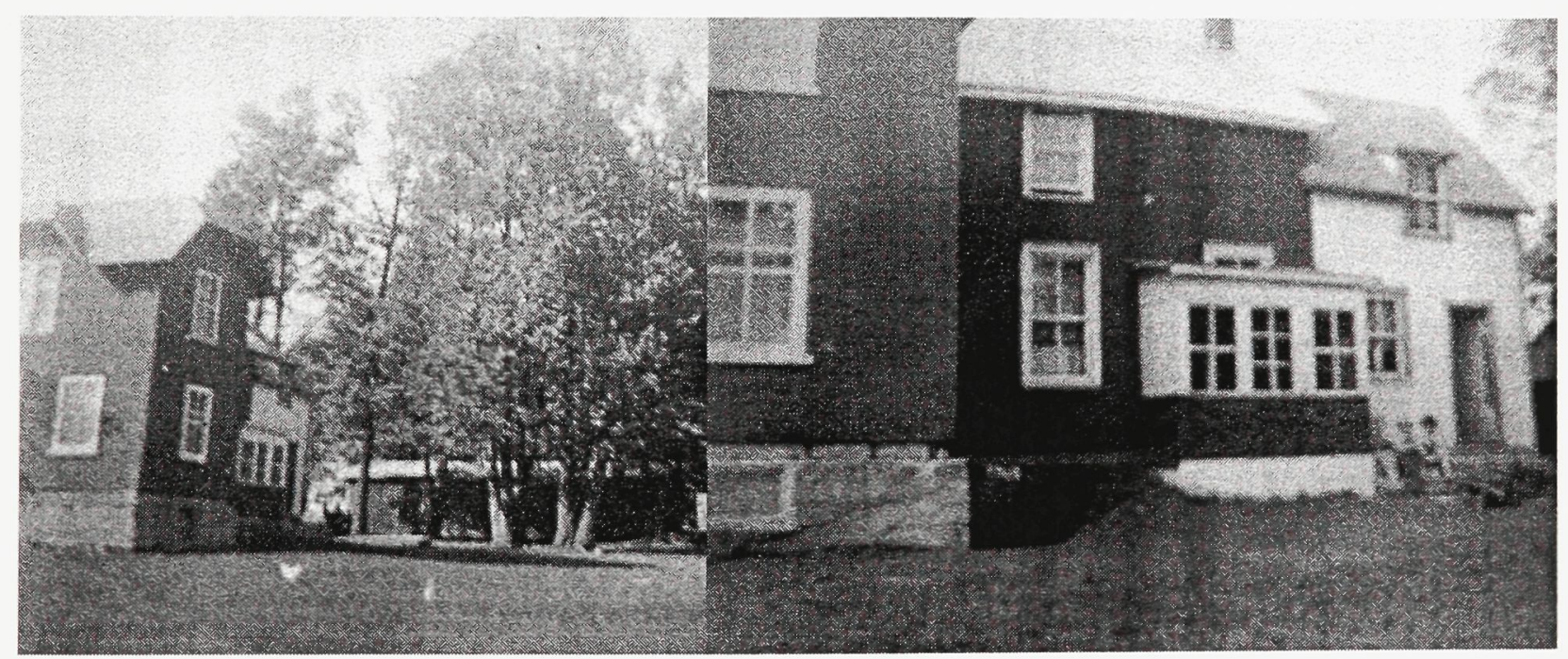

Figure 13. McKenna Homestead. Original house clad in brick. (Charles McKenna)

\footnotetext{
${ }^{110}$ Personal communication from Charles McKenna to author, November 2004.
} 
The years leading up to then were rich with a family history. Charles spoke of the developments of the land over the span of his family's inhabitation of the land. After settlement in the early 1800 s, people were offered 100 acres in compensation for clearing an acre of forest, this is how the settlers got their land. The original homestead was located much further west as illustrated on the 1867 Beldon Atlas map (Appendix 1). Initially it had been a log house which was later rolled over large logs to rest finally on the eastern edge of the property in 1912. This was around when the Canadian National Railroad laid their tracks through the settlement and at the southern border of the McKenna property. A small station built there, named Fallowfield Station after the nearby settlement, was closed around 1940. In the 1930s, a waterline was excavated to connect to the Jock river to the south called the Foster Drain. Charles McKenna was born later that decade, in 1939. His father, Samuel II, had worked in Detroit (where he saw the first tractor, and built the first one in the area) and had an affinity for antique cars. He owned a Model-A Ford; this interest was passed onto Charles, apparently, and explains why, in the depths of the forest on the site, there is an abundance of discarded car parts ranging anywhere from tire rims to full doors.

The house itself went through many transitions. Its duration on the site, unlike the majority of farmhouses left in the area was an accretive one, unlike the historical lessons provided by heritage farmhouses frozen in the past. This recalls Massey's observations regarding the classic heritage site: 


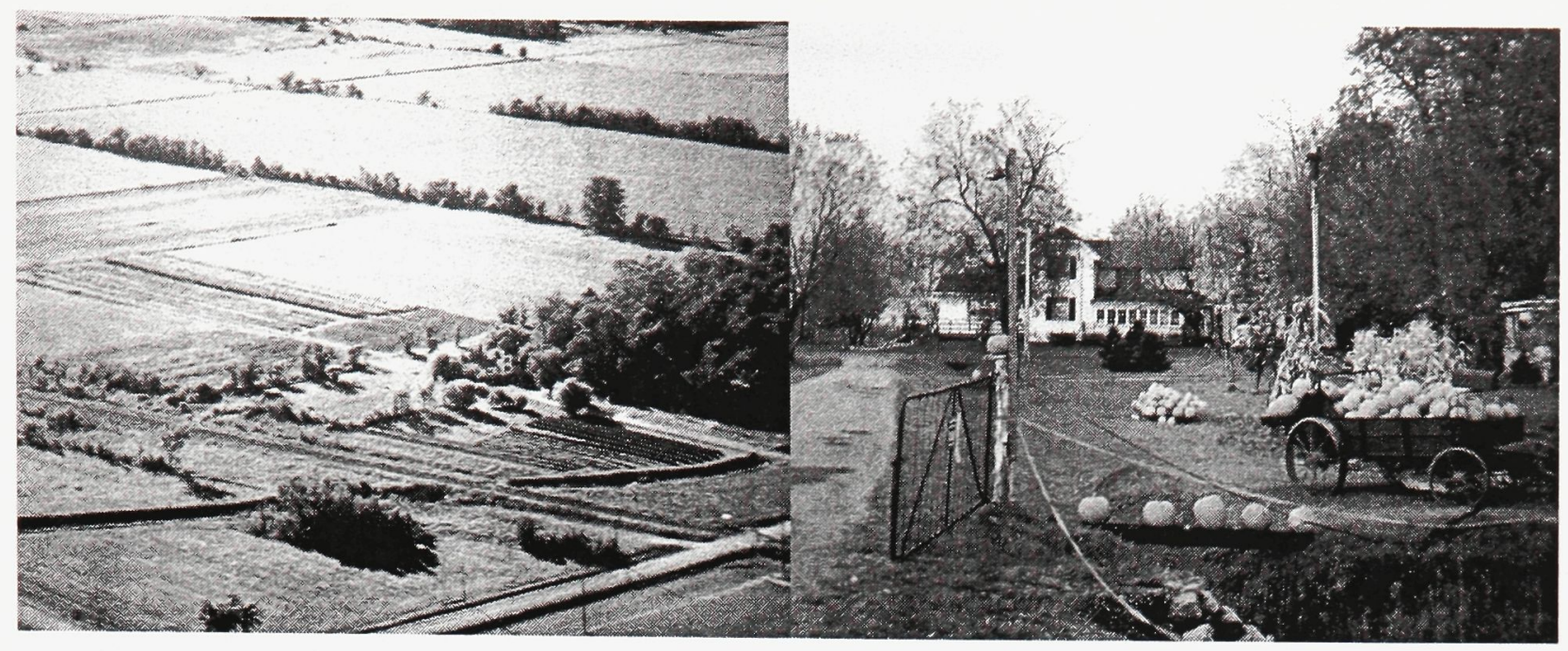

Figure 14. McKenna Farm. (Charles McKenna)

“... [that] fills in those spaces and restricts the room for interpretation and imagination. Instead of questioning memory and pre-given understandings of the past, the classic heritage site will provide them ready-made. Instead of defamiliarizing the supposedly familiar, it is meant as an aid to further familiarization. It is, by design, an understandable rather than an unsettling space, a comfortable rapprochement with another space-time."111

An extension was added and clad in brick after in 1912 (Figure 13). In 1920, a summer kitchen was added to the right end of the house. The last extension came in 1985 when Charles built a sun room on the left (south) side (Figure 14, right). After 1989, it was abandoned. Charles knew that there was activity on the site afterwards, as he came to visit the site every once in awhile. He said that in the newest extension to the house people were lighting campfires on a rug and the burn mark got bigger every time he came by. He said it was the mothers of Barrhaven that rallied together and had the fire department burn down the house and its structures due to all the activity and its ugliness. It seemed like the community perceived it as a suburban version of Solà-Morales'

${ }^{111}$ Massey 43. 
Terrains Vagues: "margins, lacking any effective incorporation...they are forgotten, oversights and leftovers which have remained outside the urban dynamic, converted into areas that are simply un-inhabited, un-safe, and un-productive. In short, these are places that are foreign to the urban system, mentally exterior in the physical interior of the city, appearing as its negative image as much in the sense of criticism as in that of possible alternative." 112 This negative image as alternative harks back to Foucault's heterotopia which appears disruptive and defiant but is rich with reconstructive possibilities and appears capable of helping Barrhaven become its own reality rather than an accumulation of borrowed parts and theories.

The meeting with the McKennas yielded results other than those of a chronological history. When questioned about the 'suburban legends' or occurrences associated with the site, Charles McKenna was not only familiar with many (postabandonment), but confirmed things that were assumed to be contrived rumours. He noted that even when the family occupied the house, the site had always had a strangeness to it that lured odd characters, partly due to the proximity of the house to the CNR. Fragments of stories unknown surfaced and reconstructed known events. Rather than clarifying the occurrences, the new information complicated them. He told stories of a traveler who appeared at the house (pre-abandonement) who was suffering a mental breakdown. The suicide of the mental patient was revised and confirmed, the events constantly changed. Through photographs I attempted to rebuild on the ruins I had seen, yet even this precise imagery did not seem spatially cohesive to the experience of

${ }^{112}$ Solà-Morales Rubió, “Terrains Vagues,” 122. 
Temporary Road. In 2004 a large sign and temporary show-home were erected on the north-west corner of the lot, at Temporary and Strandherd Road.

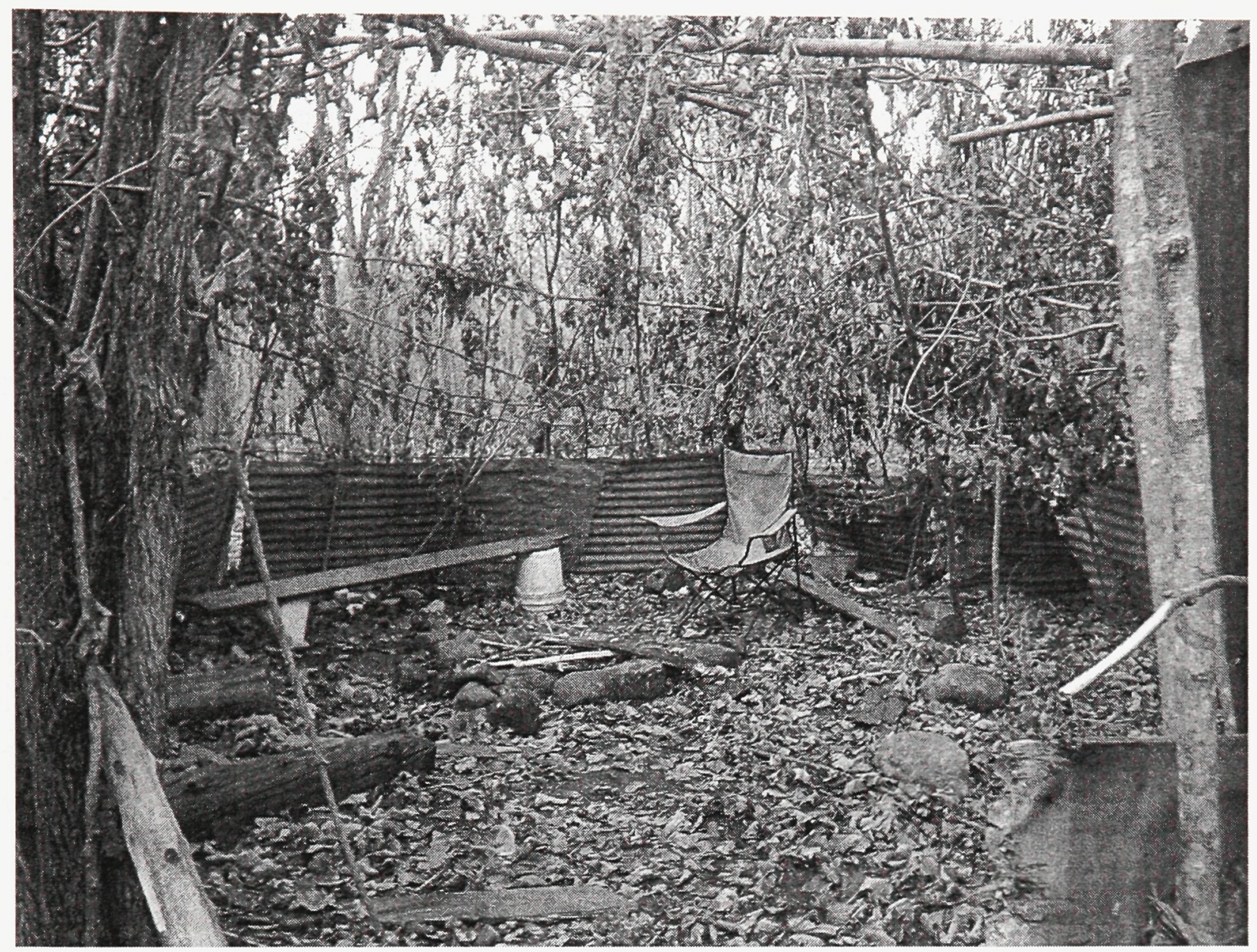

Figure 15. A Fort in the Forest.

Phoenix homes intend to begin development on the site in 2006. Temporary Road will exist no longer. Instead, it will be annexed to the suburb. A map has been provided to convey the concept layout for speculative purchasers. (Appendix 1) Construction started in June, 2005. 


\section{Methodology}

Through parts of my personal experience, those conveyed by Charles McKenna, and the circulating fragments of what may or may not be confirmable, Temporary Road presents itself as a unique place steeped in a multiplicity of times/tenses that re-circulate through experience. For the purposes of this thesis, some parts (obviously only a fraction) will be used in order to reconstruct the narrative framework in fidelity to the site that contrasts the traditional form adopted by the suburb.

\subsection{Parts for 'Tendential Narratives'}

These stories span from the last days where the site was a farm with homestead, through the introduction of Temporary Road to its northern border, its decay after the abandonment of the house up until present day. Outlined as they were told or how they are understood, these particular stories were chosen as primary narrative fragments to begin the sequential macro-frame.

\subsubsection{Fragment 1: Silver Springs (Plate 1)}

(Communication with the McKenna family, local/suburban rumour)

(These are reformed pieces of a story that first circulated when I was about 14. A mental patient was said to have escaped and killed herself in a ditch south of Temporary Road. Apparently she had hidden out in the abandoned barn.)

A woman escaped from Silver Springs Farm, a lesser known facility in Bell's Corners.

She likely followed Cedarview Road, which would lead her right to the Temporary Road property and the abandoned farmhouse. 
She hid out in the barn.

When she left, she killed herself near Trail Road.

\subsubsection{Fragment 2: Fire-pit (Plate 2)}

(Site visits, communication with the McKenna family)

When the house was abandoned, Charles McKenna said he would visit the site from time to time. People had taken things that were left behind, they had even taken the aluminum siding off of one of the sections of the house.

He noted that the last addition to the house, built in 1985, had a burn-hole in the rug. There had been a fire in the middle of the room.

Every time he came back, the circumference of the burn on the floor grew. He said it was obviously being used as a fire-pit, it was a miracle that the wood framing on the decaying house hadn't gone up in flames.

The mothers of Barrhaven became aware that the old house was being used, and they rallied to burn the house down so as to prevent any injuries to their children.

They eventually had the Nepean Fire Department destroy the house and barn. All that was left after that was the foundation of the house and a 6' aggregate enclosure that supported the barn (This is how I first found it. I entered the foundations a few times). There were remnants of the home everywhere: tires, vinyl-covered chairs, parts of a stove, a refrigerator...

If you descended into the foundation of the main section of the house, the tarred room to the left was a cistern, adjacent to the stairs. It had been covered in graffiti. In the main space of the foundation was a tire rim used as a fire-pit. 
The foundations were filled in and the aggregate wall destroyed. Again, this could be attributed to the safety concerns of the Barrhaven Community Association. There are still chunks of ash from the burning about 3 years ago.

Recently, a fort was assembled deep in the forest. Again, a tire-rim was excavated and used as a fire-pit.

\subsubsection{Fragment 3: Kids (Plate 3)}

(Communications with the McKenna family, communication with kids, site visits)

When the McKennas lived there, neighbourhood kids would come to the property and play with McKenna children.

The kids built a tree-house.

After the abandonment, Charles McKenna would find tools upon visiting the site. $\mathrm{He}$ said that children would bring their parent's tools to the site and forget them there during tree-house construction.

(In May, 2005, I visited the site with a friend to find 3 boys running around in the Foster Drain playing in the water. I 'interviewed' them.)

They went there "everyday."

They had to go home at 3:00.

They wrapped cuts in cloth bandages dipped in water from the drain.

The bank of the drain to the west was referred to as "Burr Alley" because there were lots of burrs while the south side of the drain they occupied was referred to as "Dead Man's Creek" because they had found a decapitated head of a doll in a baby carriage there. They ritually smashed beer bottles, but the reason for this was not articulated clearly. They collected 'gold' and 'emeralds' from the rocks around the tracks. 
They baptized us in drain water by dipping reeds in and splashing us with them while one boy crouched down and repeated some undecipherable mantra.

They showed us a tree-house that had been started and abandoned by other children on the east bank with strange scratches on the tree: "they say a mountain lion made these marks.”

\subsubsection{Fragment 4: Joady (Plate 4)}

(Communication with the McKenna family)

A disheveled man in clothes too small for his body, early thirties.

Mr. and Mrs. McKenna are awoken very early by a visitor at their door.

He would like to take a look at the car for sale at the end of the lot.

Mr. McKenna accompanies him down the driveway to take a look at the car.

After a brief discussion, Mr. McKenna turns toward the house to discuss the offer with his wife who is waiting in the kitchen.

As his back is turned, Mrs. McKenna notices the stranger wandering towards the barn.

She tells her husband, who admits that there is something 'off' about the stranger.

She decides to call the police.

As Mr. McKenna returns to front of the lot, he catches the stranger at the end of the path from the barn. The police are prompt and pull up the driveway.

They question the man and decide he is harmless, they note that he is "preaching the word of God." They leave and the McKennas are left with the stranger.

After another brief discussion, Mrs. McKenna decides to call the Queensway Carleton hospital because the man is acting strangely and won't acknowledge suggestions to leave. 
They take him away. The McKennas leave a contact number for him.

A few days later they receive a phone call, it is the man's wife.

She thanks them profusely for sending her husband to a safe place since "he wasn't himself." She says that her brother-in-laws will be coming by the area to find his car. She explains that they were driving back from a family reunion in Northern Ontario when her husband had a nervous breakdown.

He left her at a convenience store somewhere and drove off with the car.

He then ditched the car and followed the tracks until he came to the McKenna property. Some days later, Mr. McKenna is in the barn.

He finds a pair of pants with $\$ 300$ in a pocket and realizes that the stranger was wearing clothes from a storage area in barn that held his father's old clothing. The stranger had been living in the barn.

\subsection{Previous Investigations}

Narrative fragments were assembled into many large storyboards, organizing the shards into seemingly cohesive bodies. (Plates 1-20) This did not work as they employed a linear organization that was constantly being ruptured in order to include various possibilities for the many pieces. The constant reevaluation of the pieces yielded not one trajectory, but many, constantly borrowing from each other for support or disproval. The idea of a storyboard implies linear reading of the sequence. This form was subverted through the reevaluations of the narrative framework outlined earlier in this paper. These explorations served as a starting point from which the sequential macroframe proliferated. 


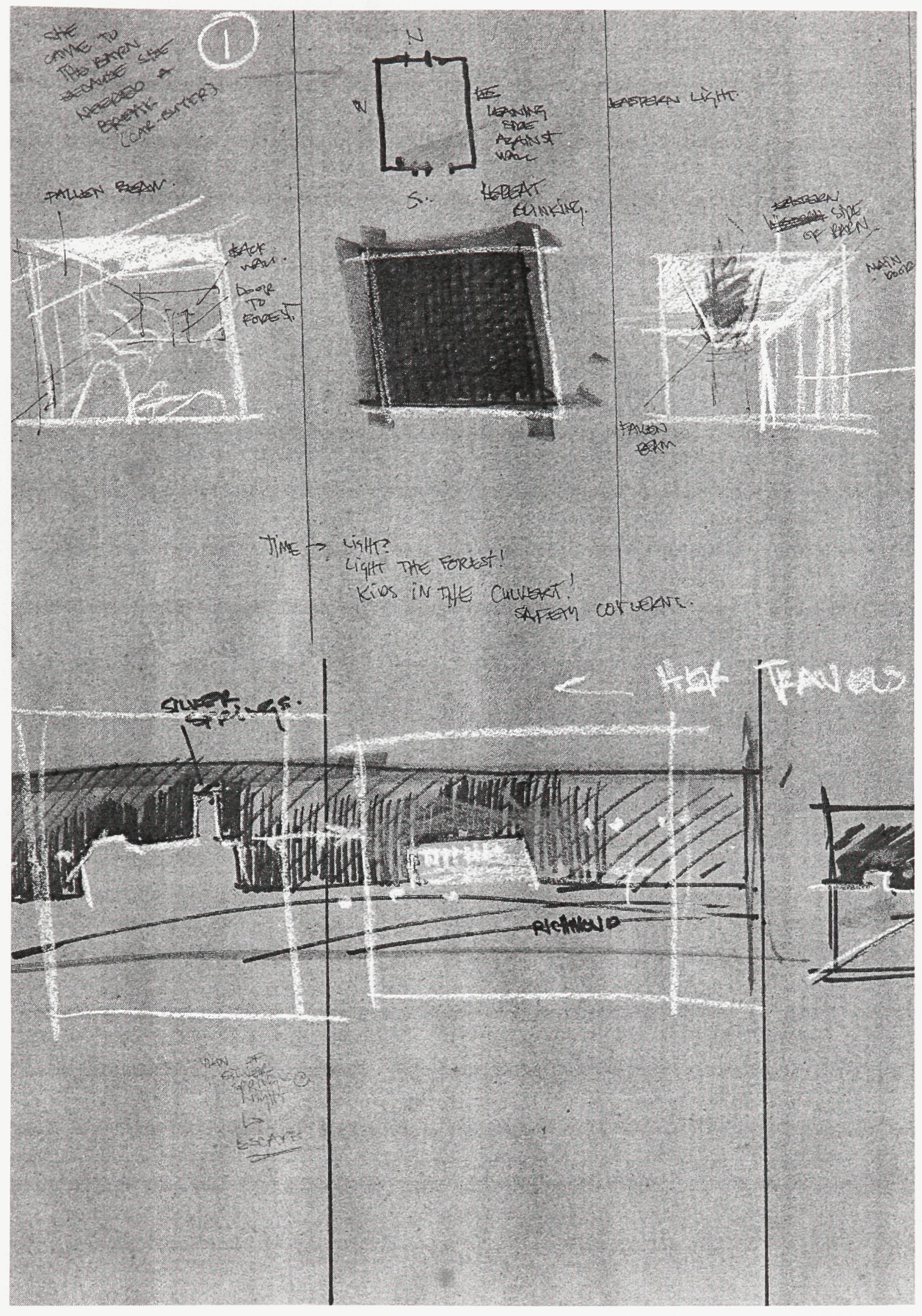

Plate 1. Silver Springs (Section 1) 


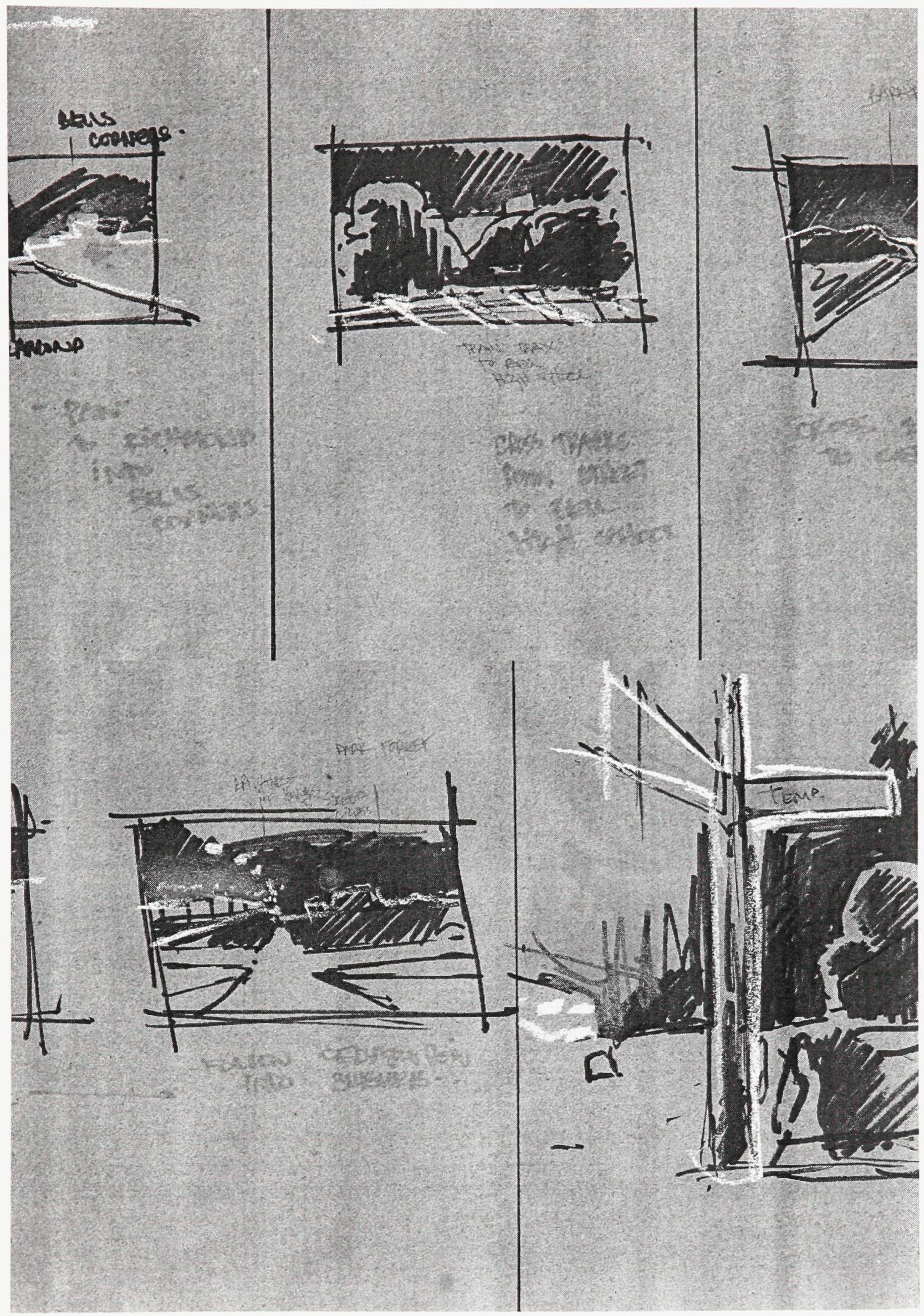

Plate 2. Silver Springs (Section 2) 


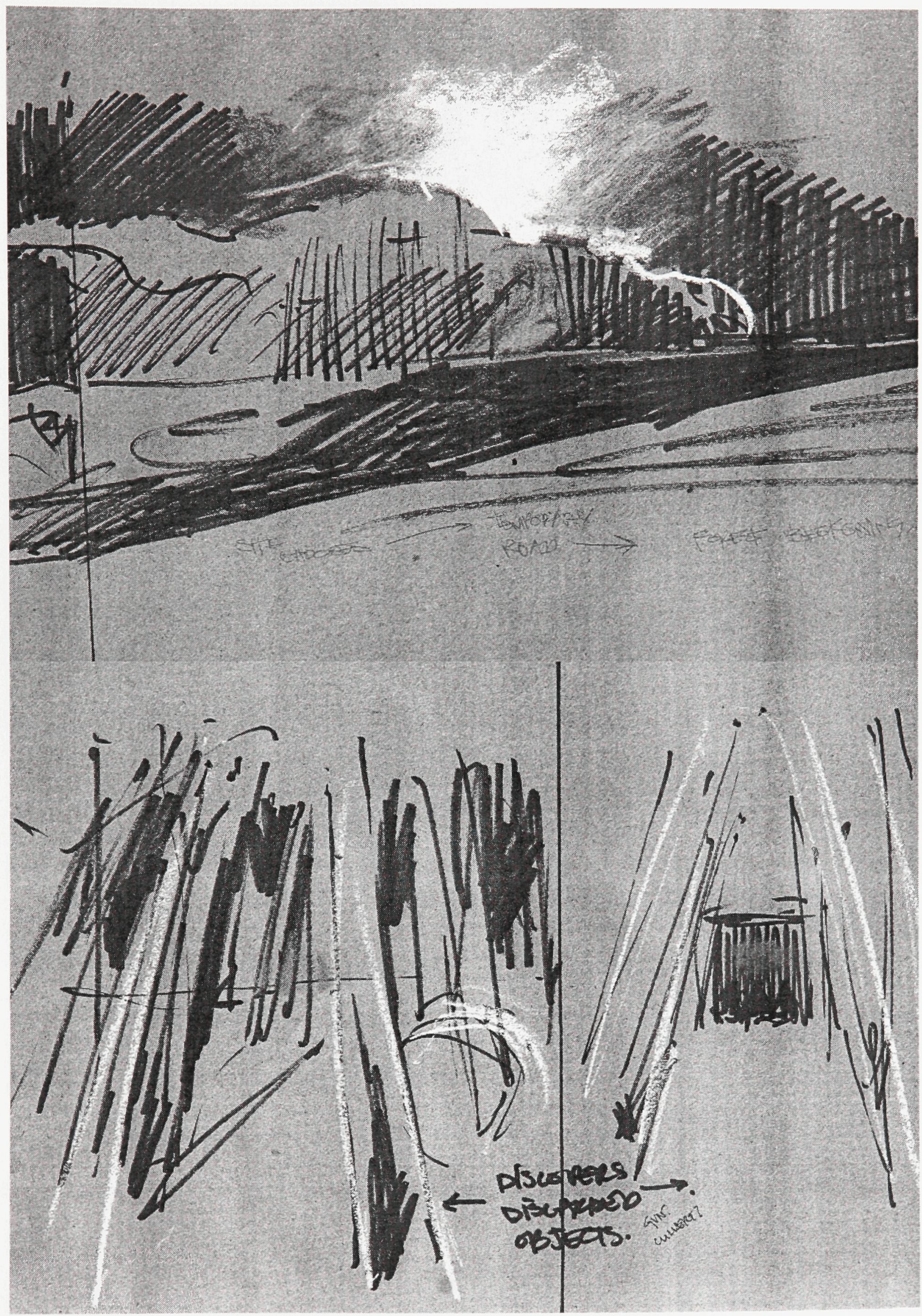

Plate 3. Silver Springs (Section 3) 


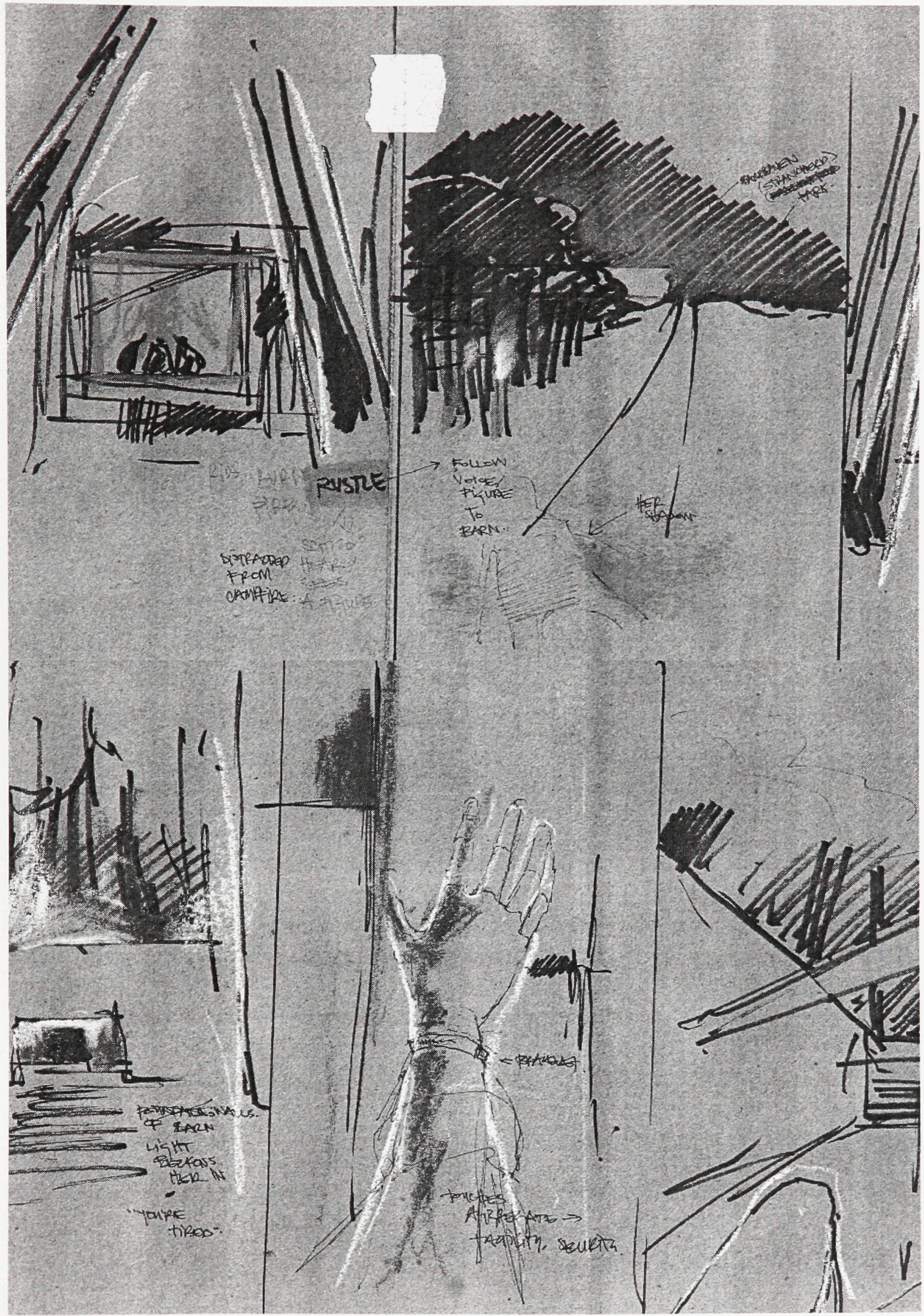

Plate 4. Silver Springs (Section 4) 


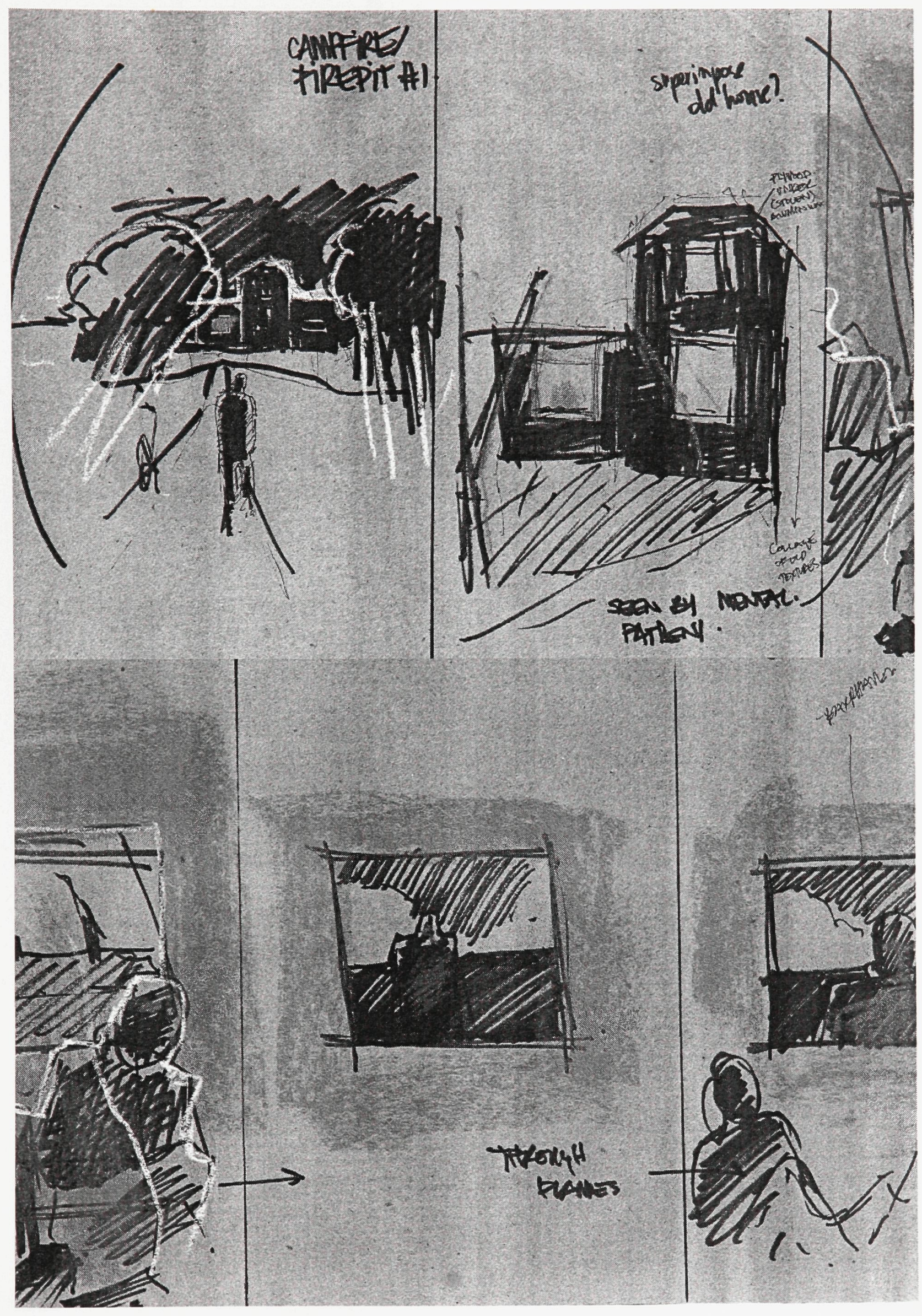

Plate 5. Fire-Pit (Section 1) 


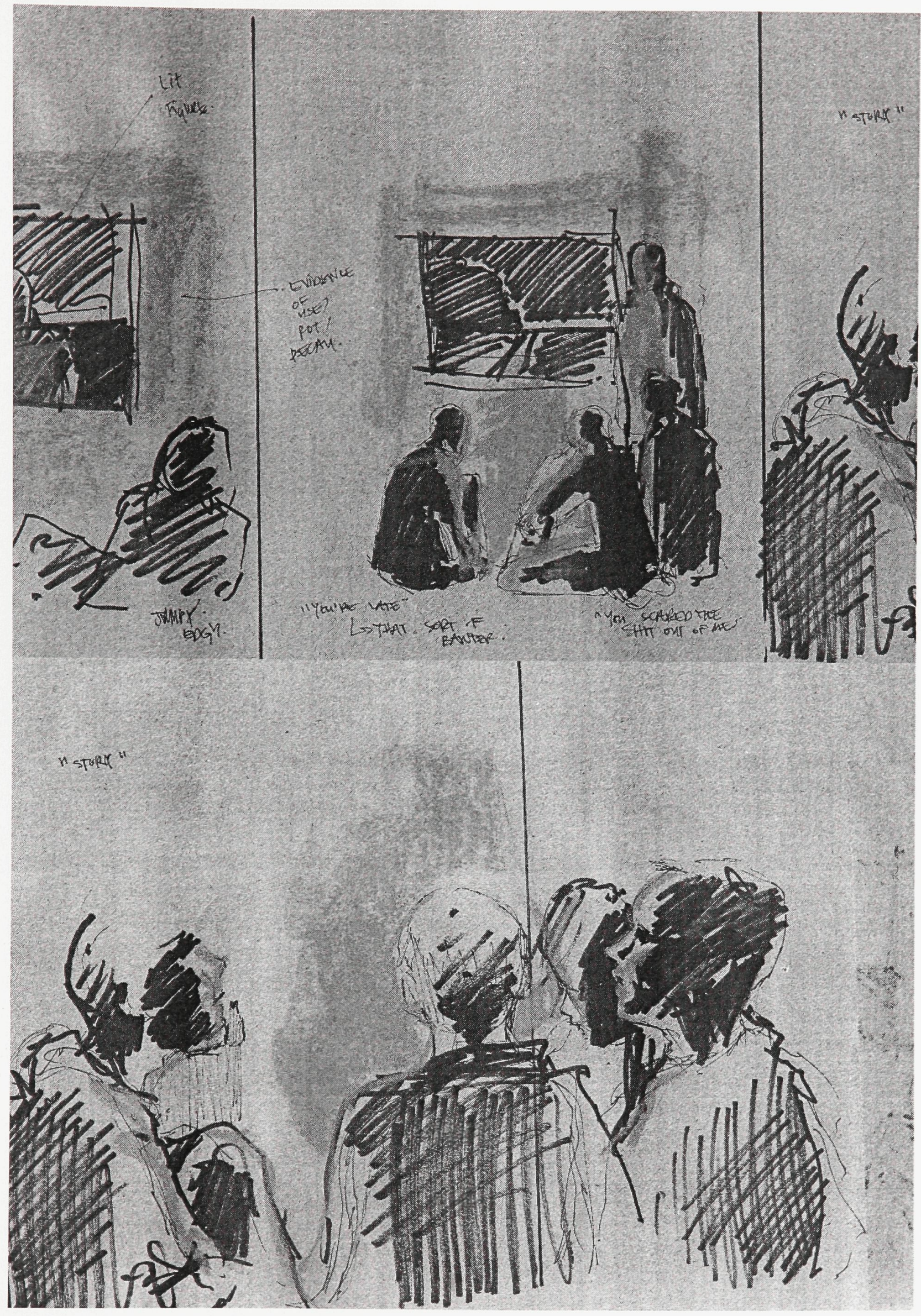

Plate 6. Fire-Pit (Section 2) 


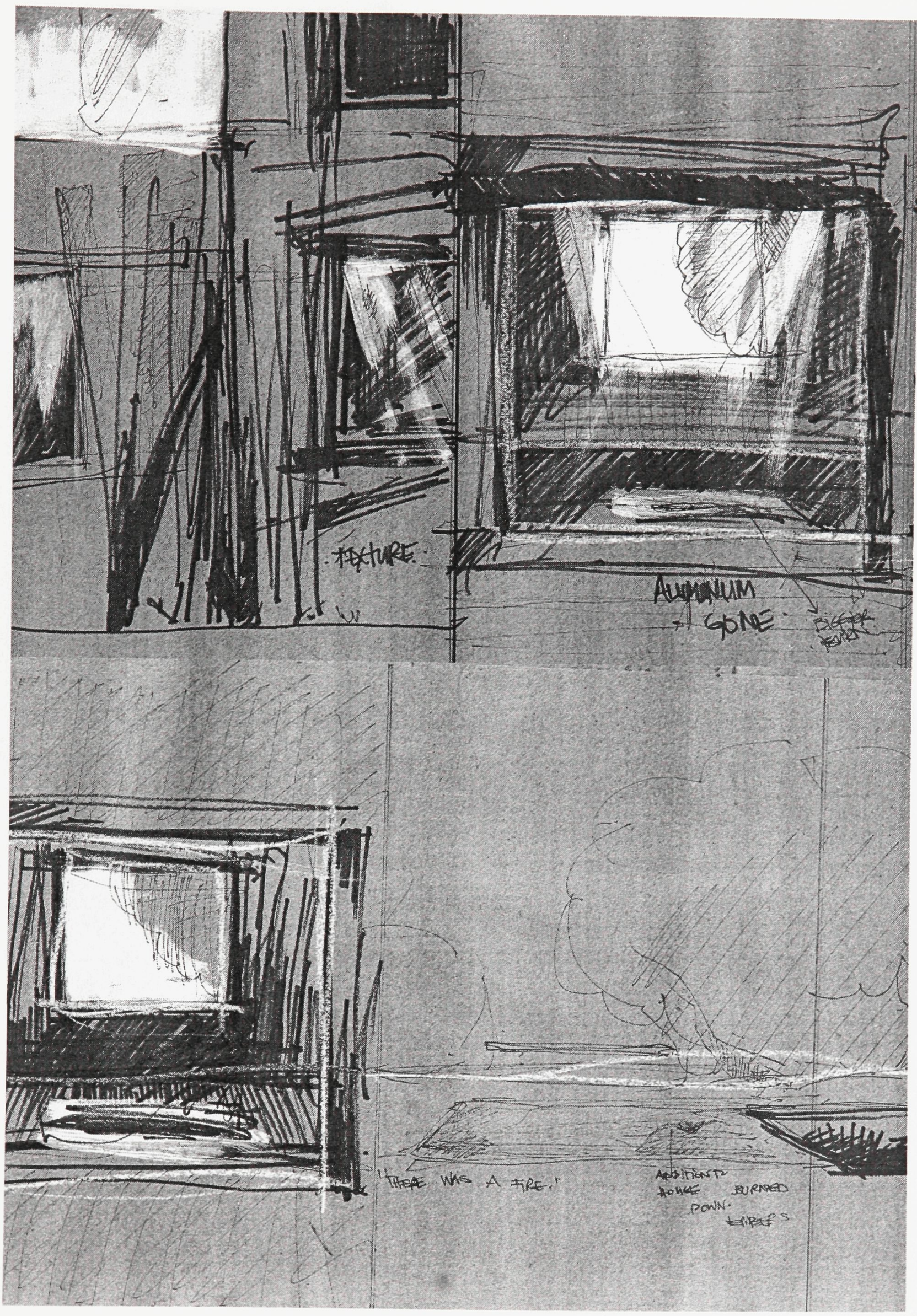

Plate 7. Fire-Pit (Section 3) 


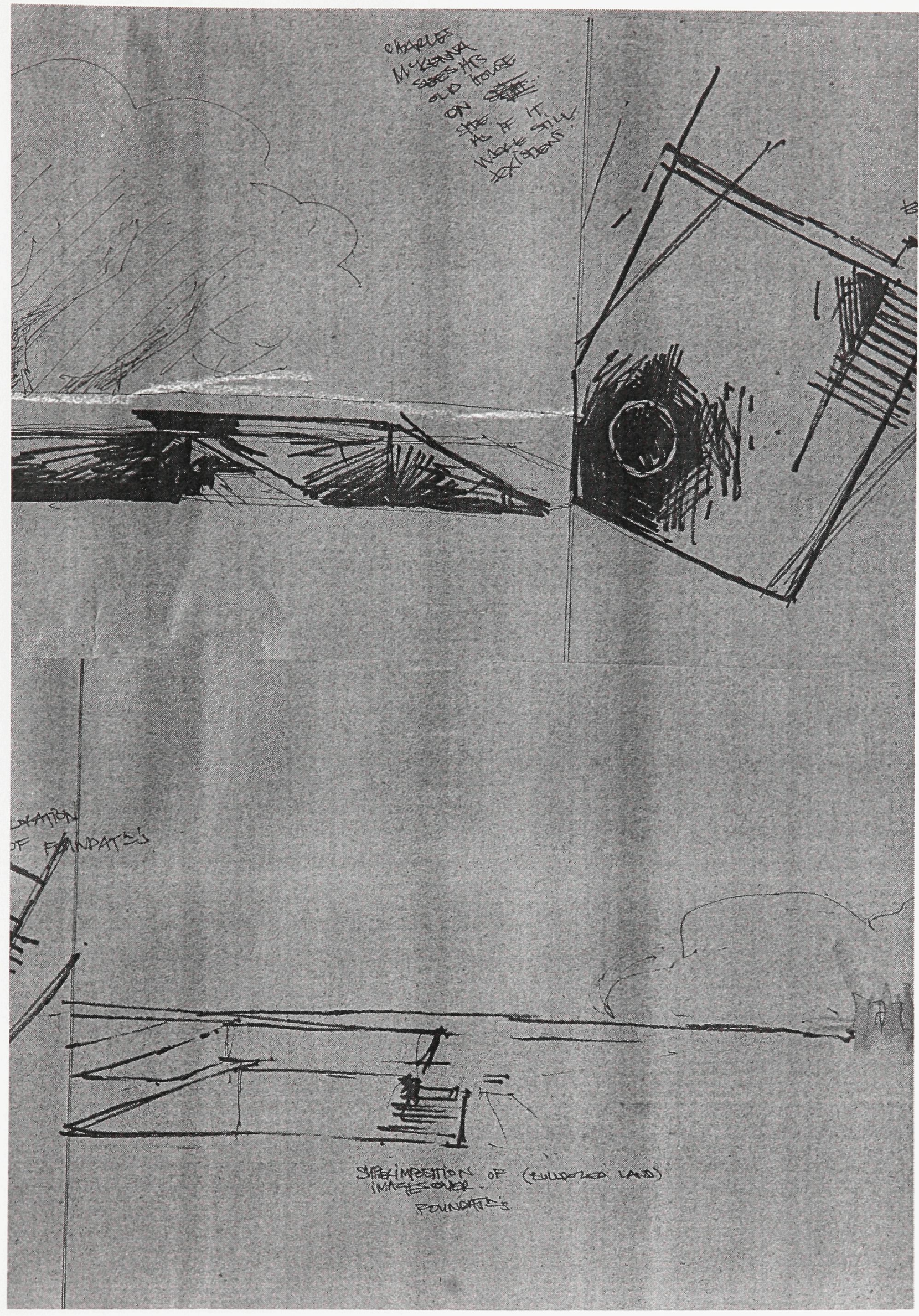

Plate 8. Fire-Pit (Section 4) 


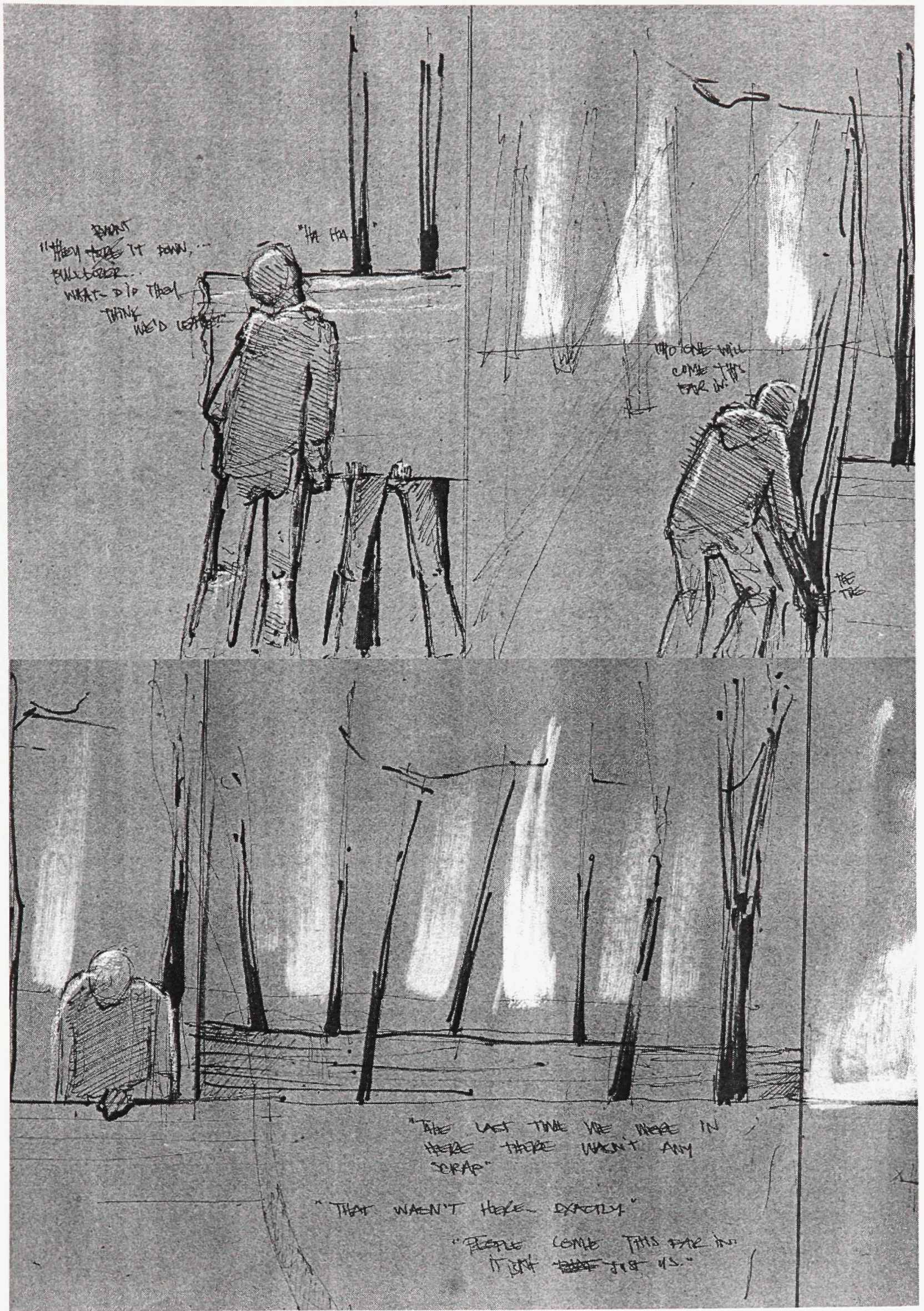

Plate 9. Fire-Pit (Section 5) 


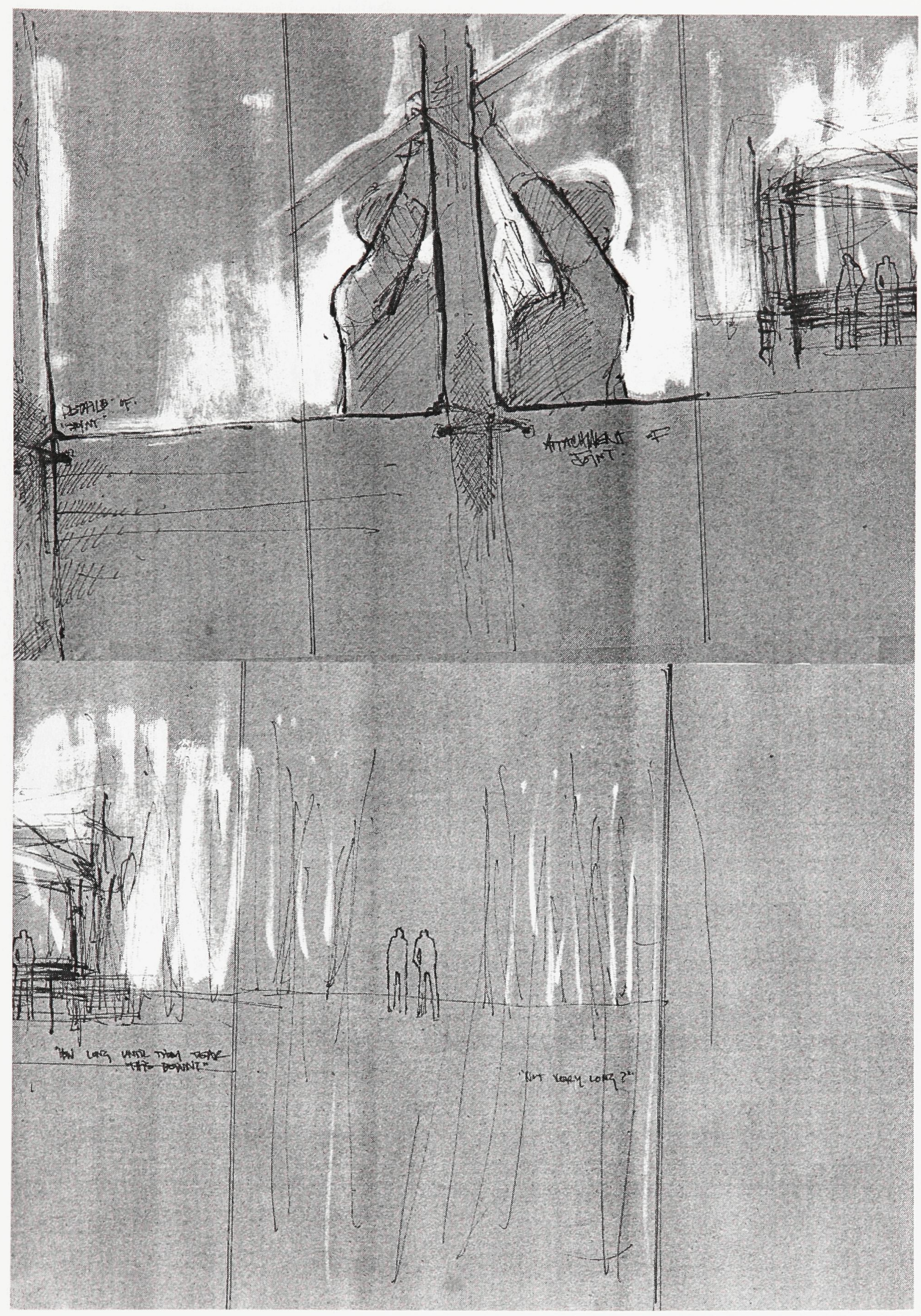

Plate 10. Fire-Pit (Section 6) 


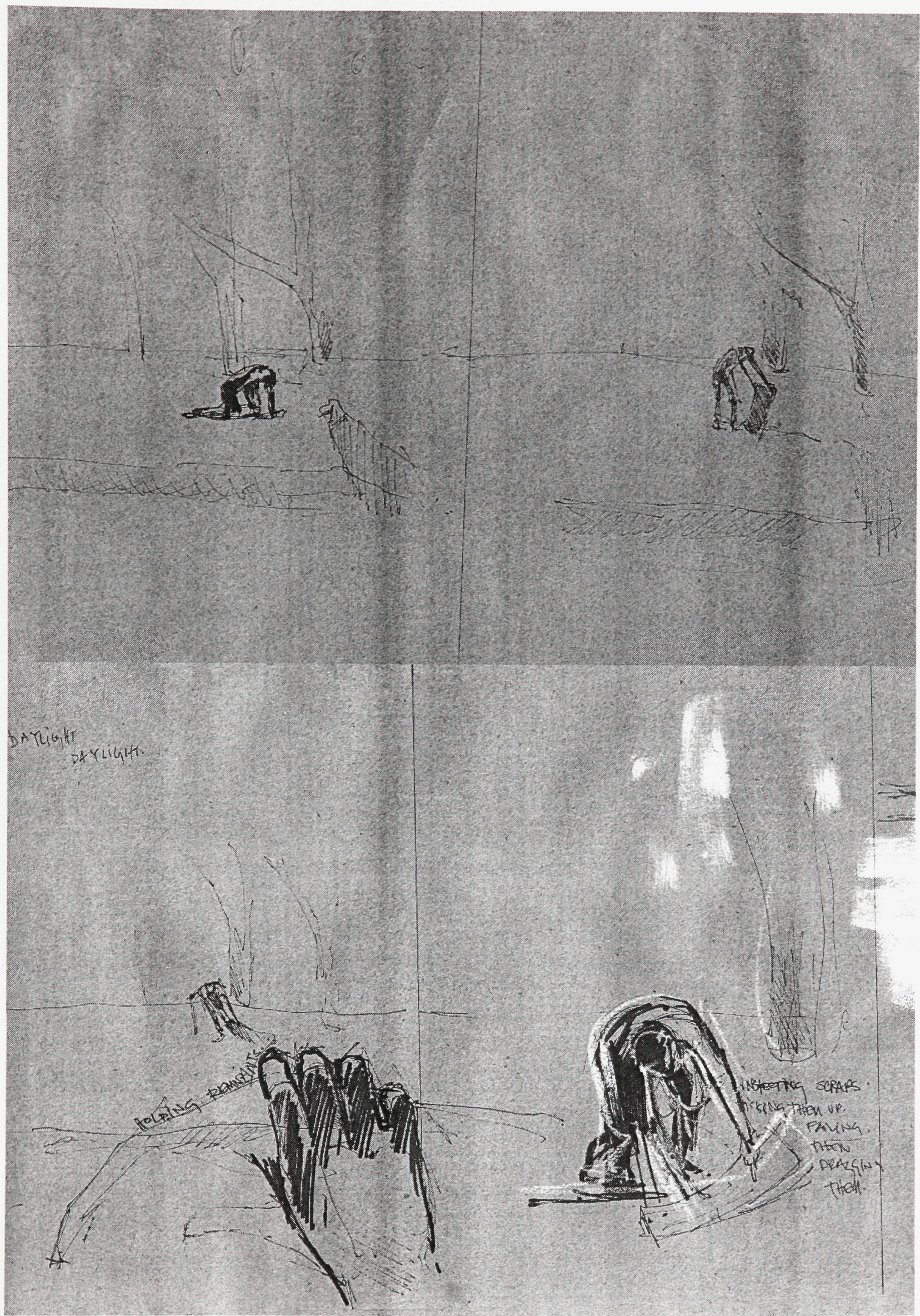

Plate 11. Kids (Section 1) 


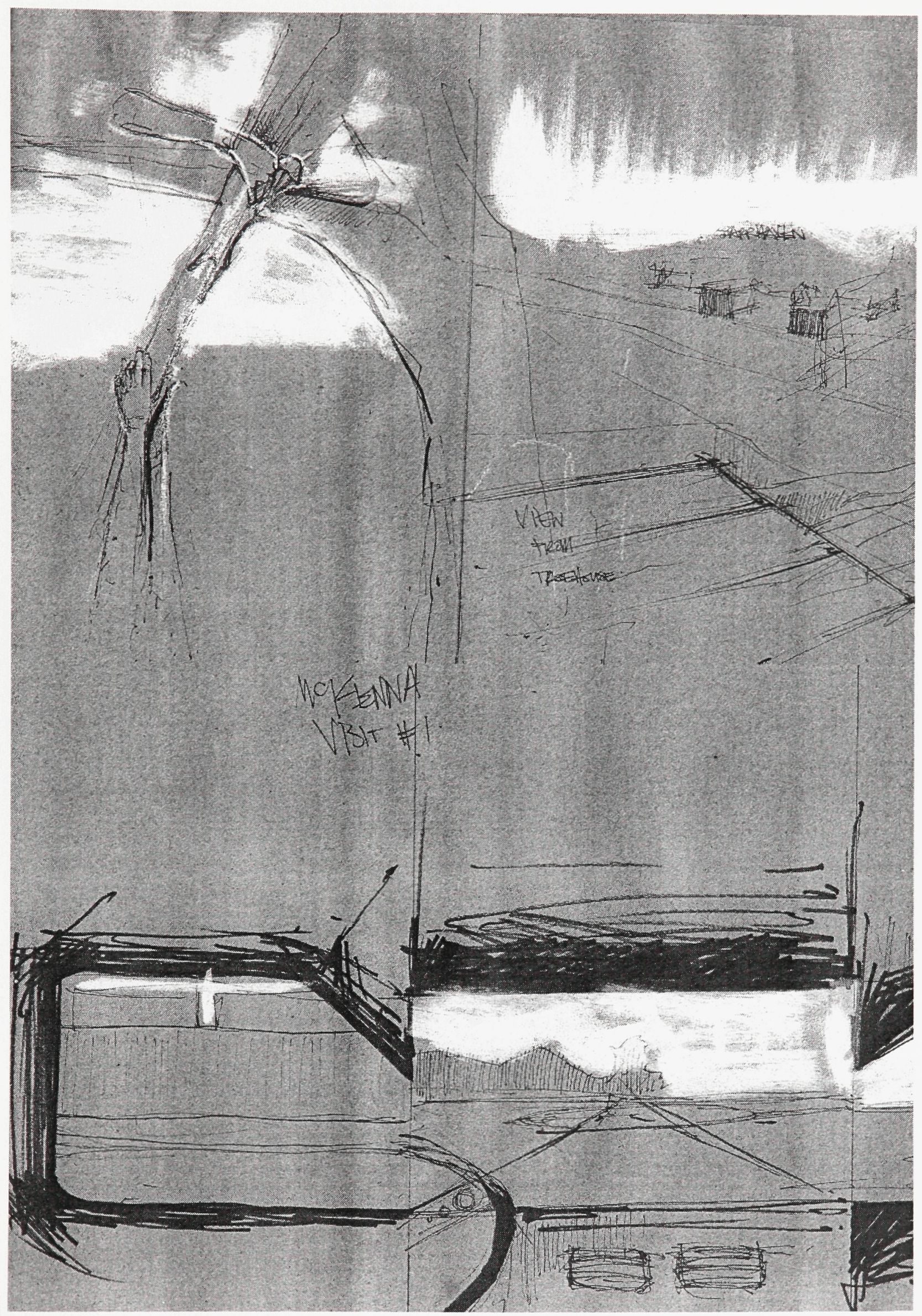

Plate 12. Kids (Section 2) 


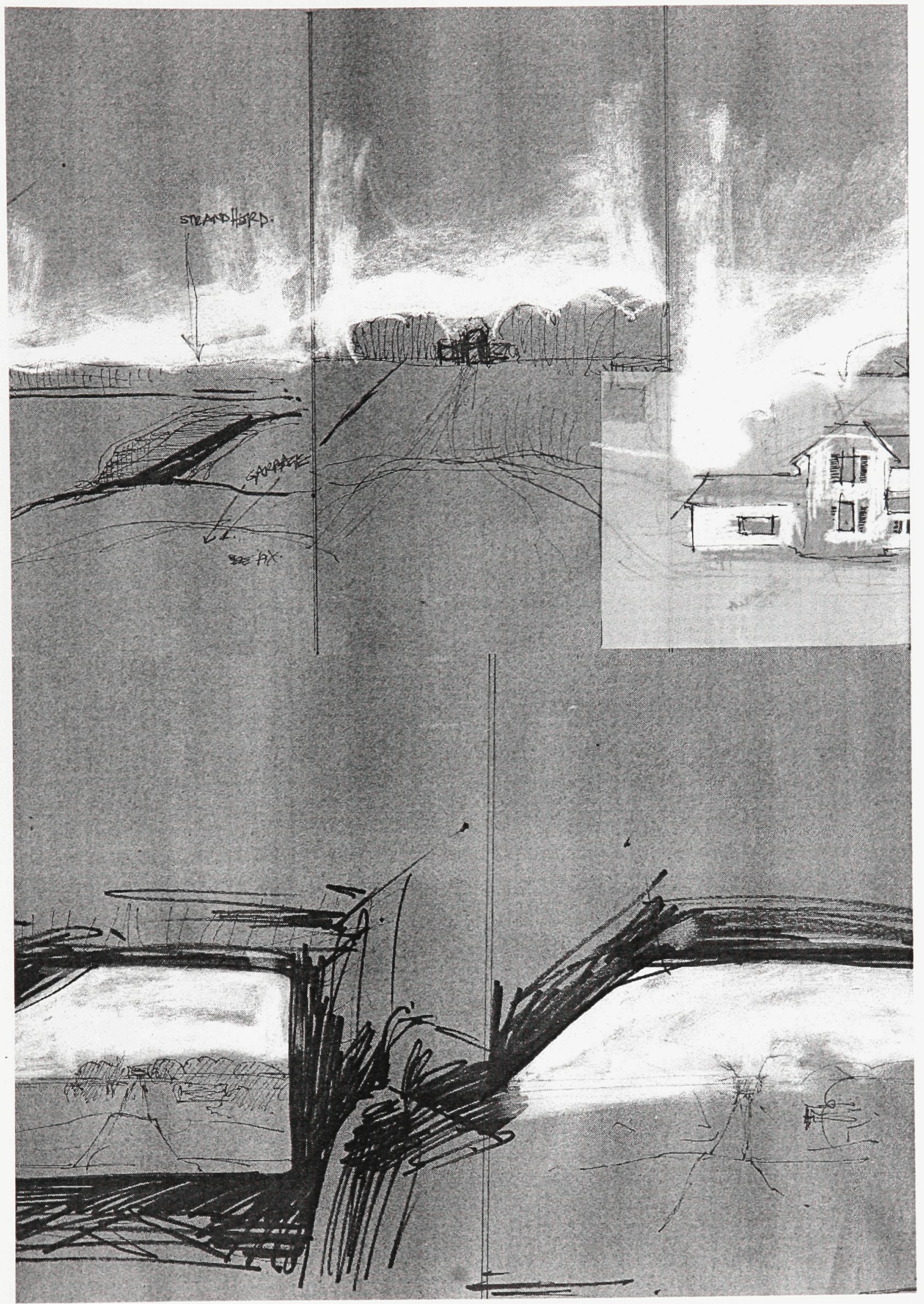

Plate 13. Kids (Section 3) 


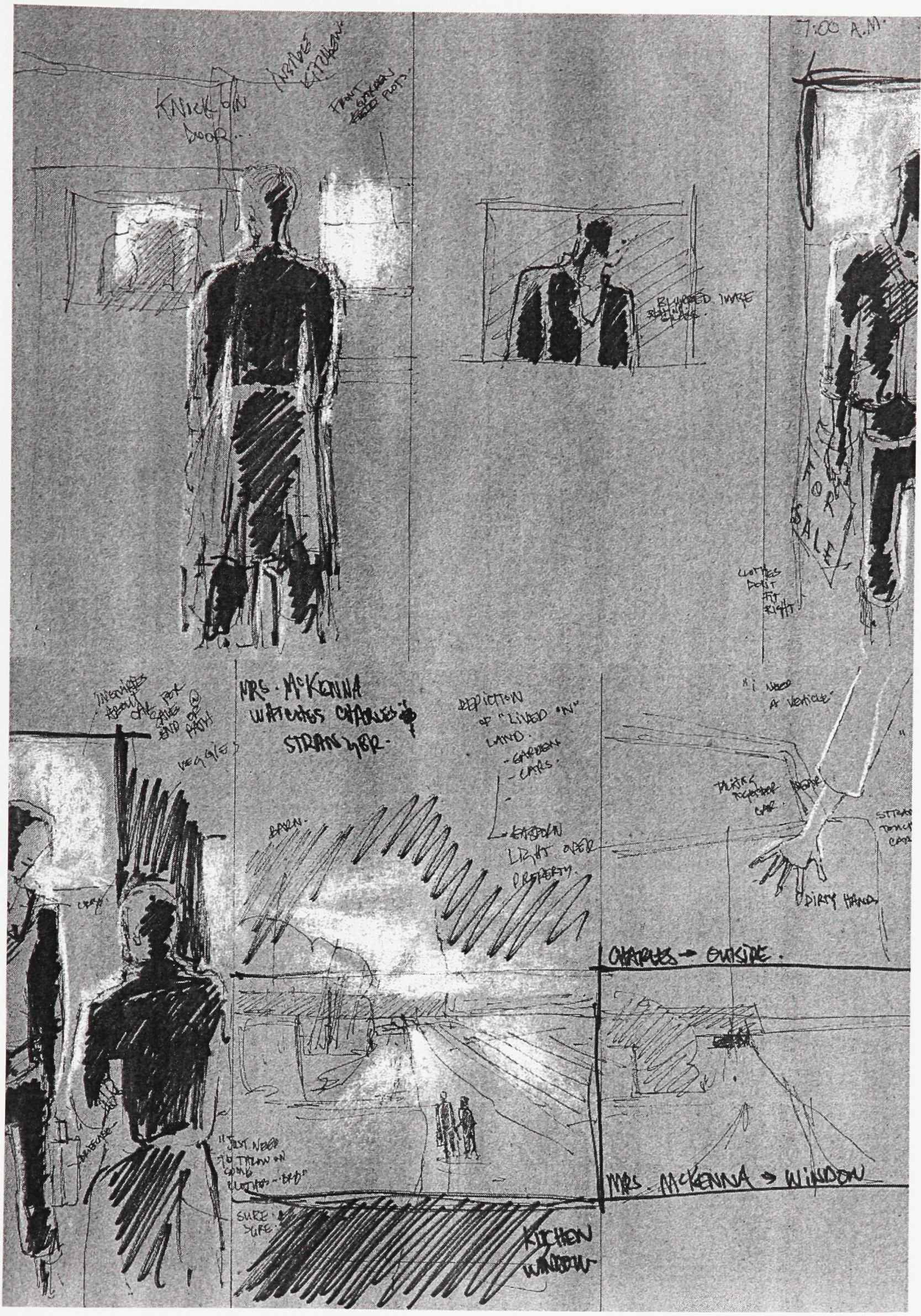

Plate 14. Joady (Section 1) 


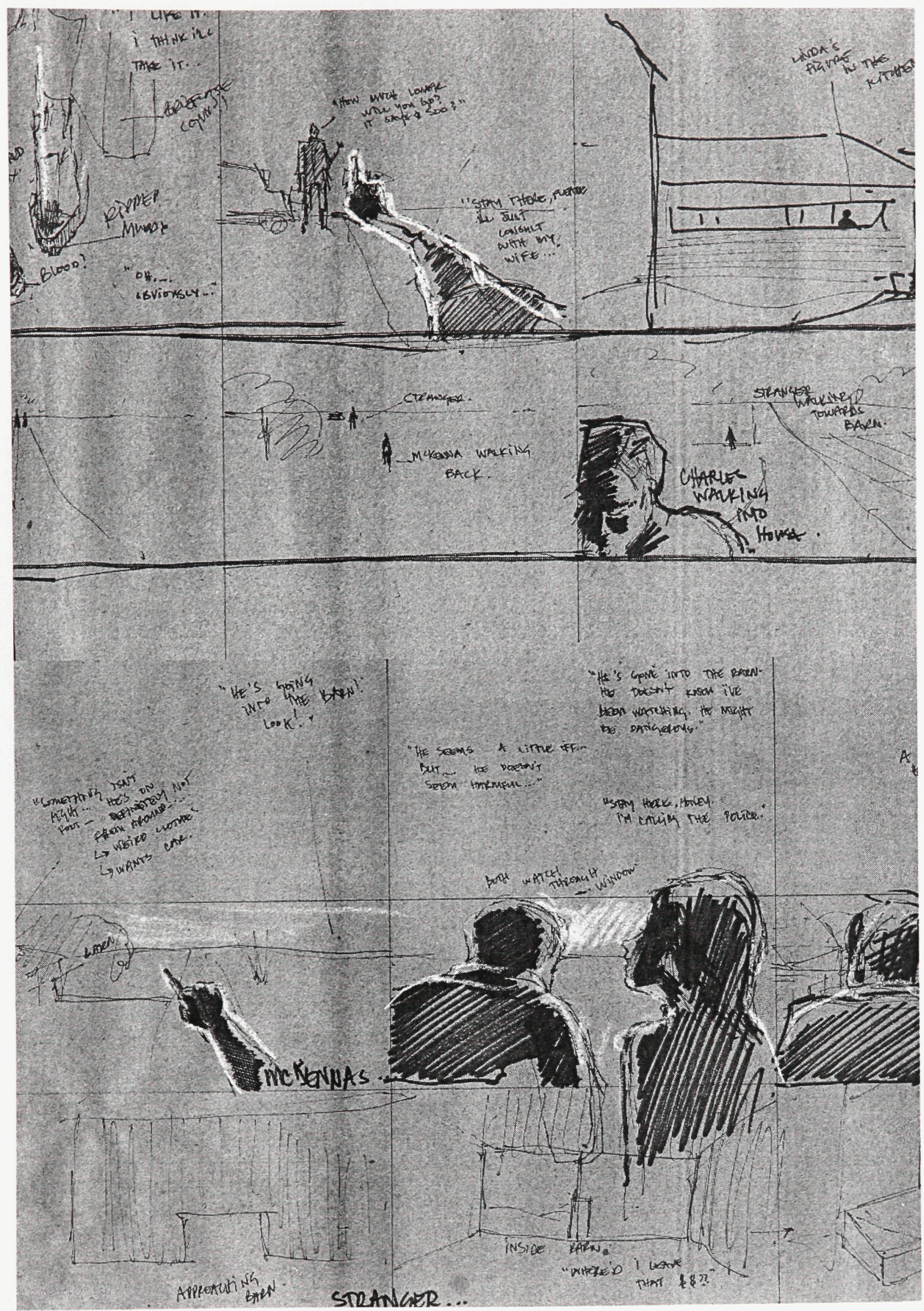

Plate 15. Joady (Section 2) 


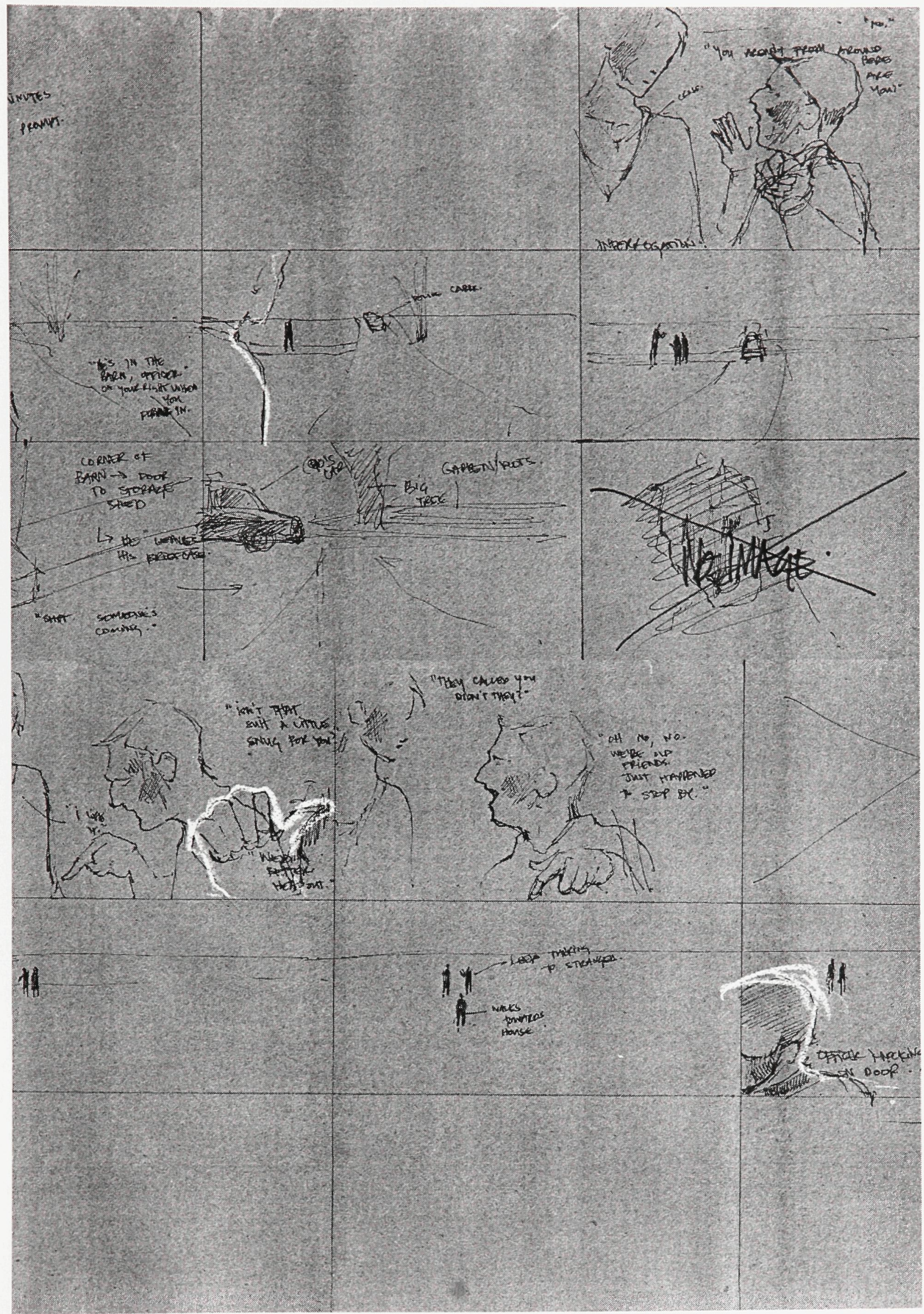

Plate 16. Joady (Section 3) 


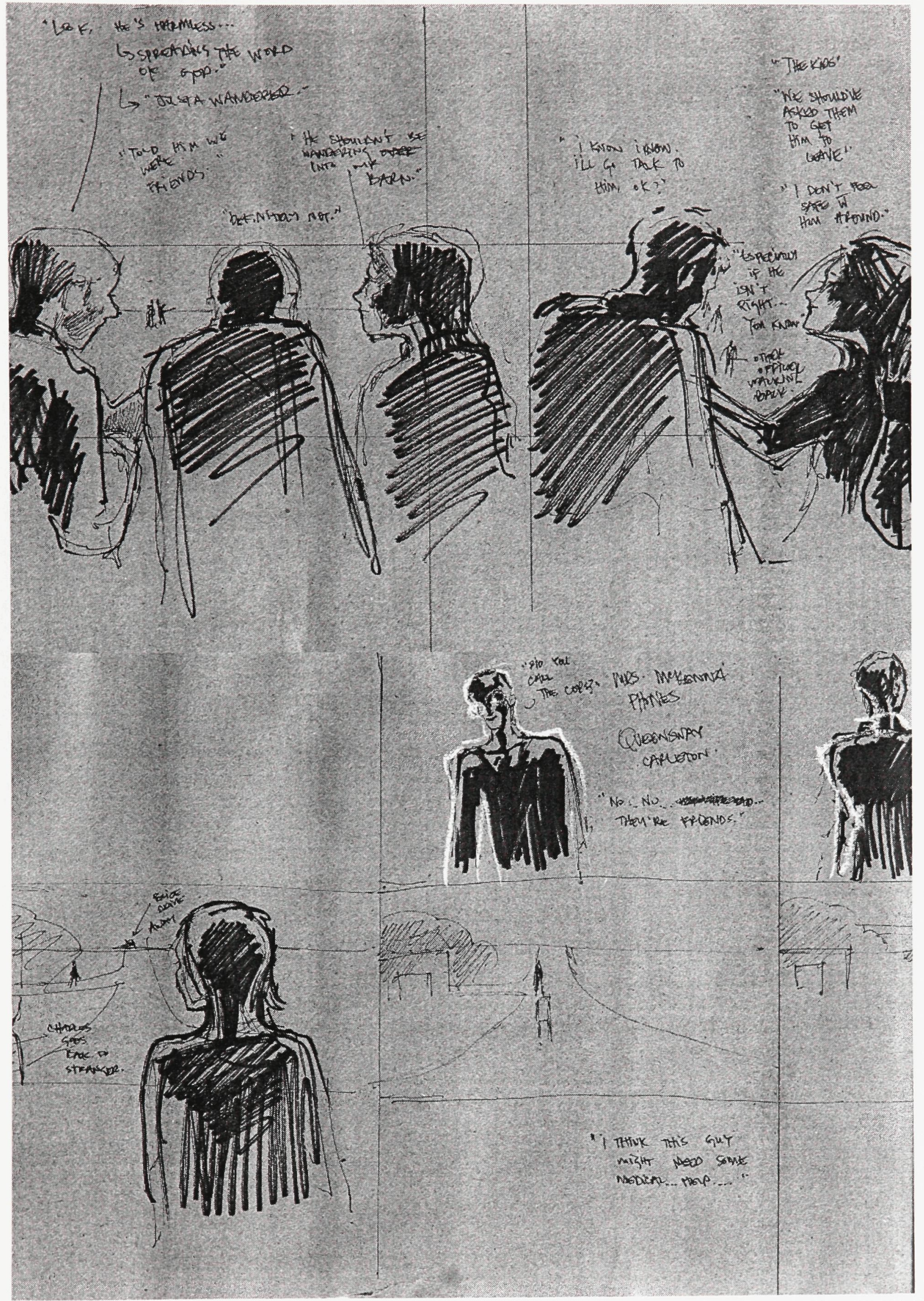

Plate 17. Joady (Section 4) 


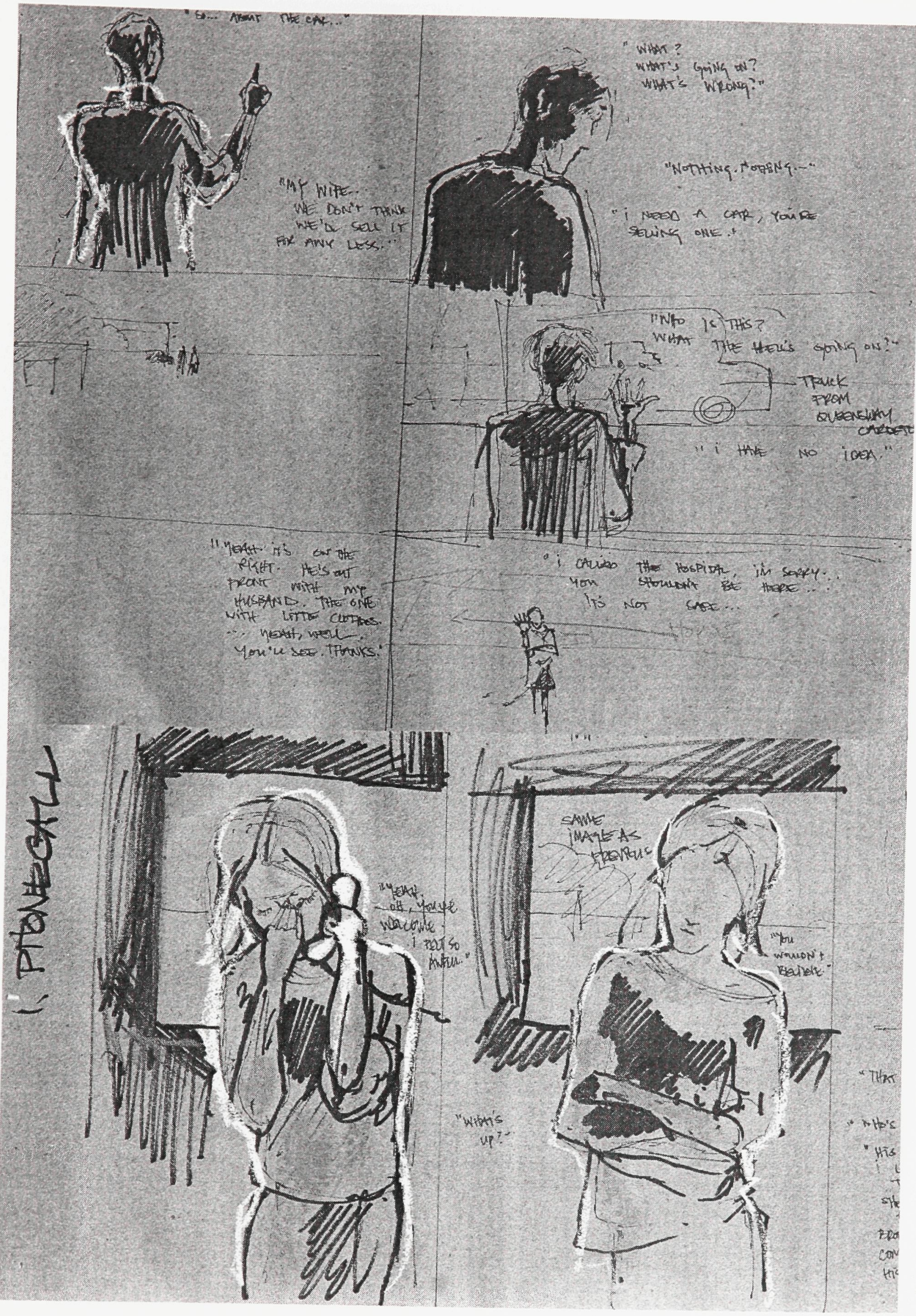

Plate 18. Joady (Section 5) 


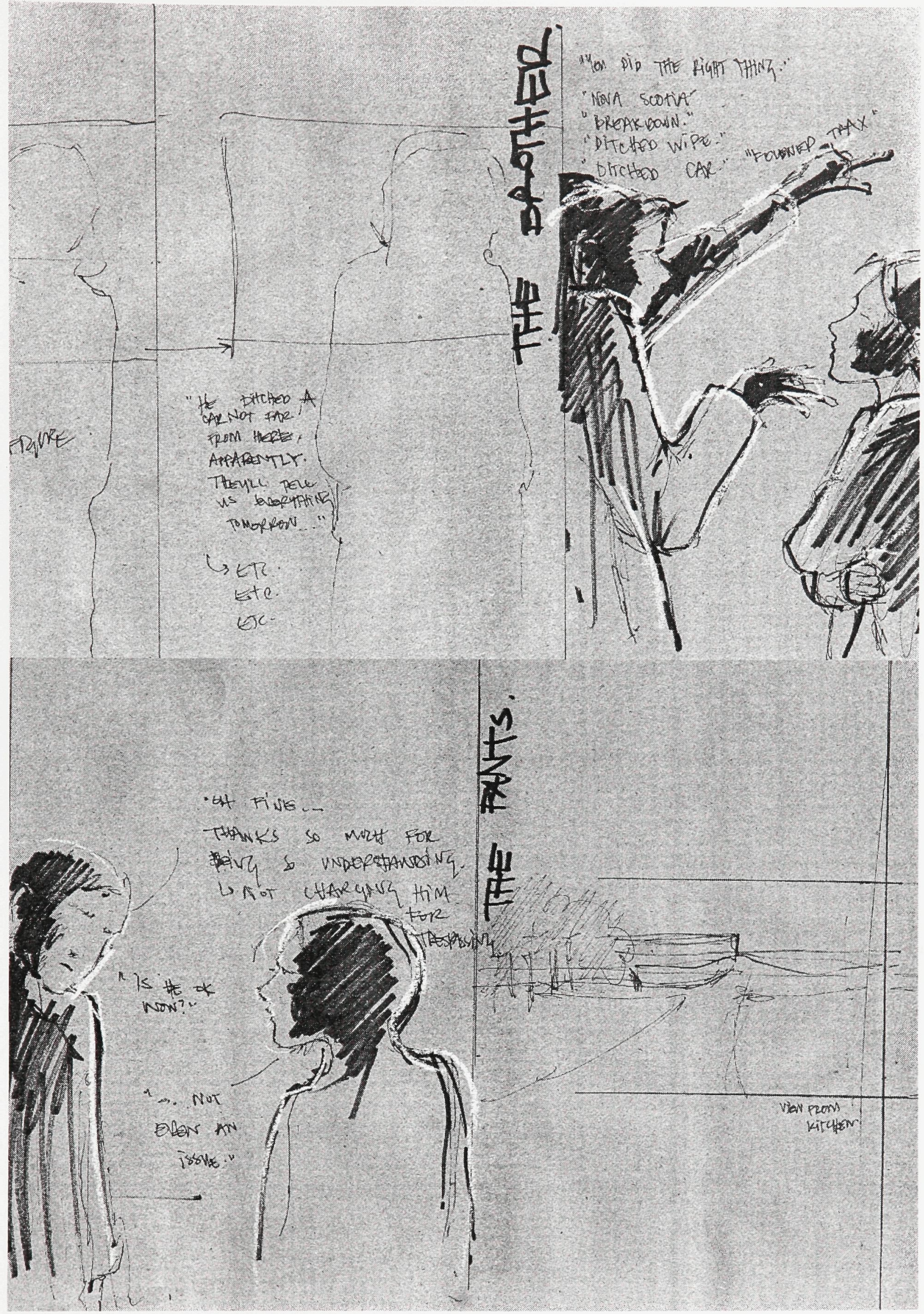

Plate 19. Joady (Section 6) 


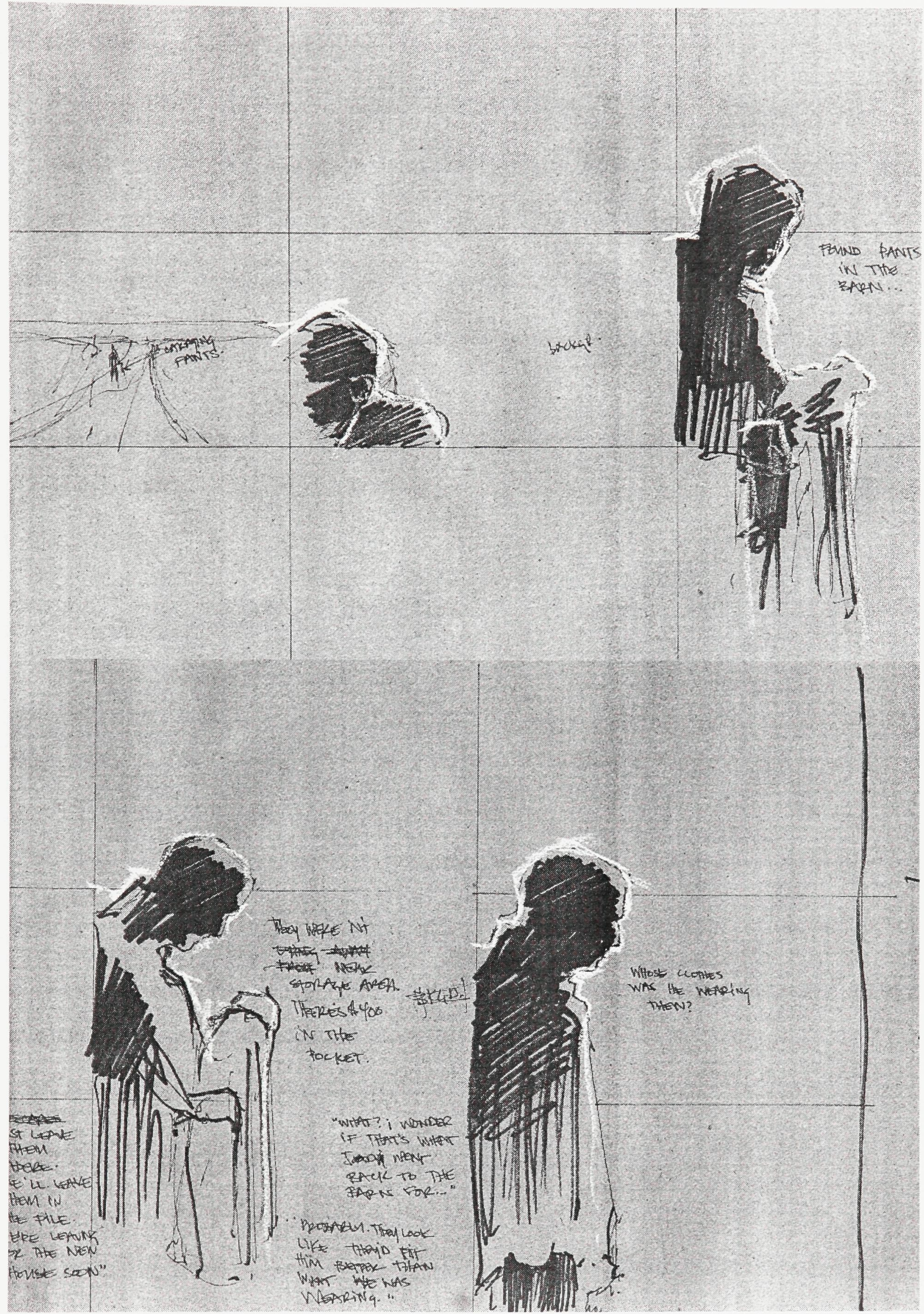

Plate 20. Joady (Section 7) 


\subsection{Development of the Sequential Macro-Frame}

As aforementioned, the sequential macro-frame will employ narrative fragments cumulatively rather than attempt to organize their parts in isolated organization. Before contacting the McKenna family, linear organization seemed to make sense of the particular events. In actuality, the realizations from reconstructing narratives and the reevaluations of drawing and linear narrative form were better adapted to the macroframe structure.

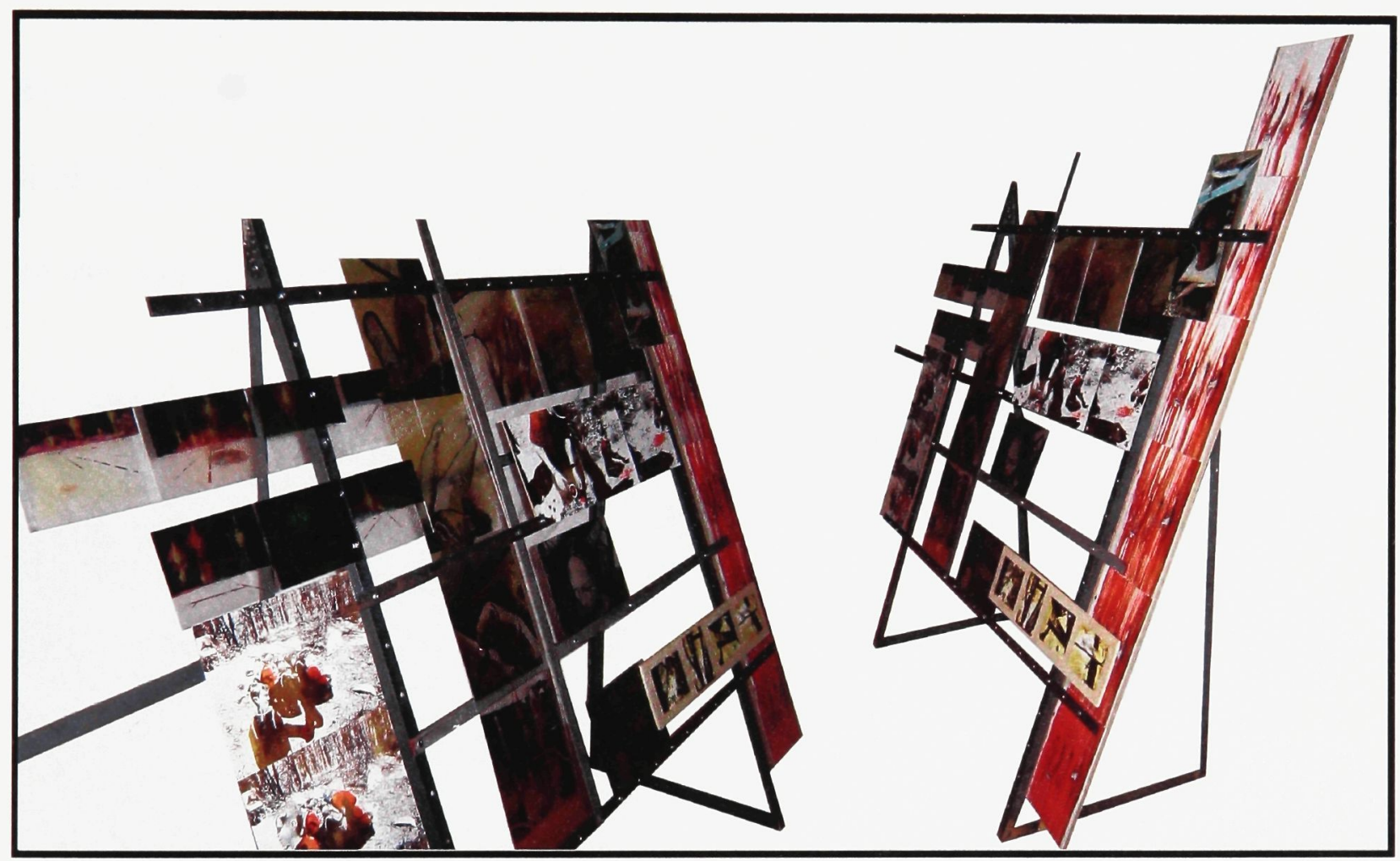

Figure 1. The Sequential Macro-Frame

The narrative fragments themselves proved to have their own complex constitutions/subfragments that made it difficult to assume any elemental frames of reference. For example, in the Silver Springs fragment (Plates 1-4), the trajectory of the escapee to her time on the site and her experience in the barn yielded separate sequences (images from which can be seen in Figure 17). 

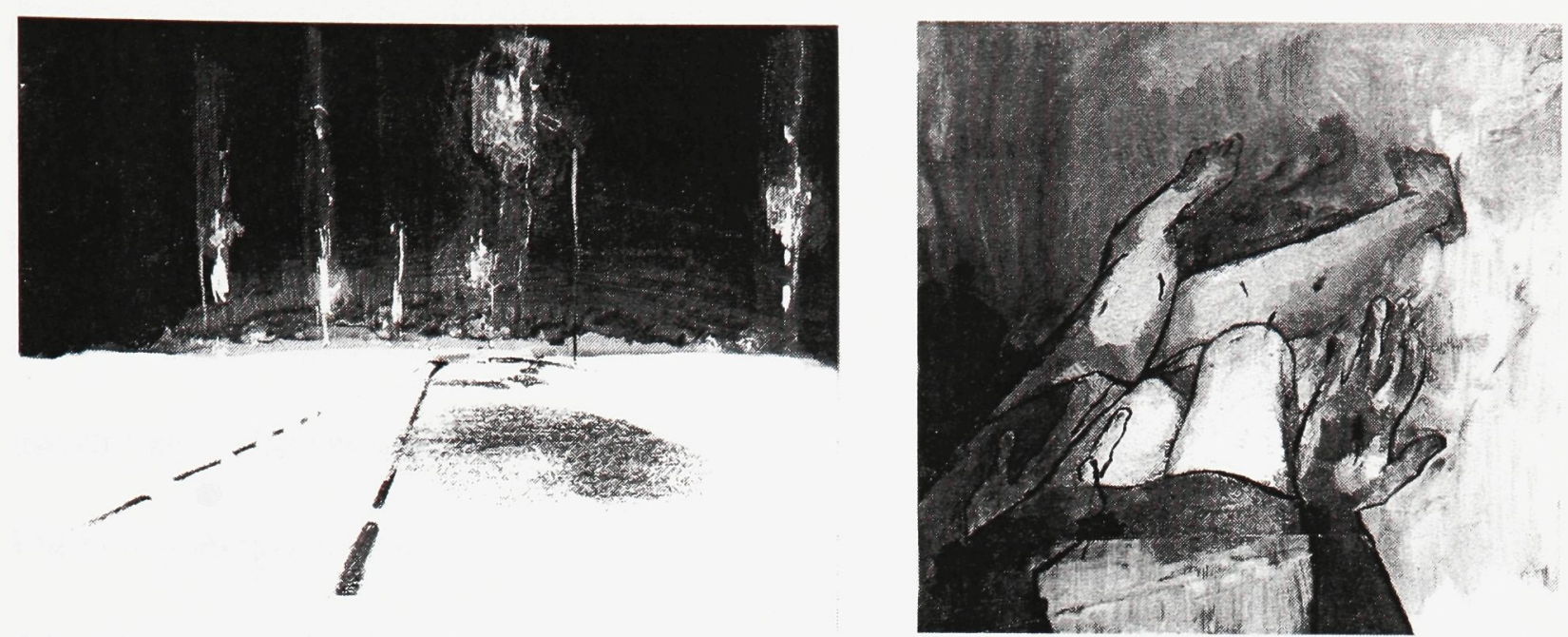

Figure 17. Images from the Sequential Macro-Frame, Fragment 1. (Silver Springs).

The repercussions of her story on that of the second and third fragments (Fire-pit, Plates 5-10, and Kids, Plates 11-13) can easily be implied as hers is a suburban story circulated by the type of experiencers included in these fragments (Figure 18).

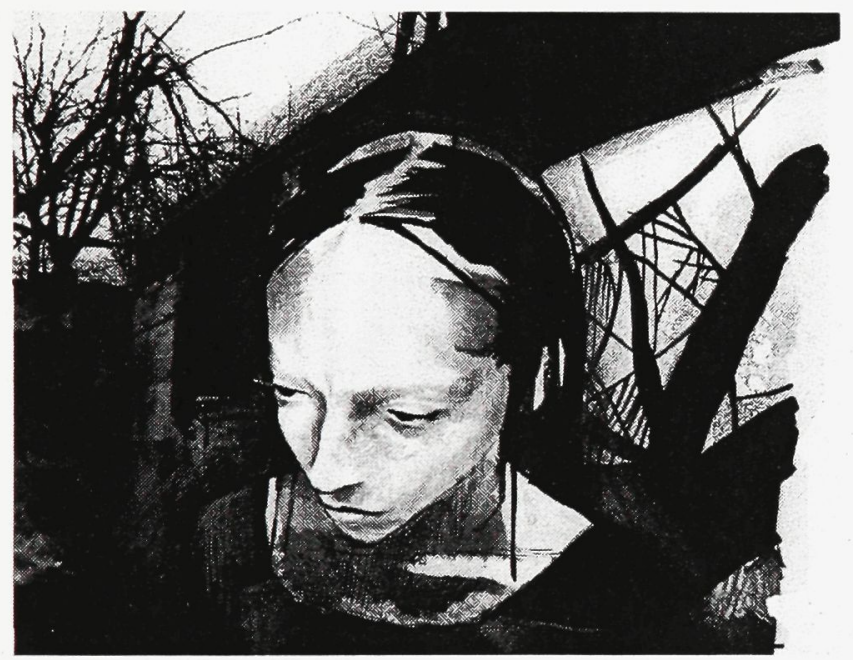

Figure 18. Image from the Sequential Macro-Frame, Fragment 2? 3?

The personification of the 'mental patient' could be incorporated into more than one fragment.

The second fragment not only deals with the relocation, reformation, and recurrence of the fire-pit, but assembly of the visitors/participants, and site changes.

The third fragment proves itself thick in composition as it touches upon the tree-house construction, remnant constructions, the projections of the three boys on their playground, and their reading of the traces of others (Figure 19). The fourth fragment 
(Joady, Plate 4) diffracts the linear oral narrative of Charles McKenna but also serves as confirmation that this site "has always attracted strange characters" both of whom sought refuge/sanctuary in the barn (establishing a relationship with fragment 1). ${ }^{113}$

As the initial narrative fragments are reconstructed to form multiple sequences, their interrelations become manifold. The reassessment of the narrative parts yields a nonlinear organization that differs from the initial storyboard explorations (Plates 21- 23). As a starting point, the first representations for the macro-frame employed the first three narrative fragments as well as disnarrated elements (those dealing with isolated single frames or issues not directly related to the narrative fragments). Through formal cues, subject matter, relations within the frame, and layering they become the means to induce design explorations of a similar richness through their conjunction with the Rules of Operation (3.2).
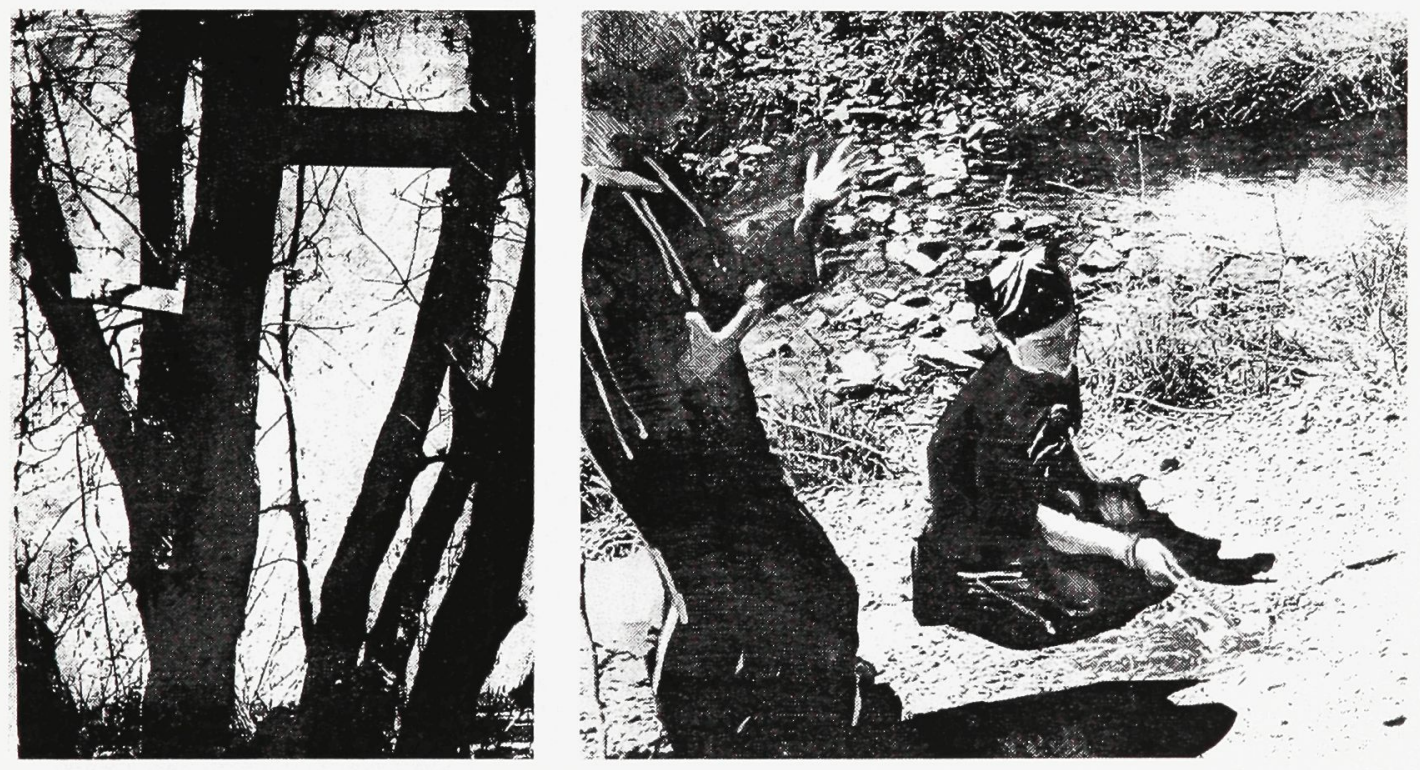

Figure 19. Images from Sequential Macro-Frame, Fragment 3. (From left): an abandoned treehouse and kids building a fire.

\footnotetext{
${ }^{113}$ Personal communication from Charles McKenna to author, November 2004.
} 

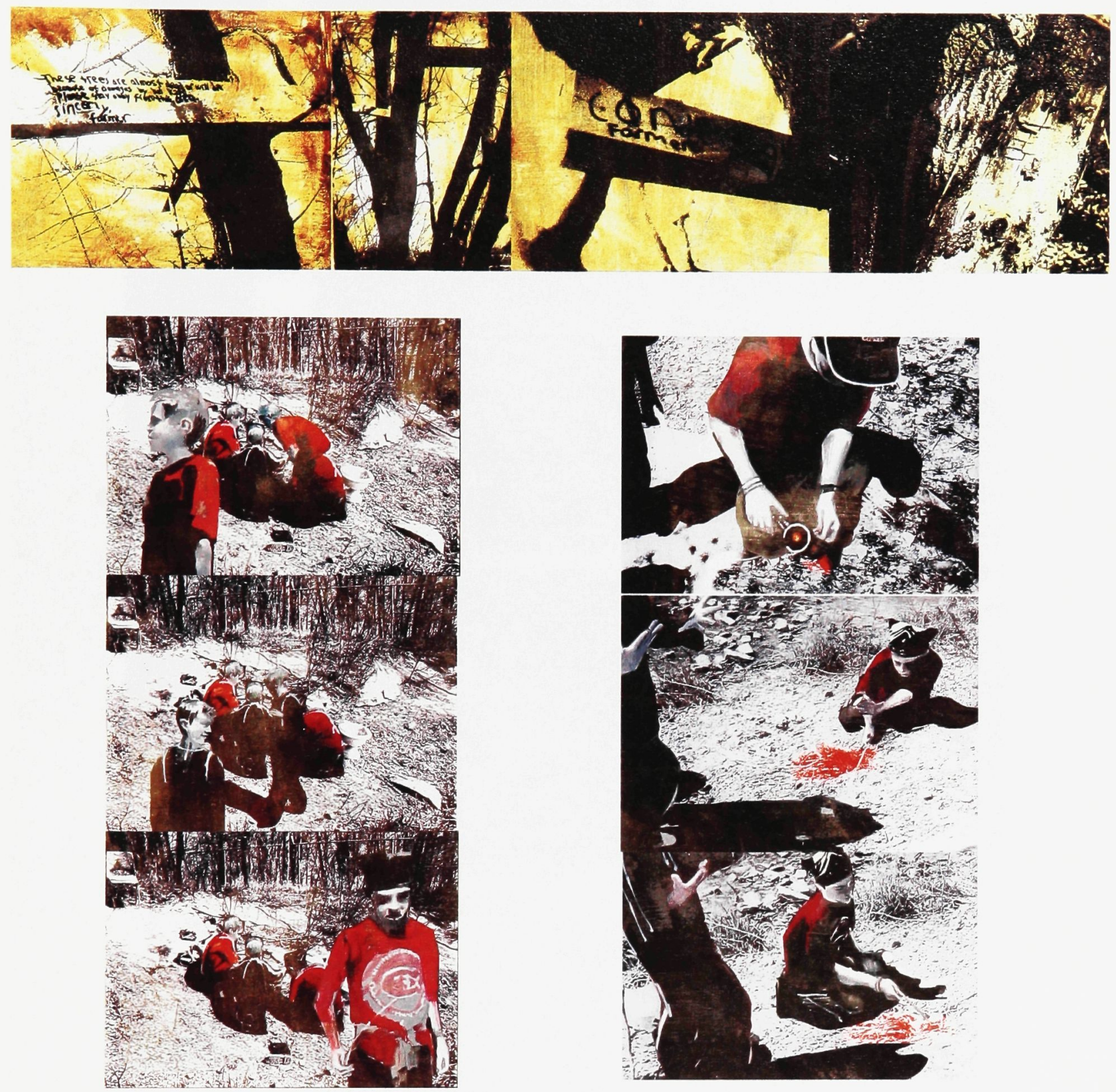

Plate 2. Images from the Sequential Macro-Frame: Fragments 2 and 3 (Fire-pit and Kids). 

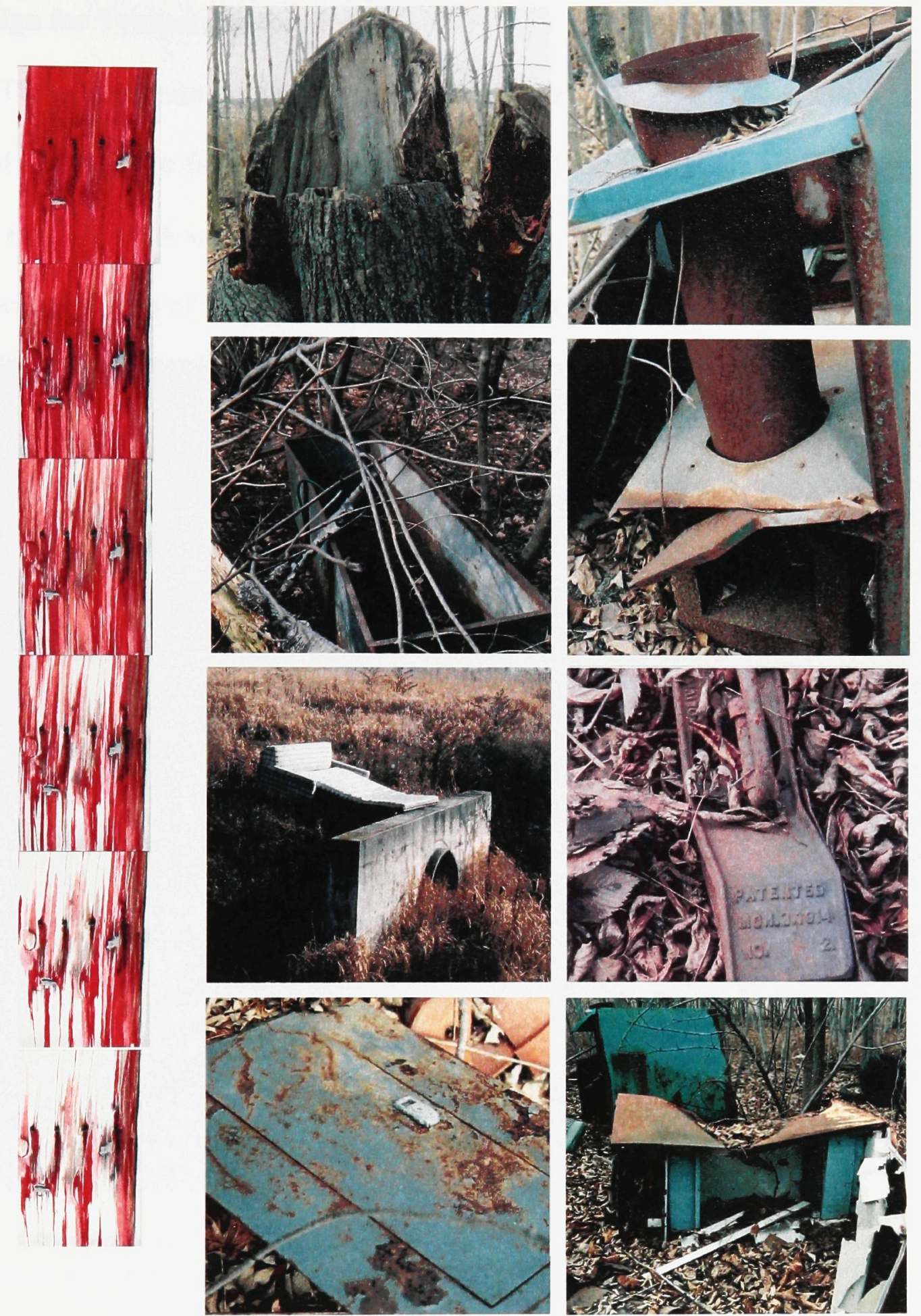

Plate 3. Images from the Sequential Macro-Frame: Disnarrated Elements. 


\subsection{Design for Temporary Road}

Through assessment of the fragments (and their subsequent fragmentations) gathered in the macro-frame and the application of the Rules of Operation, the alternative scheme took shape. A superimposition of maps became the basis of a drawing that illustrated the nature of the scheme: accretive like the macro-frame (Figure 20).

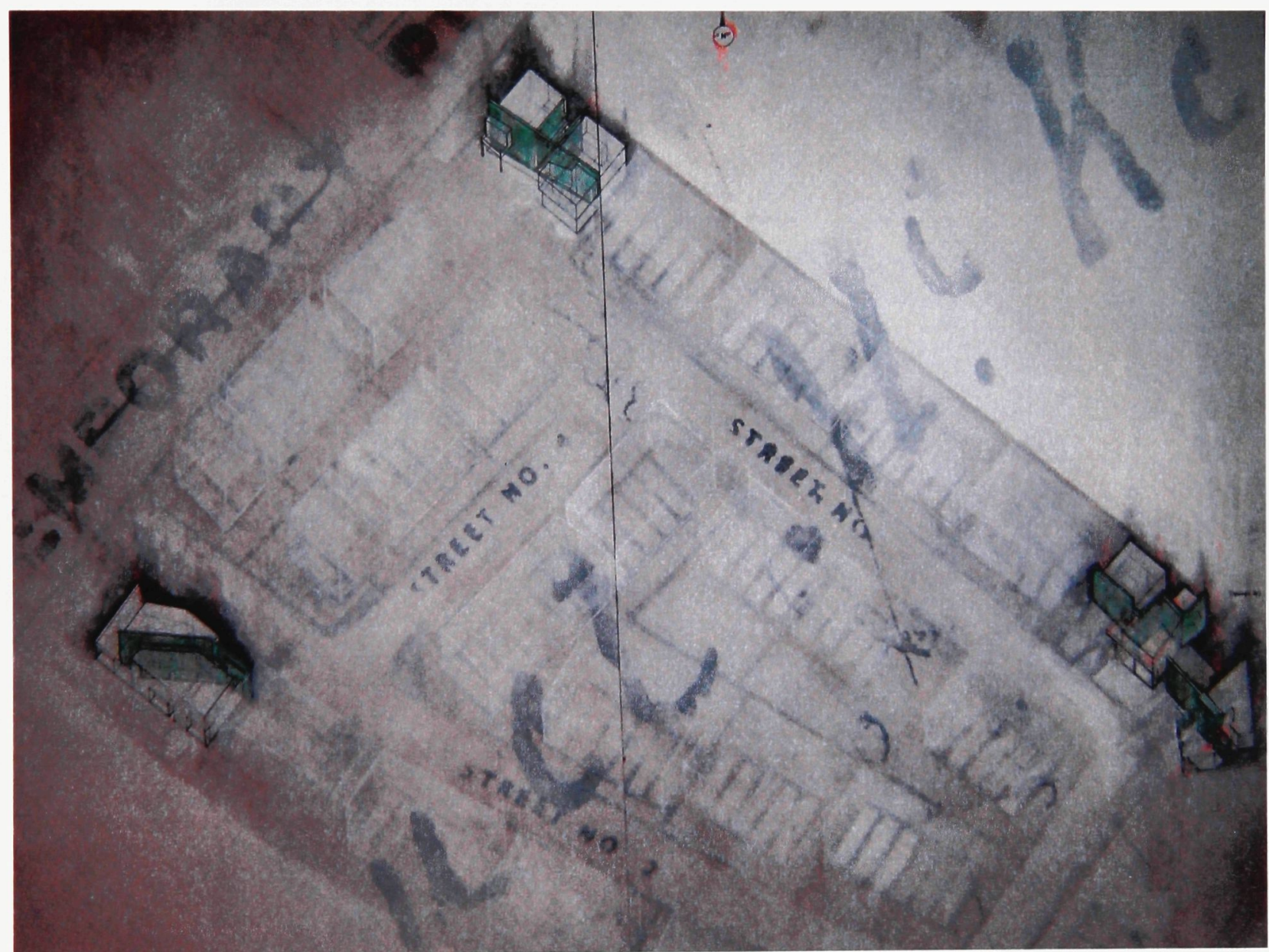

Figure 2. A Reassessment of the Developer's Scheme (Site Plan). The initial axonometric sketches convey formal and organizational contrasts against the intentions of the Phoenix Homes plan.

The rough size of the developer's intentions (emphasized through ghosted boxes) in juxtaposition with the units induced by the macro-frame create a contrast that would be reminiscent of the full realization of the alternative scheme and the adjacent housing created by Richcraft, the second developer. 

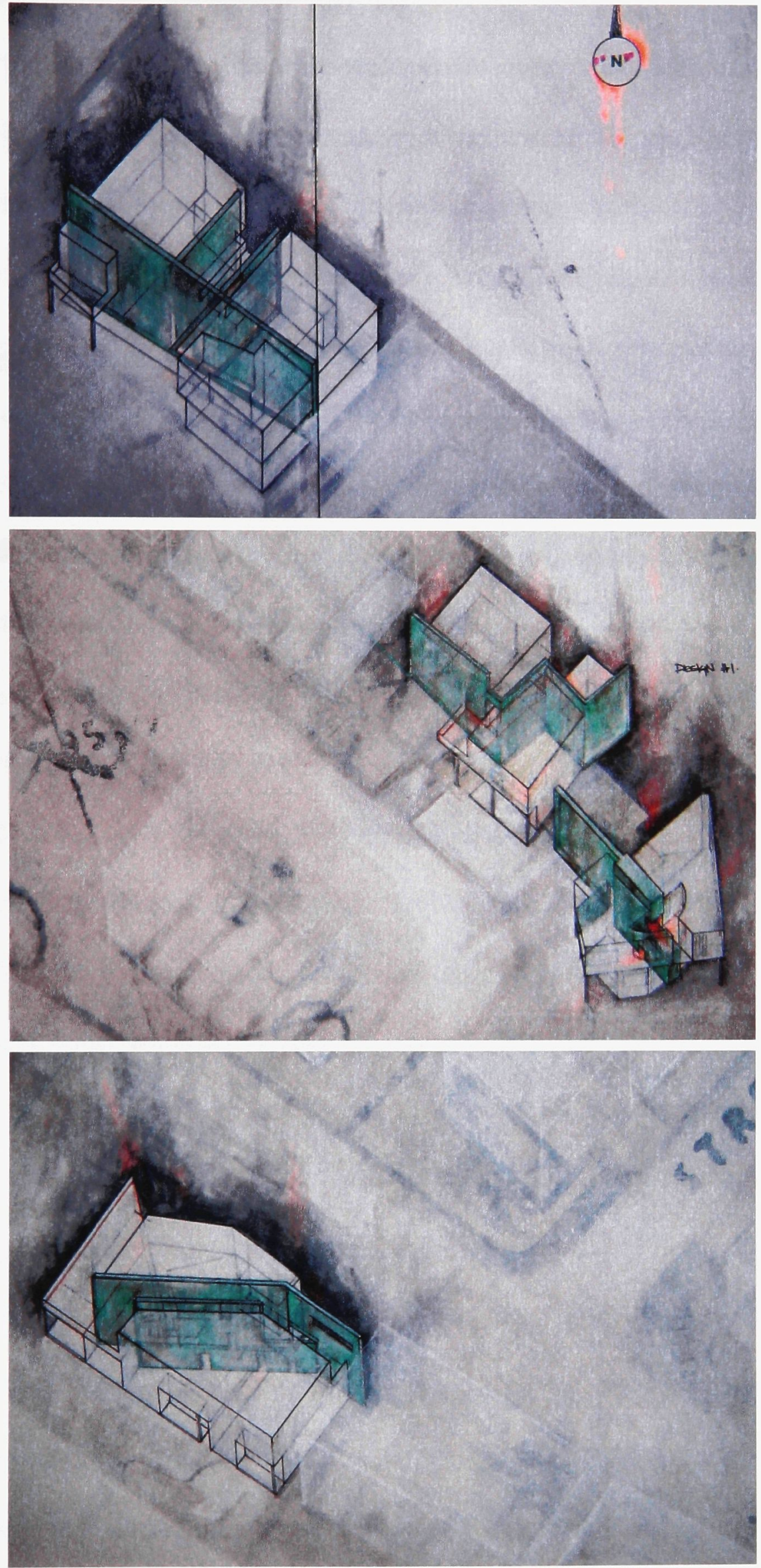

Plate 4. Details from Site Plan. 
As illustrated in Plate 24, the designs vary from row to row due to their adaptation of the fragments of the macro-frame. One case explores the inversion of domesticity to the public realm by creating a semi-private enclave with the wall (see no. 3 in the Rules of Operation) where conventionally private intimacies perforate to the outside (Plate 24, top). The next case (Plate 24, middle-left) employs a wall that follows the foundations of the original homestead while exploring the textural explorations from disnarrated explorations of decaying wood. Beside this row housing stands another group that draws from the Fire-pit stories to create a private/semi-private hearth from the wall. Another case (Plate 24, bottom) fragments a linear trajectory based on the mental-patient's path by creating alternate routes through the wall-space.

Two of these cases (Plate 24, middle) were further developed in plan to explore the division of private, semi-private/public, and public spaces (Plates 25, 26). Consistent reference to both the old homestead (through recognition of the old foundations) and the developers plan help to create the spaces. Further development of one of these rows (Plates 27, 28) clarifies these spaces and their application in the fundamental conditions of the site: those which recurred through the narrative fragments of the site: assembly and sanctuary. In this detailed design, the hearth-wall provides both a separation between the neighbouring units as well as a means for interaction through its perforation: a shared, outdoor fire-pit. When the smaller (potentially one-person) unit is further developed (Plates 30, 31), manifestations of the macro-frame become more evident. The condition of the fire-pit explicitly referenced by the narrative fragments involving the boys and recurring fire-pits on site create a basis by which to proliferate the notion further into an adaptable design that invites many potential social situations as well as provides an 
instance unique to the row of houses as a particular. Opportunities such as these debunk developer logic one small step at a time as they do not adhere to the linear efficiency of that type of design process. Rather, these explored conditions reference a nature unexploited by the suburb and exemplified in Temporary Road.

\section{CONCLUSION}

As an alternative to the housing schemes offered by developers such as Richcraft and Phoenix, this prototype questions the processes by which suburban communities such as Barrhaven are founded. Rather than leveling and intervening on the site (whitewashing all that came before) the operations suggested and tested here reevaluate the relationship between the site and building to create an accretive scheme employing fragments of narratives and findings unique to it. The role of the drawing is emphasized in its communication of the architect's disposition towards site and user - to what degree of sensitivity does the architect acknowledge their importance? Unlike the banal repetition of the home in the developer's plan, this approach builds for human consciousness in that it asks the viewer, user, or experiencer to make her own unique connections of the represented and built; understand the surroundings and contents (and consequent relationships) of the occupied space. Through this particular attempt, both site and user fortify their importance in what is built upon their individual realities. This stance is reminiscent to that of Robbe-Grillet's to the reader when he said: 

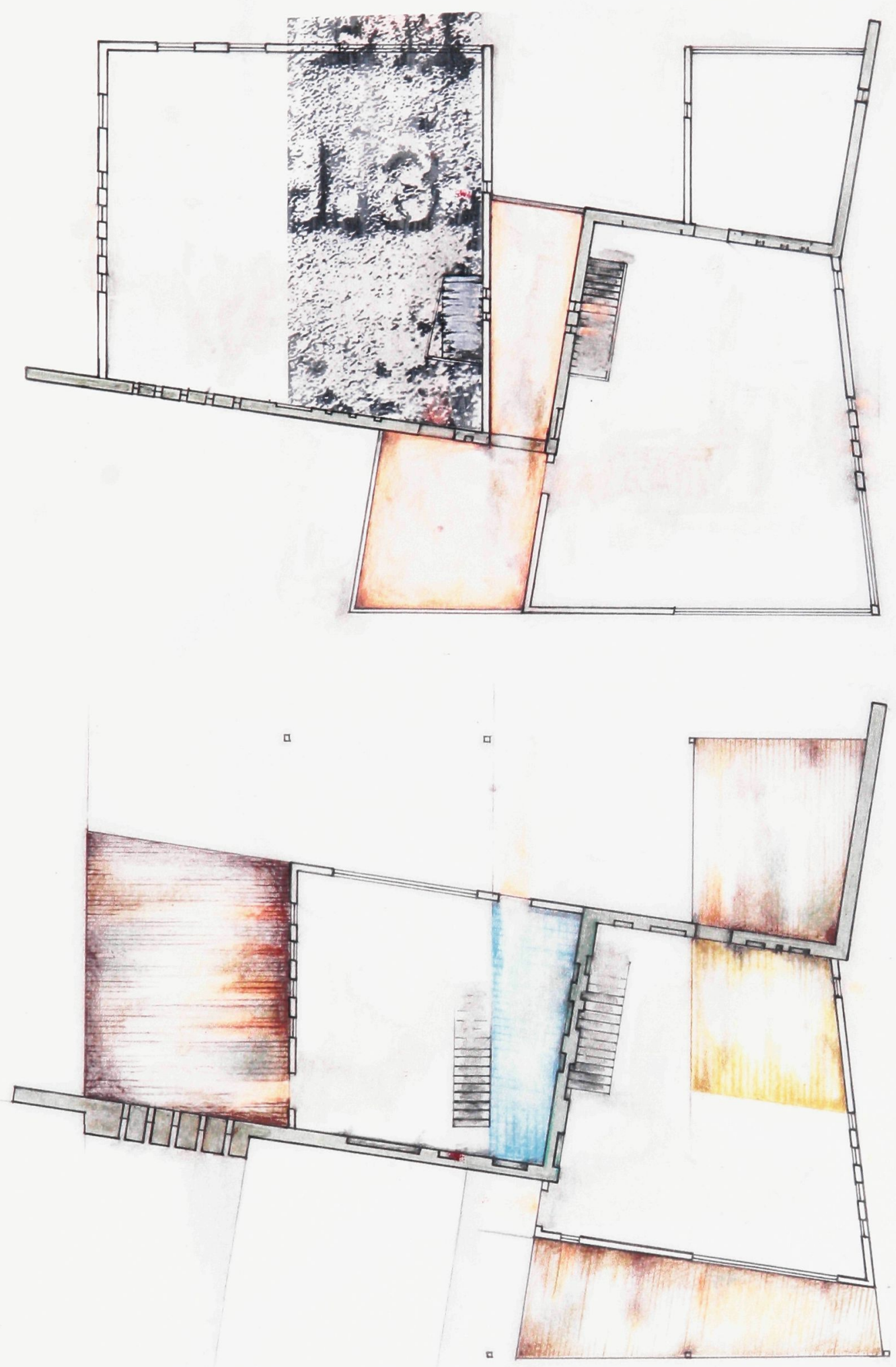

Plate 5. Design \#1: A Row in the Housing Scheme. Spaces are delineated by referring to the old foundation walls and the developer's plan. Ground floor (bottom) and second floor (top). 

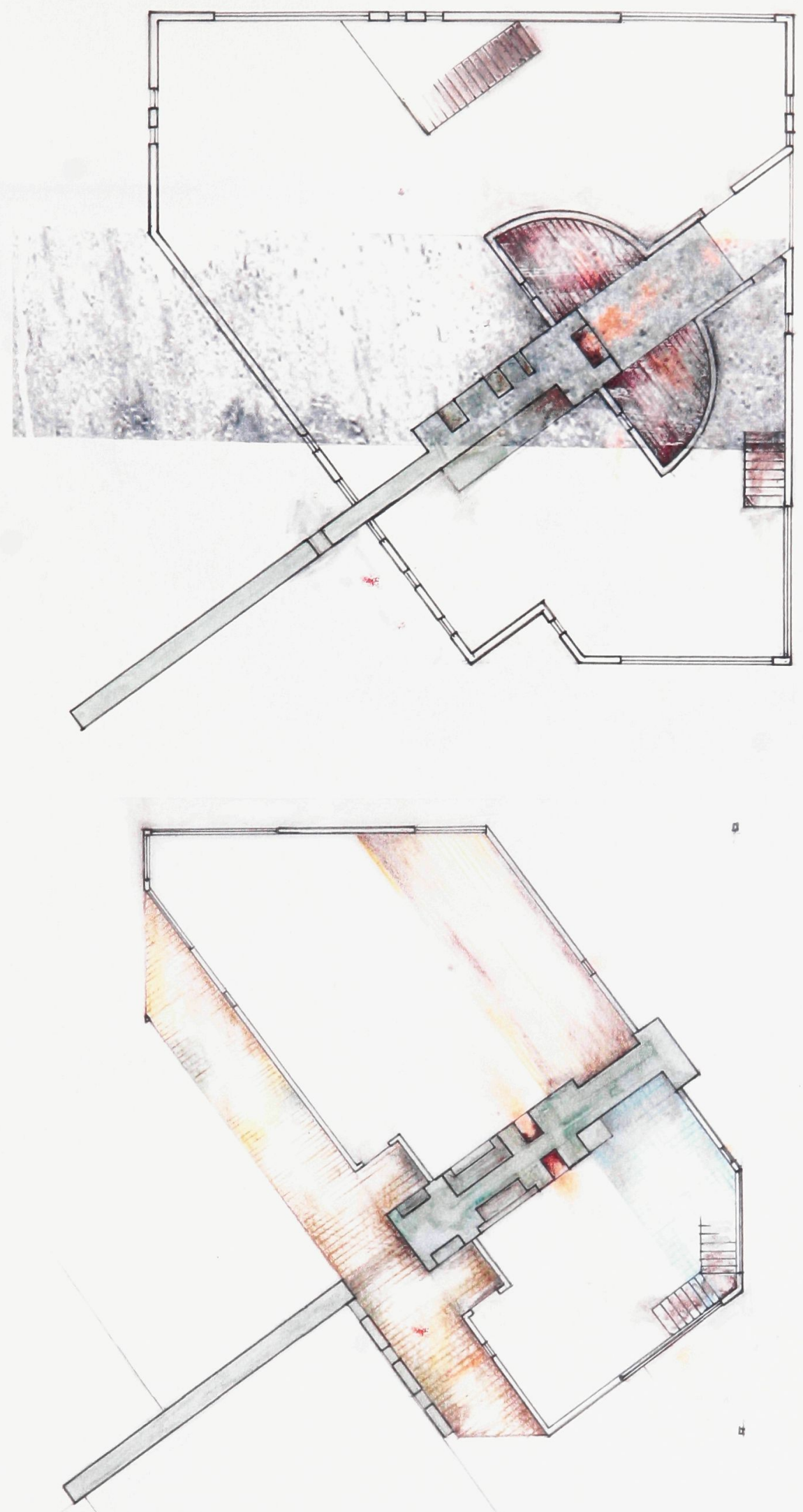

Plate 6. Design \#2: A Row in the Housing Scheme. Moments for assembly and sanctuary are created (through a hearth-wall) to re-instigate the potential for these fundamental conditions of the Temporary Road site. Ground floor (bottom) and second floor (top) 


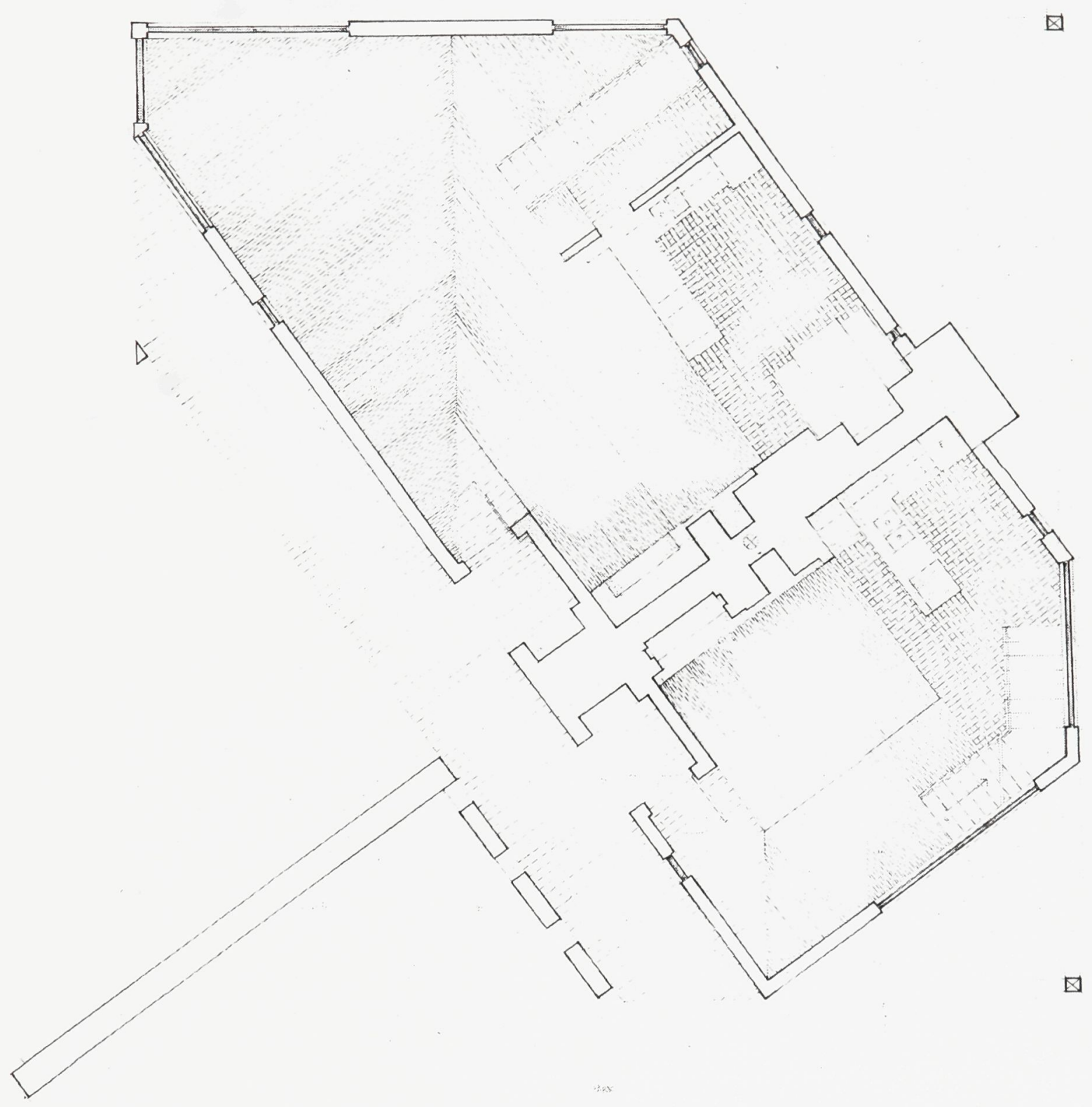

Plate 27. Ground Floor of Design \#2. Here, the row (originally laid out as three homes by the developer) consists of two units, the first much smaller than the second, facilitating the interaction of different types of households. 


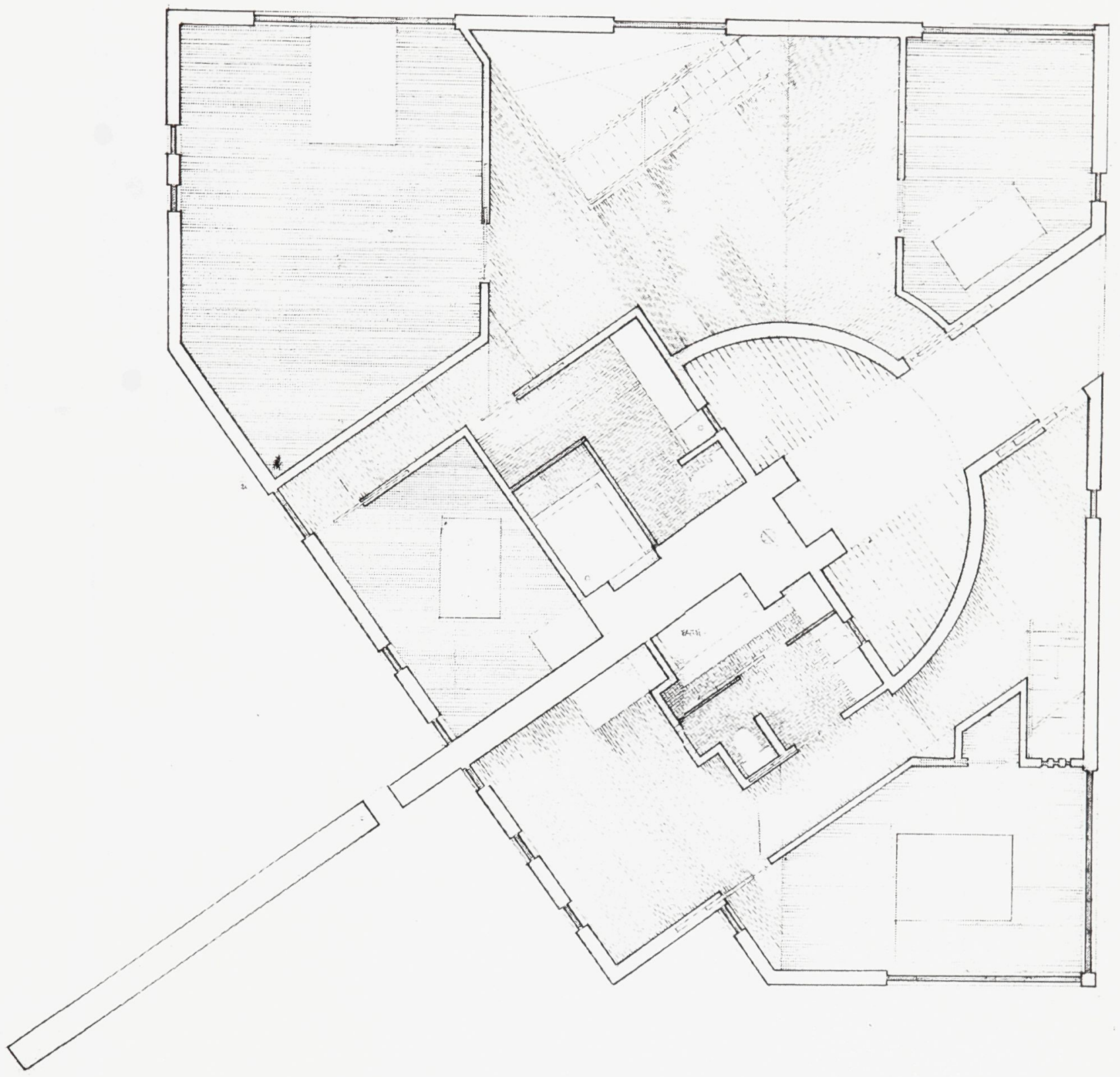

Plate 28. Second Floor of Design \#2. The central fire-pit provides a means for assembly and interaction. It acts as a mediator between two private realms. Texture and material prove their importance despite the dry, developer-like choice of line drawing. 


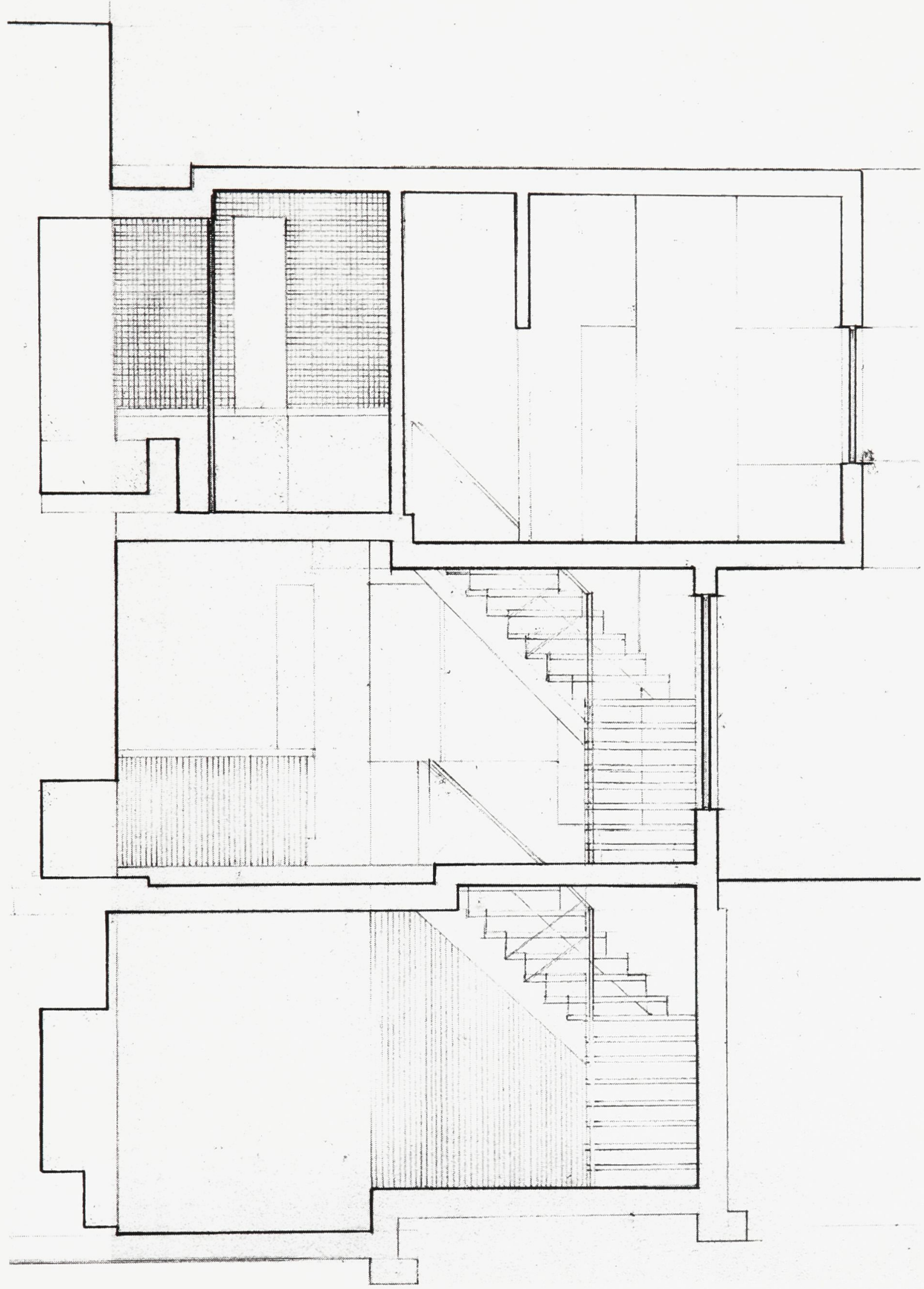

Plate 29. Section Through Small Unit in Design \#2. Perpendicular cut through hearth- wall demonstrates the extension of materiality from the ground plane to the vertical. 


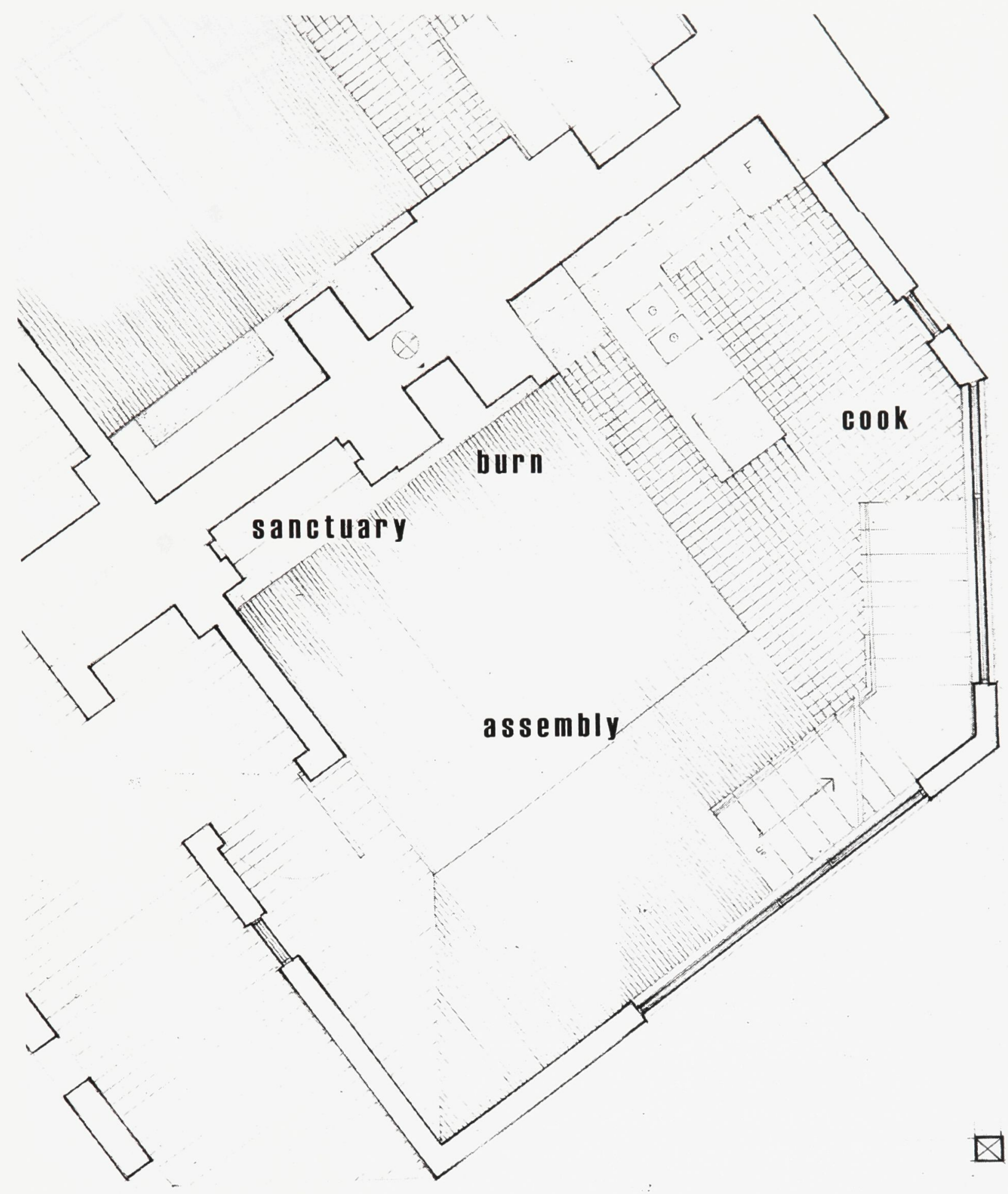

Plate 30. Detail: Design \#2, Ground Floor. Rather than the processional outlining of spaces typical of developer propaganda, this drawing is labeled according to the conditions it investigates rather than dictating spatial function. Niches are created in the wall to provide moments of sanctuary and safety and an intimate connection and acknowledgement of the wall element. 


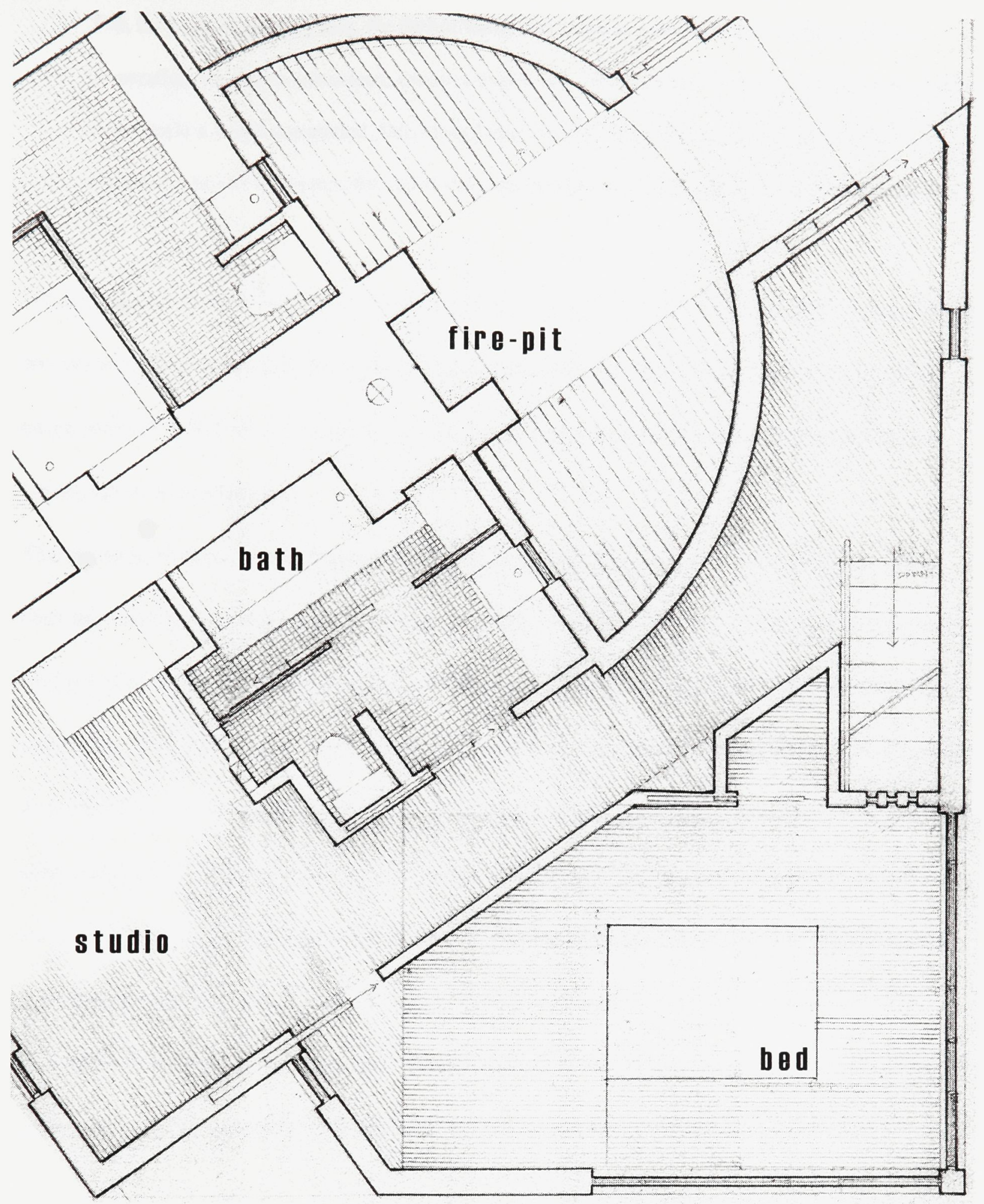

Plate 31. Detail: Design \#2: Second Floor. Conveyed here is the unique living situation cultivated around conditions and moments rather than functionality or efficient logic. The fire-pit encourages the communication of neighbours. The placement of materials helps to create a dialogue between public and private. Materials are allowed to submit to/resist the elements (weather, traffic) forming yet another dialogue between user and home. 
"For, far from neglecting him, the author today proclaims his absolute need of the reader's
cooperation, an active, conscious, creative assistance. What he asks of him is no longer to receive
ready-made a world completed, full, closed upon itself, but on the contrary to participate in a
creation, to invent in his turn the work - and the world - and thus to learn to invent his own life."114

Though the ease and linearity of suburban living are perpetuated in part by succumbing to the norms of specialized authorities (the developer, the retailer), inhabitants may be empowered by the consciousness of the complexity of their surroundings and the acceptance of unknowns.

The manifestations of the fragments in the building do not heed linear reading. They undergo metamorphoses that may subvert their original 'truths' (meanings, sequences, and plots of narrative) and make them adaptable to the spaces formed by framing and openings. The building is not a vessel, but porous; the frame is not closed, but selective. A multiplicity of formal and functional relationships and interpretations can be formed incrementally, feeding back into the sequential macro-frame, and reconstructing it - at once satiating the blank spaces laid out by the inevitable future plan and allowing the inhabitant to project and form her own reality. In order to supplant suburbia as the 'debaser of residents,' this scheme encourages the participation of the user through her awareness of her surroundings and the implicit processes she projects onto them.

\footnotetext{
${ }^{114}$ Alain Robbe-Grillet. For a New Novel: Essays on Fiction (Salem, New Hampshire: Ayer Company Publishers Inc., 1984) 156.
} 


\section{Appendix 1. Maps}

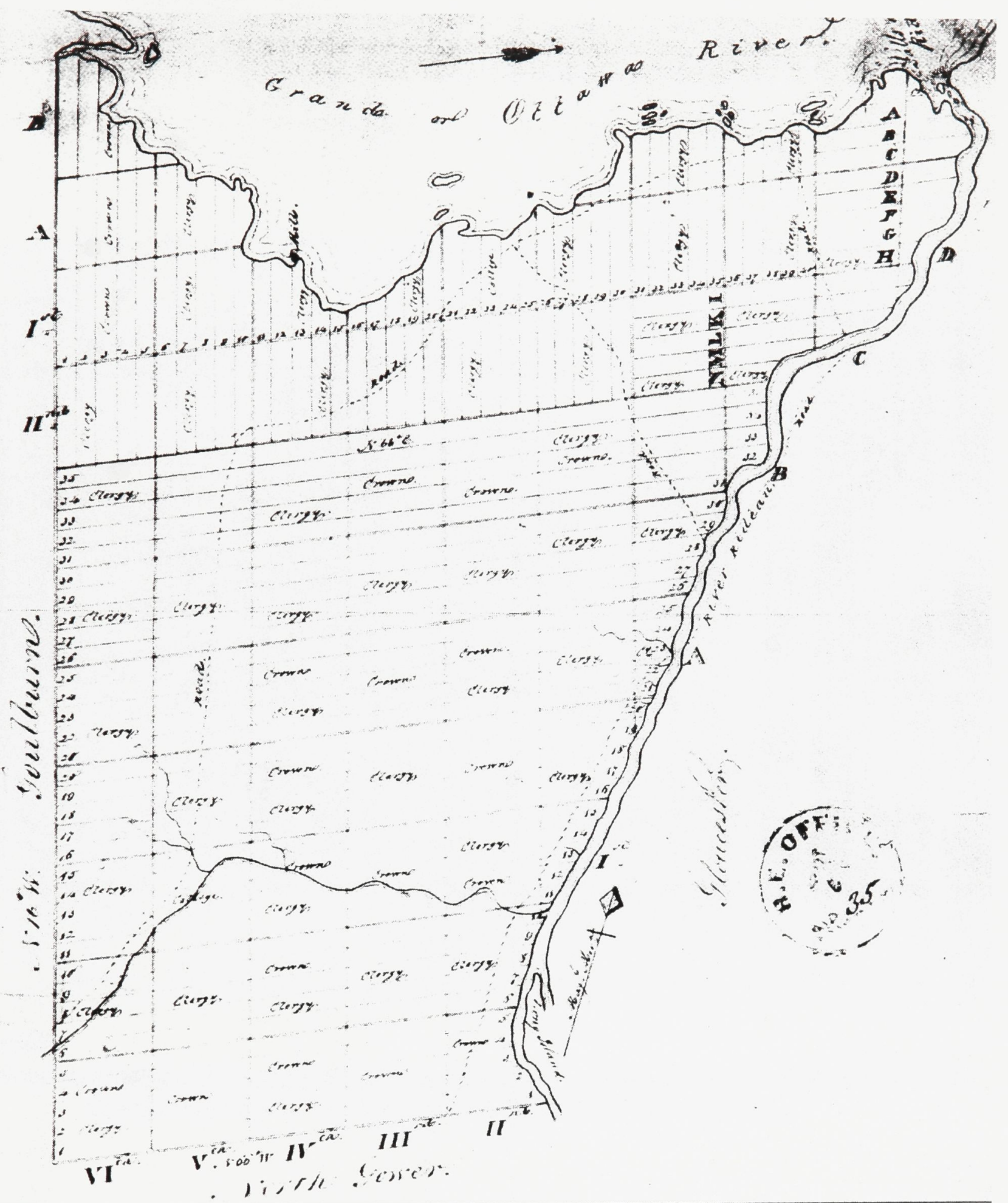

Anthony Swalwell's plan of 1830 shows the earliest roads: the possible Black Rapids in 1814, the government road of 1815 from Hull along Indian trail bushed out by. Ira Honeywell from the Ottawa River to the Rideau, and the Richmond Road. cut through by soidiers in 1818.

1861

Source: Elliott, Bruce S. The City Beyond : A History of Nepean, Birthplace of Canada's Capital, 1792-1990. Nepean, Ont.: City of Nepean, 1991 


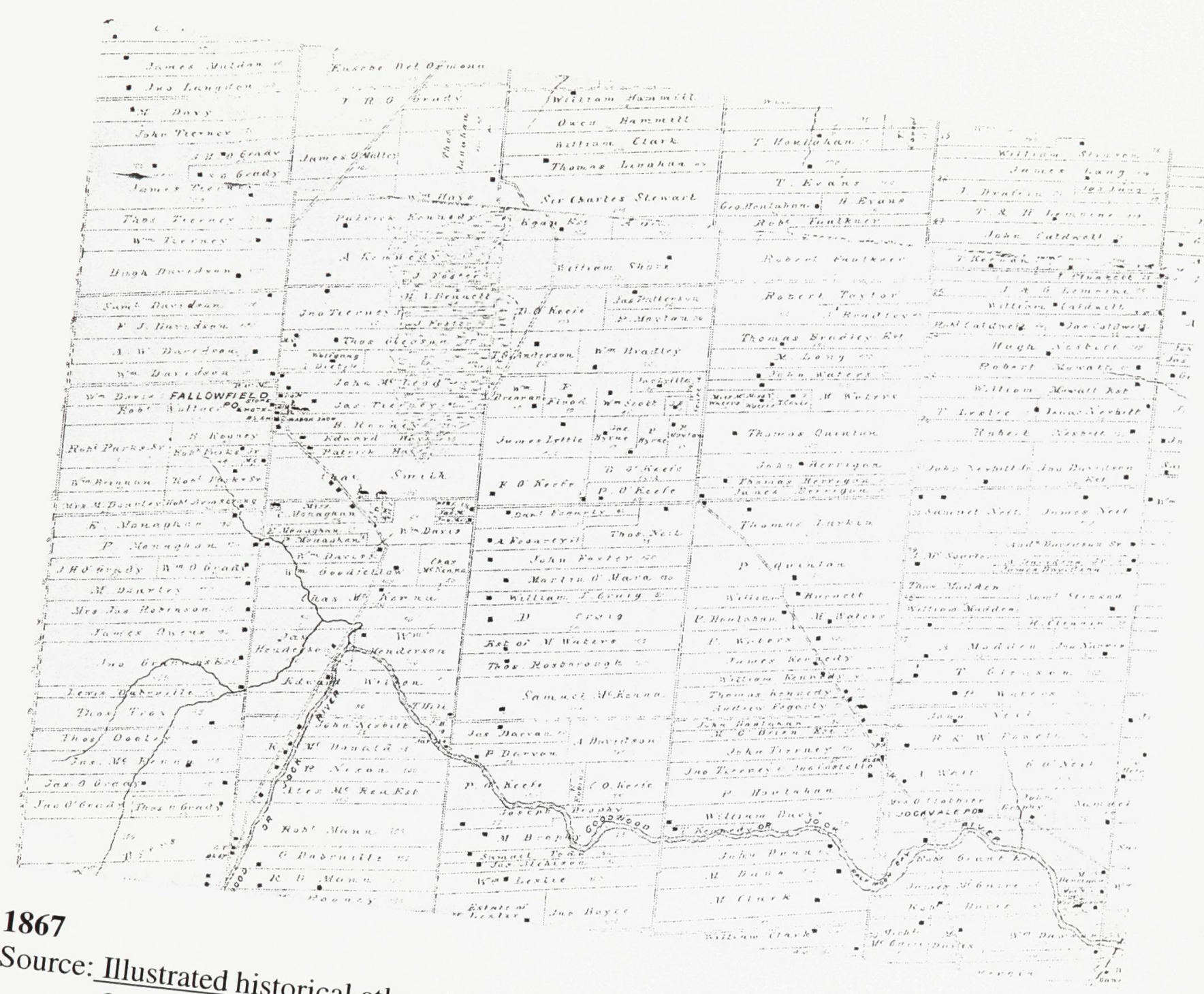

Ont. Campbellford, Ont.: Wilson's Publishing Company., 1997 . 


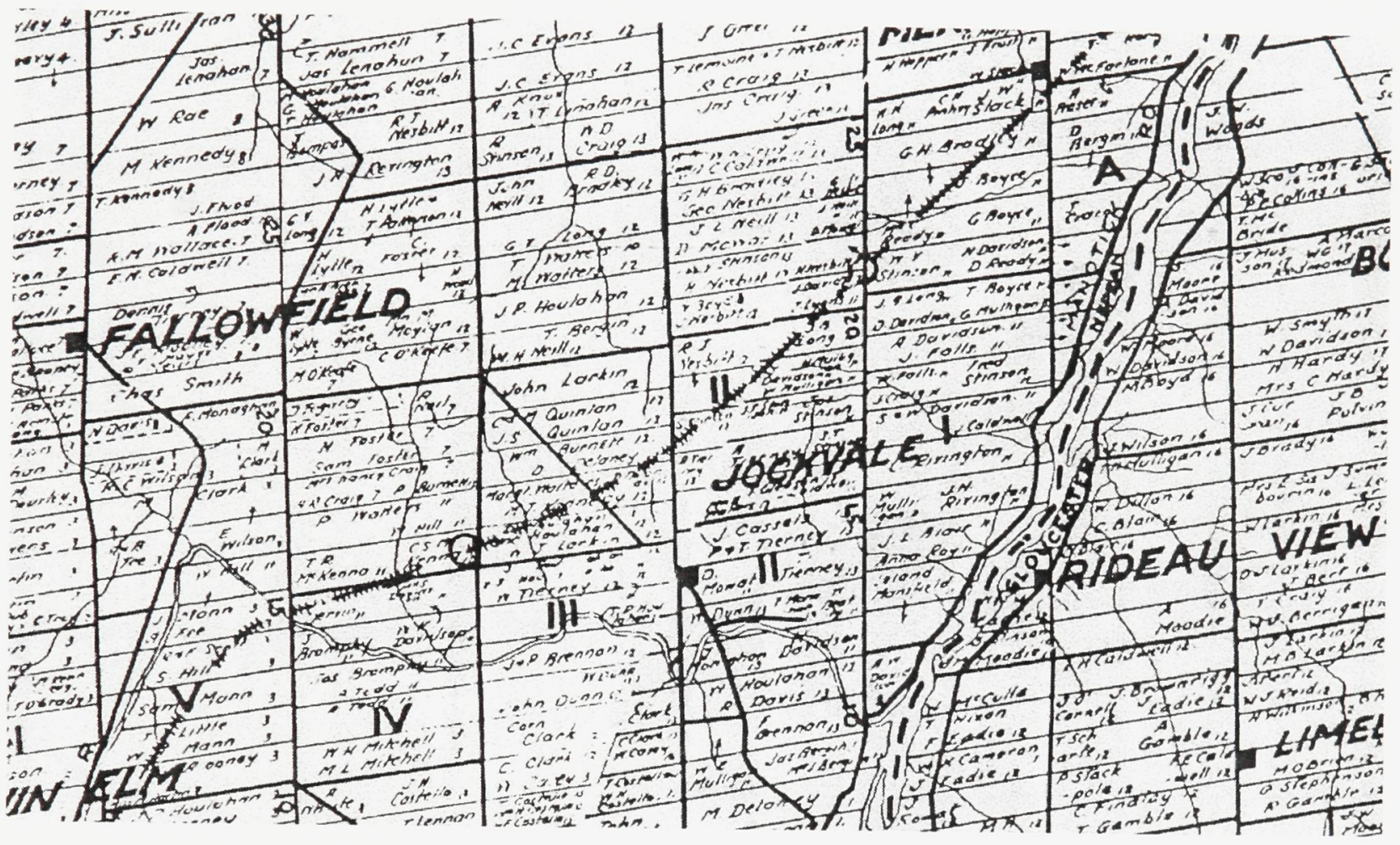

\section{8}

Source: Township of Nepean census, 1938. 


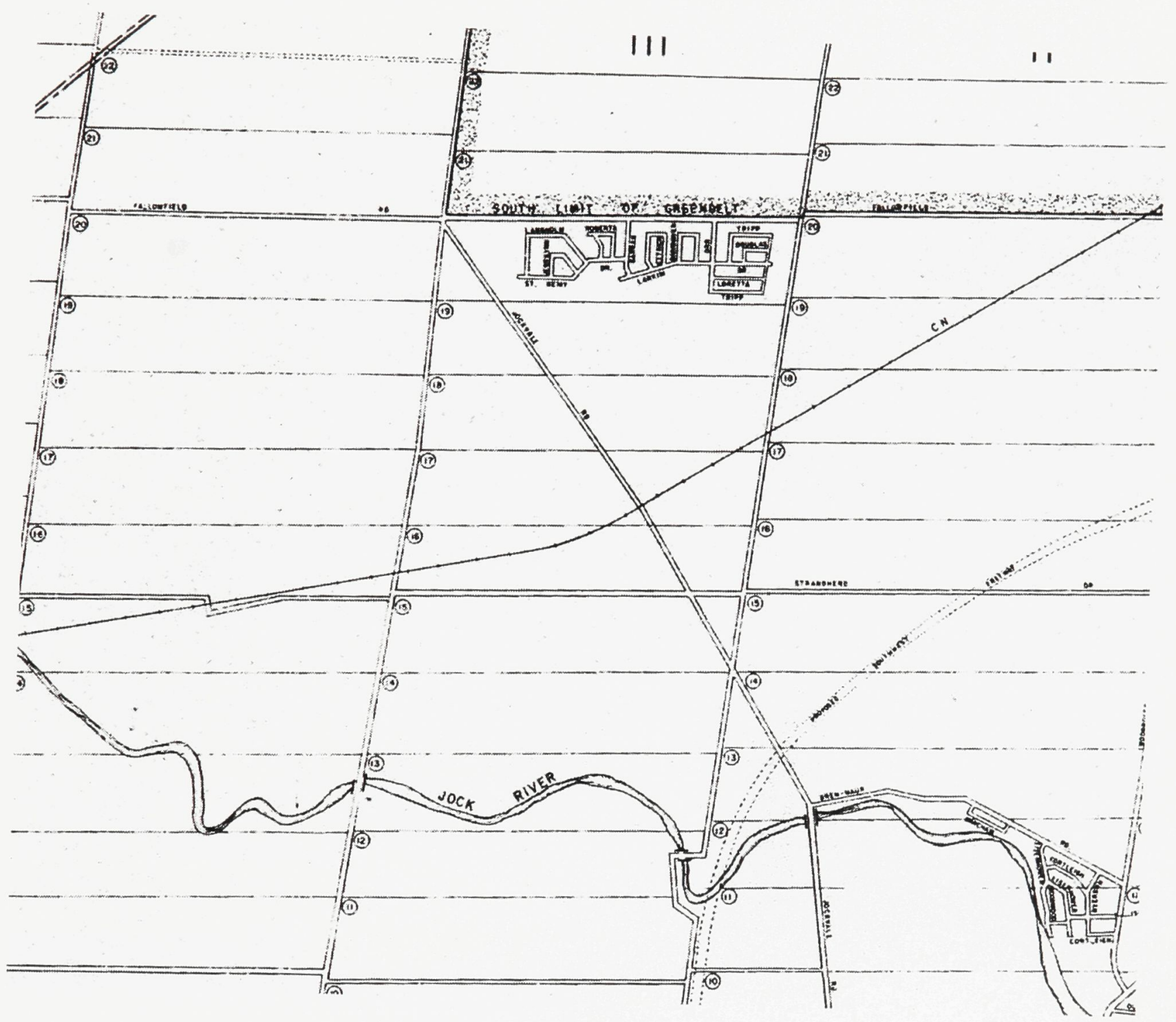

Barrhaven, 1970

Source: Carleton University Map Collection 


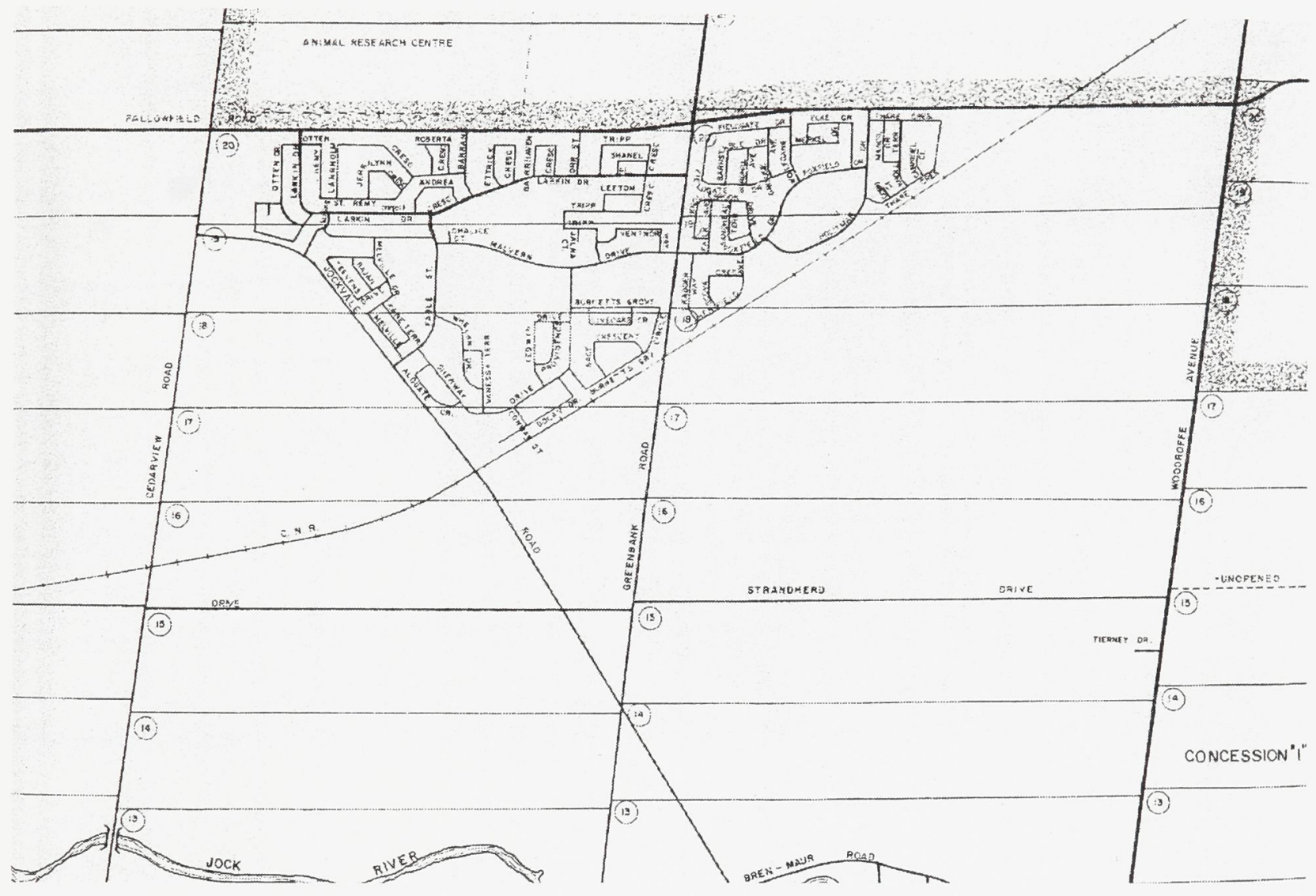

\section{Barrhaven, May 1975}

Source: Carleton University Map Collection 


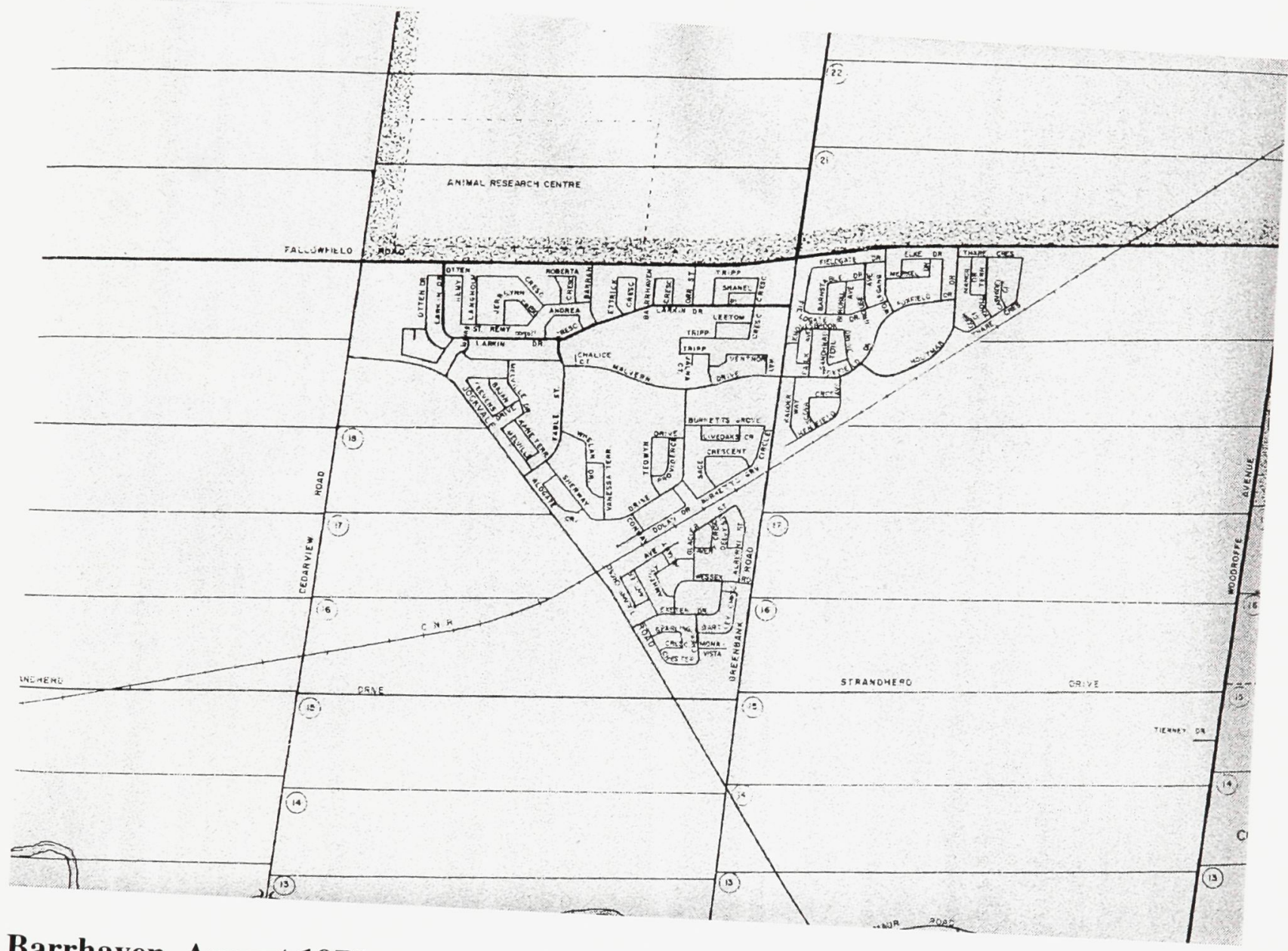

\section{Barrhaven, August 1975}

Source: Carleton University Map Collection 


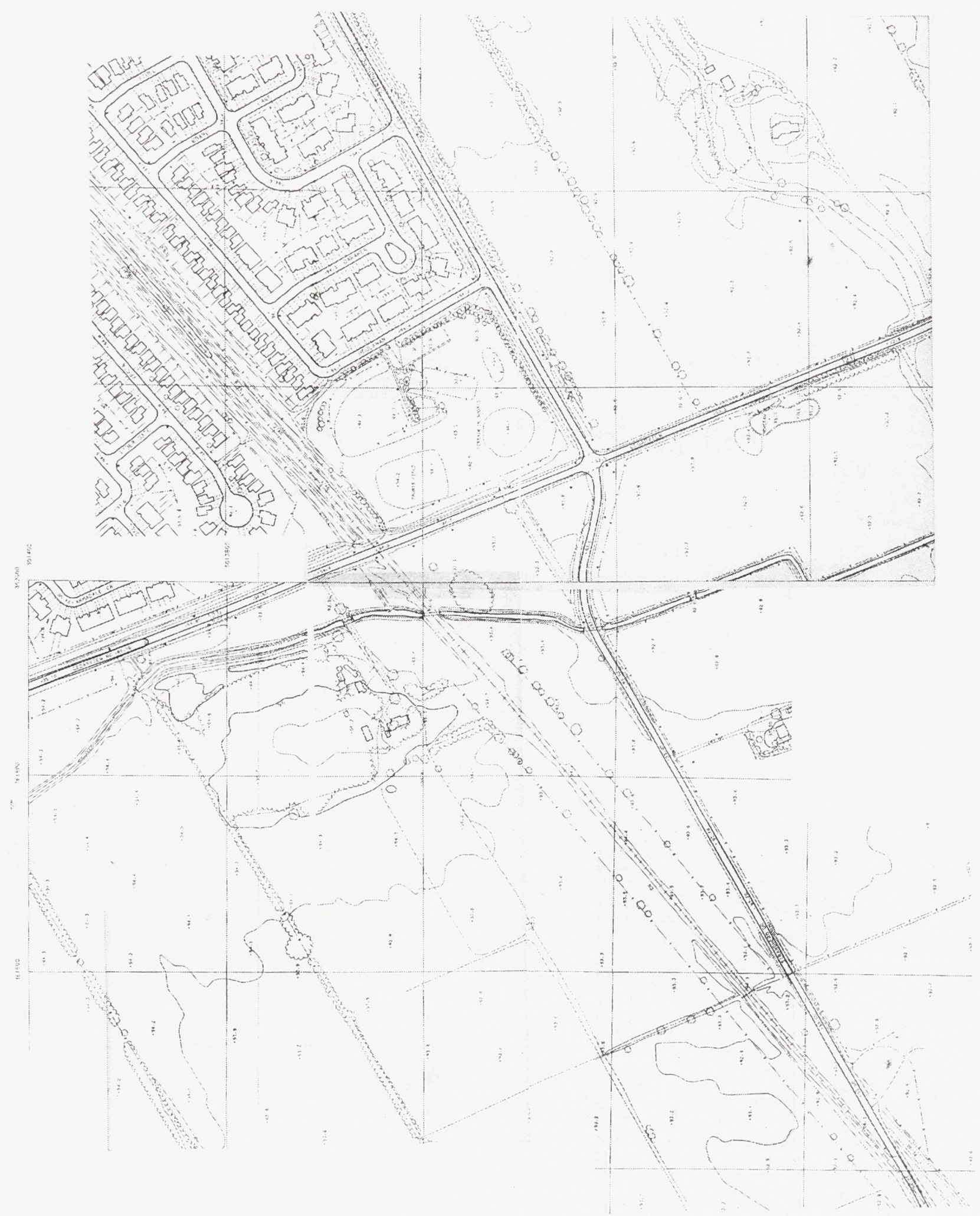




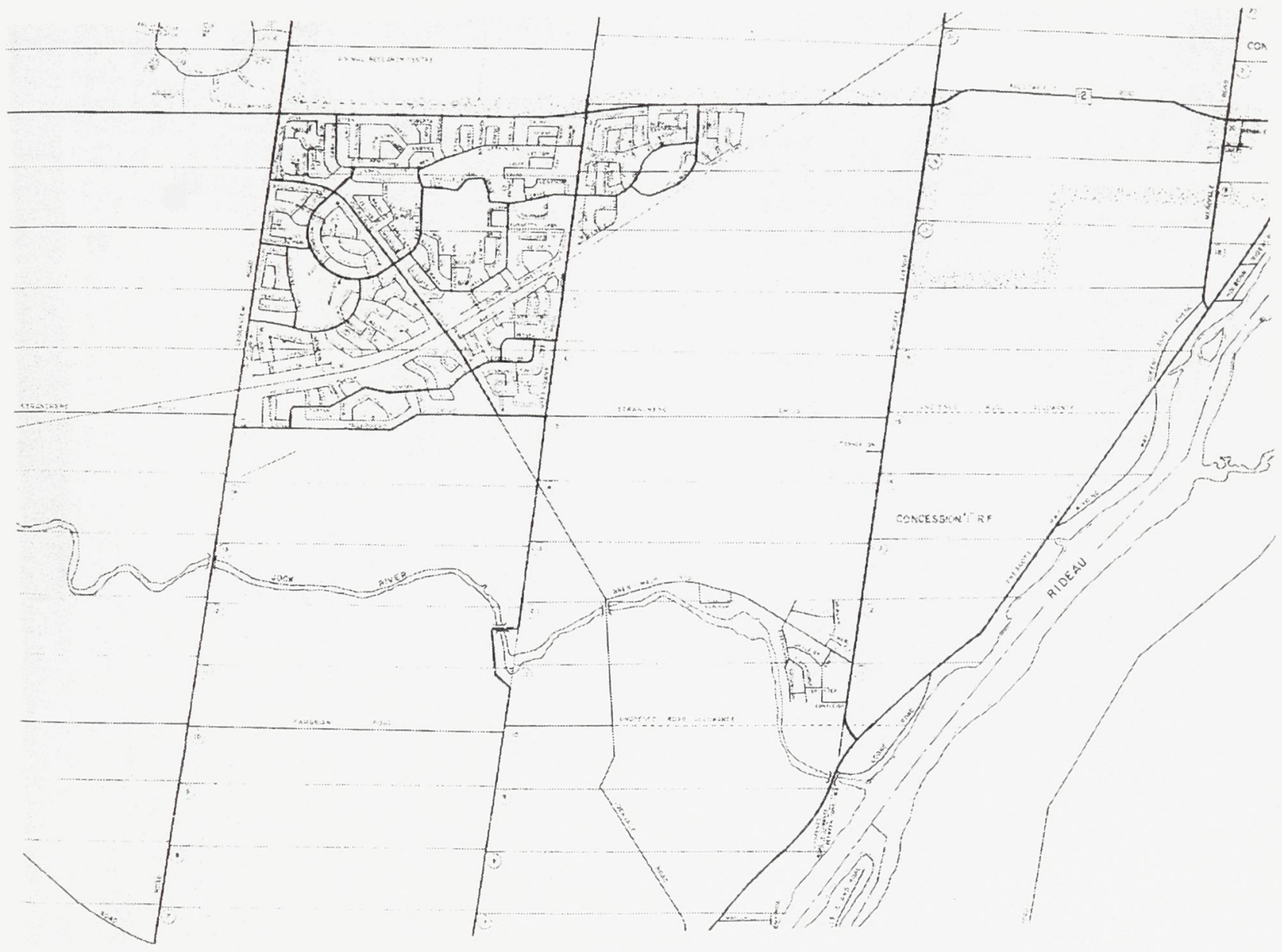

\section{Barrhaven, 1990}

Source: Carleton University Map Collection 


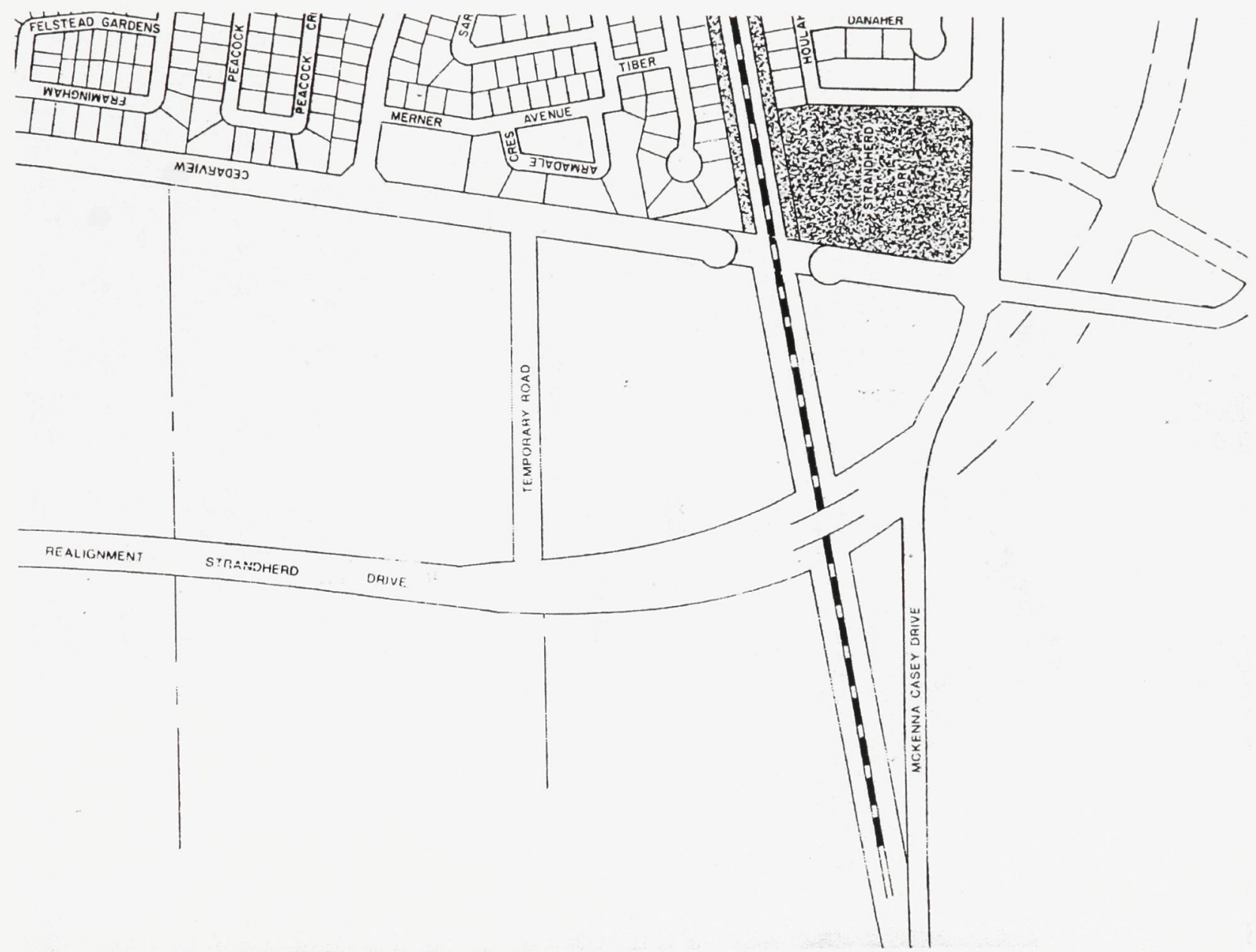

1996

Source: Carleton University Map Collection 


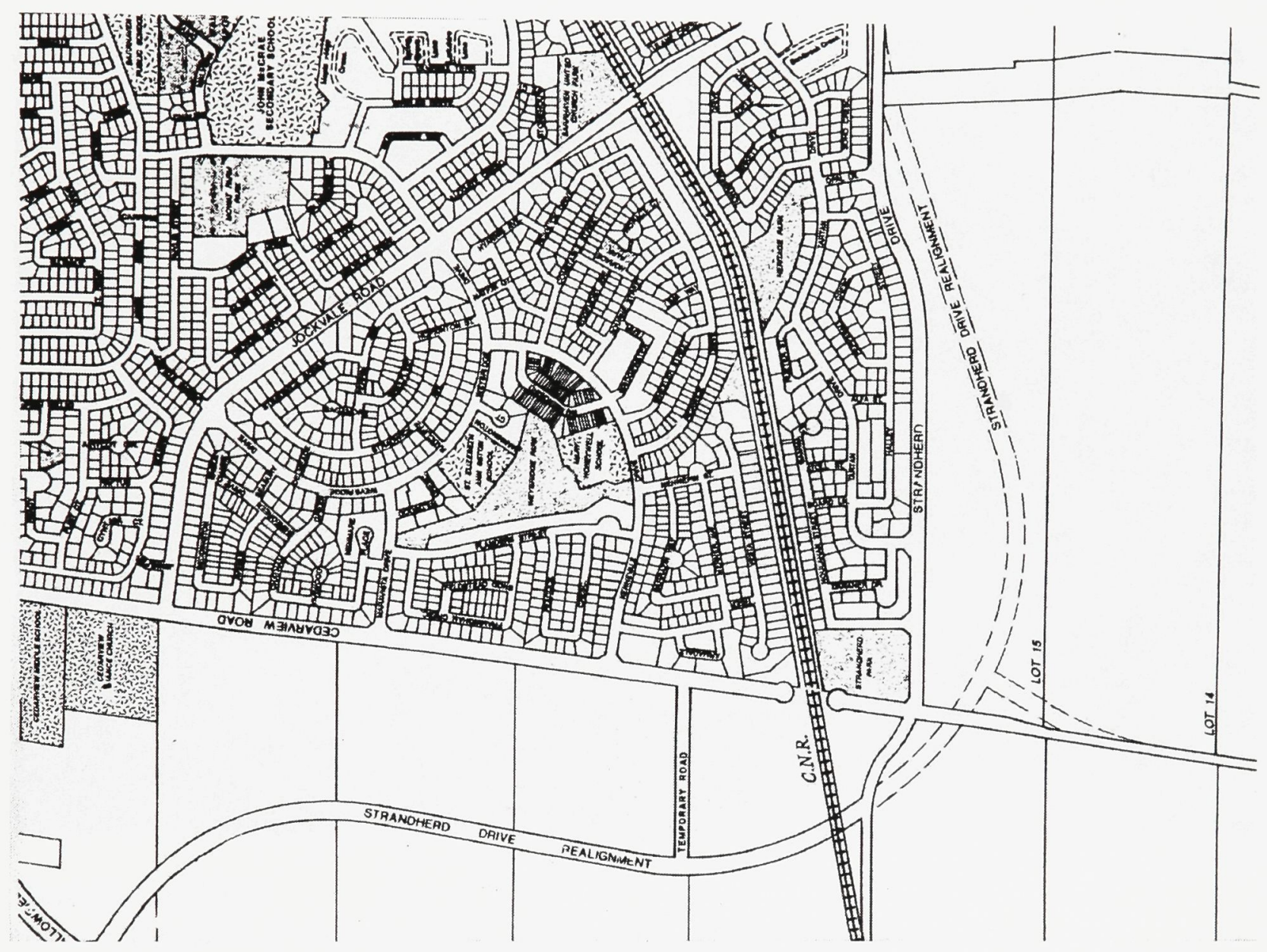

1998

Source: Carleton University Map Collection 


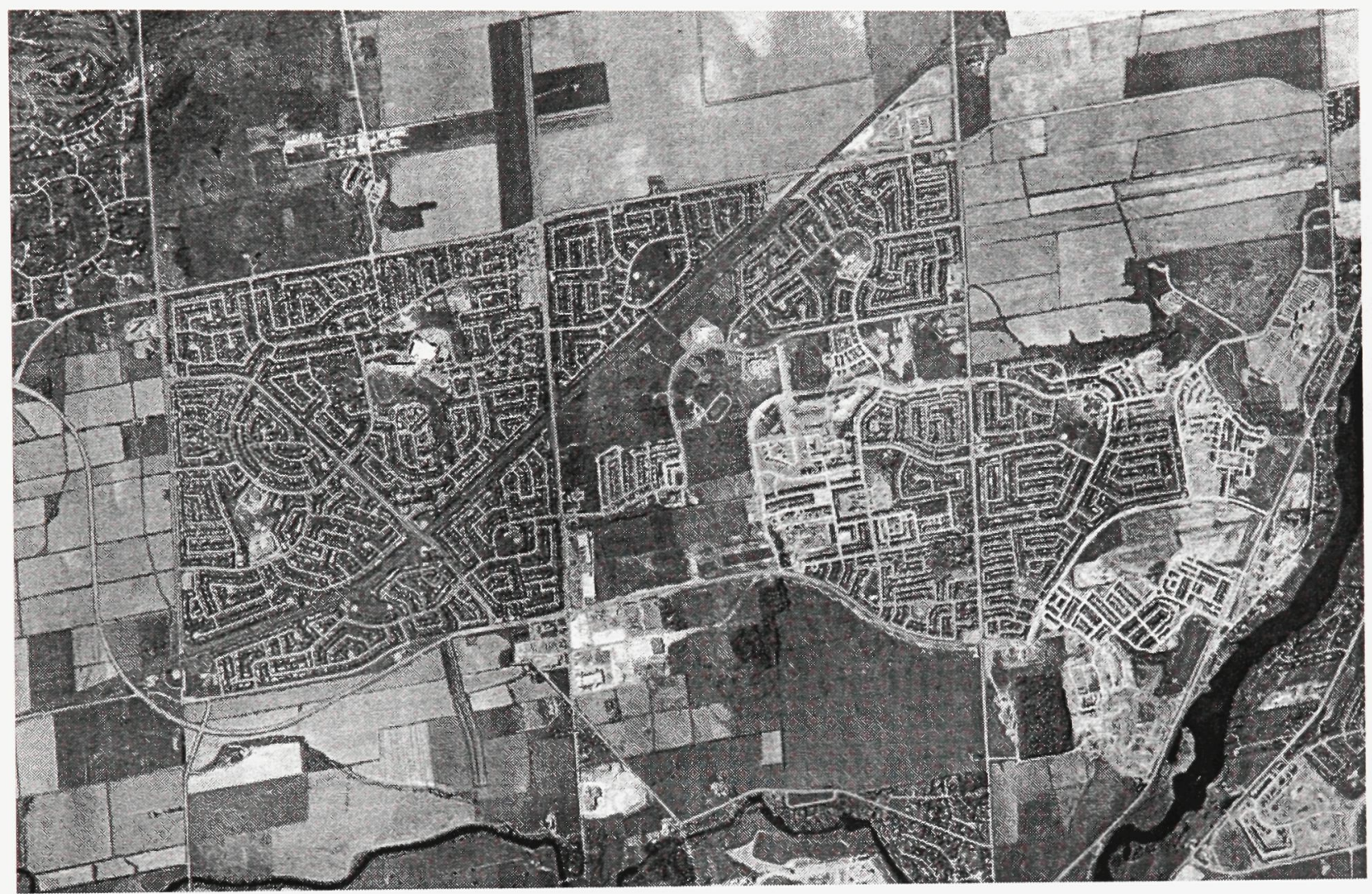

\section{Barrhaven, 2001}

Source: http://www.ottawa.ca/city_services/maps/atlas/index_en.html 


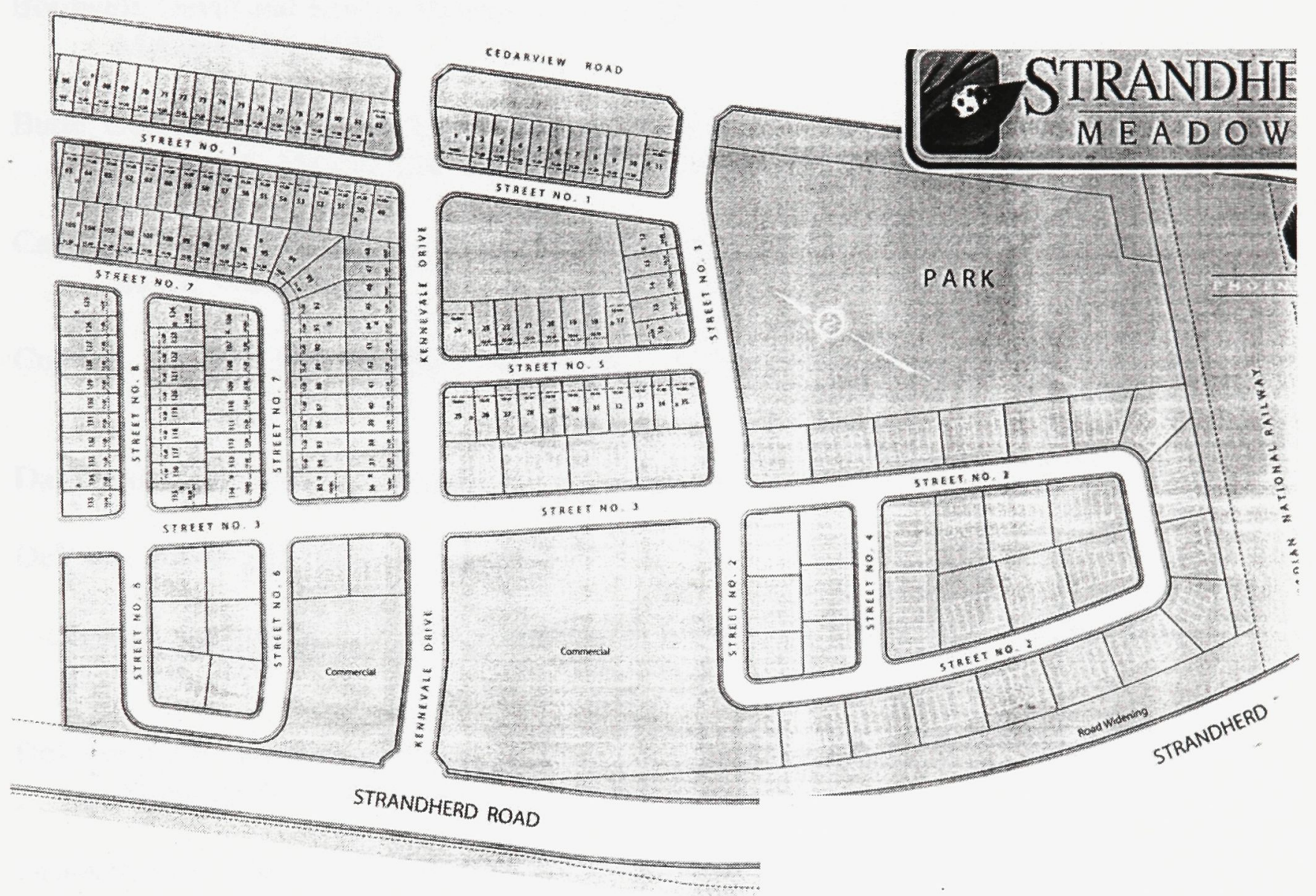

2004

Source: Phoenix Homes 


\section{Bibliography}

Augé, Marc. Non-places: an introduction to an anthropology of supermodernity. London: Verso, 2000.

Barthes, Roland. Mythologies. London: J. Cape, 1972.

Beldon, H. and Co._llustrated historical atlas of the county of Carleton, Ont. Toronto: Belden, 1879.

Bogue, Ronald. Deleuze on Cinema. New York: Routledge, 2003.

Bordwell, David and Kristin Thompson. Film Art: an Introduction. New York: McGraw-Hill, 1997.

Butte, George. I Know That You Know That I Know: Narrating Subjects from Moll Flanders to Marnie. Columbus: The Ohio State University Press, 2004.

Cache, Bernard. Earth Moves: The Furnishing of Territories. Cambridge, Mass.: The M.I.T. Press, 1995.

Cuddon, J. A. The Penguin Dictionary of Literary Terms and Literary Theory. London: Penguin Books, 1999.

Davidson, Cynthia C., ed. Anyplace. Cambridge, Mass.: M.I.T. Press, 1995.

Deleuze, Gilles. Difference and Repetition.

---. Francis Bacon: The Logic of Sensation. Minneapolis: University of Minnesota Press, 2003.

Deleuze, Gilles and Félix Guattari. A Thousand Plateaus: Capitalism and Schizophrenia. Minneapolis: University of Minnesota Press, 1987.

Drooker, Eric. Flood: A Novel in Pictures. Milwaukie, OR.: Dark Horse, 2002.

Elliott, Bruce S. The City Beyond : A History of Nepean, Birthplace of Canada's Capital, 1792-1990. Nepean, Ont.: City of Nepean, 1991.

Ernst, Max. Une Semaine de Bonté : A Surrealistic Novel in Collage. New York: Dover Publications, 1976.

Evans, Robin. Translations from Drawing to Building and Other Essays. Cambridge, Massachusetts: The M.I.T. Press, 1997. 
Farr, Dennis (co-curator). Francis Bacon: A Retrospective. New York: Harry N. Abrams, 1999

Fludernik, Monika. Towards a 'Natural' Narratology. London; New York : Routledge, 1996.

Foucault, Michel. The Order of Things. New York: Routledge, 2002.

Gaiman, Neil and Matt Wagner. Neil Gaiman's Midnight Days. New York: Vertigo/D.C. Comics, 1999.

Gutting, Gary. "Post-structuralism.” Routledge Encyclopedia of Philosophy. Ed.

E. Craig. London: Routledge (1998): 22 June 2005

$<$ http://www.rep.routledge.com/article/N045SECT1>

Hejduk, John. Victims. London: The Architectural Association, 1986.

Hill, Jonathan (ed.) Architecture - The Subject is Matter. London and New York: Routledge, 2001.

Klein, Naomi. No Logo: Taking Aim at the Brand Bullies. Toronto: Vintage Canada, 2000.

Lefebvre, Henri. Dialectical Materialism. London: Cape, 1968.

---. The Production of Space. Oxford and Cambridge, Mass.: Blackwell, 1991.

Lingwood, James (ed.) House/Rachel Whiteread. London: Phaidon, 1995.

Lyotard, Jean-François. The Postmodern Condition: A Report On Knowledge.

Minneapolis: University of Minnesota Press, 1984.

Meville, Herman and Bill Seinkiewicz. Moby Dick (Classics Illustrated). New York: Berkley, 1990.

Prince, Gerald. Narratology: the Form and Functioning of Narrative. Berlin and New York : Mouton, 1982.

Rieser, Martin and Andrea Zapp (eds.). New screen media : Cinema/Art/Narrative . London: British Film Institute Publishing, 2002.

Ricoeur, Paul. Time and Narrative. Chicago: University of Chicago Press, 1984-1988. 
Robbe-Grillet, Alain. For a New Novel: Essays on Fiction. Salem, New Hampshire: Ayer Company Publishers Inc., 1984.

Sherlock, Maureen P. "Moral minimalism and the suburban spectacle." Art Papers 22.3 (1998): 22-25

Smith, Catherine. "Looking for Liminality in Architectural Space." Limen: Journal for Theory and Practice of Liminal Phenomena no.1 (2001): 02 May 2005 $<$ http://www.cartage.org.lb/en/themes/Arts/Architec/ArchitecturalStructure/ LookingforLiminality/LookingforLiminality.htm>

Spiegelman, Art. Maus: A Survivor's Tale. New York: Pantheon Books, 1997.

Solà-Morales Rubió, Ignasi. Differences: Topographies of Contemporary Architecture. Cambridge, Mass.: The M.I.T. Press, 1997.

Stokstad, Marilyn. Art History, Revised Edition. New York: Harry N. Abrams, 1999.

Swift, Graham. Waterland. London: William Heinemann Ltd., 1983.

Tabachnick, Stephen E. "Of Maus and Memory: The Structure of Art Spiegelman's Graphic Novel of the Holocaust." Word and Image 9.2 (1993) 154-62.

Toolan, Michael J. “Concepts of Narrative.” Style 34.2 (2000): 168.

Tschumi, Bernard. Architecture and Disjunction. Cambridge, Mass.: The M.I.T. Press, 2001.

Turpin, Ian. Ernst. New York: Phaidon Press Inc., 1993.

Van der Klei, Alice. “Repeating the Rhizome.” SubStance \#97 31.1 (2002): 49-55.

Vonnegut, Kurt. Breakfast of Champions, or Goodbye Blue Monday. New York: Dell., 1973.

Wagner, Karl and Kent Williams. Tell Me, Dark. New York, D.C. Comics, 1998.

Weschler, Lawrence. Mr.Wilson's Cabinet of Wonder. New York: Vintage, 1992.

Wolf, Werner. "Narrative and narrativity: a Narratological Reconceptualization and its Applicability to the Visual Arts." Word and Image 19.3 (2003): 180-193. 